\title{
ENGR
}

530.85

Un3h

no. 19 , rev.

\section{FIRE-LOSS PREVENTION}

OF

FEDERAL FIRE COUNCIL

SECOND EDITION

1945

ENGINEERING LJBRARY 



\author{
FEDERAL WORKS AGENCY \\ Major General Philip B. Fleming \\ Administrator \\ PUBLIC BUILDINGS ADMINISTRATION \\ W. E. Reynolde \\ Commissioner
}

\title{
MANUAL OF FIRE-LOSS PREVENTION \\ of the
}

\section{FEDERAL FIRE COUNCIL}

\section{SECOND EDITION}

[Supercedea National Bureau of Standards Handbook H 19

Issued 1945

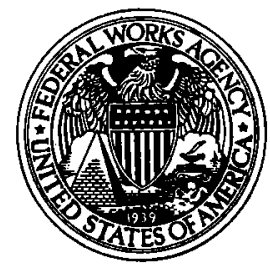

\section{ENGR}

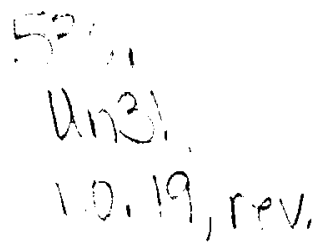

UNITED STATES

GOVERNMENT PRINTING OFFICE

WASHINGTON : 1945

For sale by the Superintendent of Documents, U. S. Government Printing Office Washington 25, D. C. - - Price 30 cents 


\title{
PREFACE TO SECOND EDITION
}

This issue of the Manual of Fire-Loss Prevention, the first edition of which was published in 1934, includes revisions and additions made in part to cover improvements in the past 10 years in methods of preventing and controlling fires. Such methods remain dependent largely on the elimination of preventable fires and abatement of loss from those that originate, by the use of appropriate designs and materials in building construction and the installation of applicable fire alarm and extinguishing equipments, to the extent justified by the hazard.

We trust that this publication and the further work of the Federal Fire Council will assist not only in decreasing the fire loss incurred in connection with Government activities, but also that they will constitute a substantial contribution in this general field. Progress therein will be furthered by well considered applications to fire-hazard conditions of the principles herein presented.

'This publication was prepared under the auspices of the committees of the Federal Fire Council and approved by its membership, censisting of representatives from all Government ageneies interested in the construction, maintenance, and use of Federal buildings. Acknowledgments are due in appreciation of the time and counsel given by members and others in its preparation.

\author{
W. E. ReYNoLns, \\ Chairman, Federal Fire Council.
}

JUNe 14, 1945. 
Preface $_{1}$

I. Introduction

1. Scope $\ldots \ldots \ldots$

2. Arrangement .................. 1

II. Conditions determining outlay for loss prevention . _...- 2

1. Fire-loss ratios

2. Justifiable expense for protection

3 . Coordination of protection measures

III. Fire-resistance classification of building materials, members, and assemblies........... 6

1. Fire-testing procedure $\ldots$

2. Fire-resistance classifications _............... 8

(a) Columns . . .

(b) Walls and partitions............ 10

(c) Floor beams, girders, and slabs....... 11

(d) Opening protectives............... 12

1. Class A openings.

2. Class $B$ openings . . .

3. Class $C$ openings. .

4. Class D openings .

5. Class $\mathrm{E}$ and $\mathrm{F}$ openings ........ 13

6. Openings into vaults and record rooms

(e) Roofing materials

3. Severity of building fires.................. 15

(a) Fire severity in fire-resistive buildings.... 15

(b) Fire-exposure in conditions in non-fireresistive buildings ................ 17

IV. Fire-resistance classification of building types.

1. Fireproof

(a) Classes

(b) Range in fire resistance attainable $\ldots \ldots 18$

2. Masonry walls with interior wood or unprotectedmetal framing . . . . .

(a) Classes

3. Incombustible construction . .

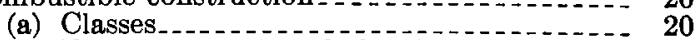

(b) Effect of span length, height, and loading. 21

4. Wood construction................ 21

(a) Classes

(b) Effect of materials and details ...... 22

V. Structural control of fire spread . .

1. Height limitations . . .

2. Area limitations . .

3. Protection of vertical and horizontal communications .............. 23

4. Protection against exterior exposure

(a) Spacing of buildings

(b) Protection of exterior openings_...... 25 
VI. Means for egress

1. General requirements and assumptions....... 27

(a) Determination of population

(b) Number of exits................... 27

(c) Location of exits................ 28

(d) Unit of exit width.................. 28

2. Doors and doorways........ 29

(a) Exit capacity of doors

(b) Mounting and hardware for doors

(c) Horizontal exits...................... 30

3. Stairways, ramps, and elevators $\ldots$

(a) Exit capacities

(b) Construction of stairs.

(c) Exits from stairs

4. Outside stairs, fire escapes, ladders, and chutes... 31

(a) Location and limitations

(b) Exit capacity

(c) Construction

5. Lighting and marking of exits

6. Enclosure of exit ways........ 33

VII. Safeguarding common hazards

1. Heating and ventilation 33

2. Electric lighting and power

(a) Conductors and their protection

(b) Oil-filled apparatus . . .

(c) Motors

(d) Grounding

(e) Hazardous locations

3. Gas installations

4. Lightning protection

VIII. Safeguarding special hazards

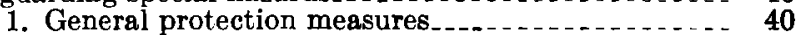

2. Hazards during construction, demolition, and alteration . .

3. Structural provisions against the explosion hazard. 41

IX. Construction and equipment for protection of records . . . 44

1. Building construction and finish........... 44

2. Record vaults $\ldots \ldots \ldots 4$

3. Record rooms

4. Record storage buildings

5. Film vaults

6. Equipment........ 46

(a) Furniture $\ldots \ldots \ldots$

(b) Portable record containers

7. Film cabinets........ 47

X. Fire-alarm and watchman's supervisory equipment.... 48

1. Manual fire-alarm systems .............. 49

(a) Types and specifications .......... 50

(b) Location of stations $\ldots$

2. Automatic fire-alarm systems

(a) Types and operating details

(b) Specifications and installation details ... 54

3. Watchman's supervisory systems . . . . 
X. Fire-alarm and watchman's supervisory equipment-Con.

4. Adaptation of interior automatic-telephone exchanges for transmission of fire alarms and super-

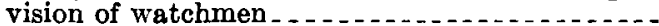

5. Outside central station service

6. General installation requirements . .............

7. Municipal fire alarms

8. Conditions requiring installation of given types of equipment

XI. Fire extinguishment

1. General methods of extinguishment

(a) Classes of fires

1. Class A fires .

2. Class B fires................. 59

3. Class $C$ fires . . . . .

(b) Extinguishing agents

1. Water

2. Soda-acid

3. Foam

4. Carbon tetrachloride ........ 62

5. Carbon dioxide............... 63

6. Steam........ 64

7. Dry powdered material_._. . . . . 65

8. Freezing-point depression $\ldots \ldots-65$

(c) General types of fire-extinguishing equipment.

2. Portable fire-extinguishing equipment

(a) Rating of hand fire extinguishers

(b) Types of portable extinguishers........ 68

1. Soda-acid type _............. 68

2. Water type (self-propelled)

3. Loaded stream extinguishers . . . . 69

4. Water tank with pump...... 69

5. Water pails, tanks, and casks... 69

6. Foam extinguishers _.......... 69

7. Carbon-tetrachloride extinguishers. 69

8. Carbon-dioxide extinguishers_._-_ 69

9. Dry-powder types _.......... 70

10. Extinguishers on wheels _...... 70

(c) Recharges for portable fire extinguishers_- 70

(d) Spacing of portable extinguishers...... 71

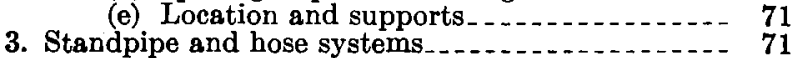

(a) Water supply for standpipes....... 72

1. Water supplies for large hose.... 72

2. Water supplies for small hose $\ldots . . .74$

3. Location of pressure tanks . . . . 75

4. Fire pumps _... 75

5. Enclosures_... 76

(b) Spacing and location of standpipes ..... 76

(c) Range of hose streams of restricted height -77

(d) Size of standpipes. .

(e) Hose outlets, hose, nozzles, and valves ..- 78

(f) Allowable pressures and pressure-reducing devices. 
XI. Fire extinguishment-Continued Page

4. Automatic-sprinkler equipments . . . . . . . . . . . . . 82

(a) Scope of application

(b) Types . .

(c) Heads for automatic-sprinkler systems _.. 85

(d) General installation details . . ........ 86

(e) Water supplies for sprinklers.......... 88

(f) Fire-alarm and supervisory equipment_.. 89

5. Fixed carbon-dioxide fire-extinguishing systems... 89

6. Foam fire-extinguishing systems . . . . . . . . . . 91

7. Water spray systems _.................... 92

8. Outside private protection.

(a) Water supply

(b) Details of the system.

(c) Hose

9. Public water supply

10. Public fire brigade

XII. Fire causes and their elimination $\ldots$

1. The fire waste.

2. Causes of fires............. 98

3. Possibilities in fire control

4. General fire-prevention measures

(a) Review of plans for new construction and equipment

(b) Temporary construction and installations_ 102

(c) Plan of fire-protection facilities......... 103

(d) Heating, lighting, and power equipment.. 104

(e) Service equipment and furniture . . . .... 104

(f) Flammable liquids and other hazardous materials . . . . . .

(g) General maintenance.

(h) Reports on fires

(i) Organization for fire-loss prevention . . . 107

XIII. Protection of records and valuables.

1. Value of records

2. Classification by value $\ldots$

3. Means of protecting records

(a) Duplication

(b) Special housing

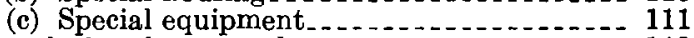

4. Disposal of useless records . . . . .

5. Planning and maintaining a records protection program

6. Handling of damaged records

7. Protection of other valuables............... 116

XIV. Maintenance of fire-protection equipment

1. General maintenance requirements $\ldots$

2. Care of standpipe and hose systems

3. Maintenance of sprinkler systems _.......... 118

4. Maintenance of hydrants and rubber-lined hose _- 120

5. Care of fire pumps and tanks............... 121

6. Supervision of fixed carbon-dioxideand foam systems. 121

7. Maintenance of portable fire extinguishers . . . . . 122

8 Fire-alarm and supervisory equipment $\ldots . . . . . .122$ 
Paga

XV. Organization for combating fires

1. Low or moderate-hazard occupancies in fireprøof buildings, with public protection available _. _ 123

2. Hazardous and institutional occupancies. . . . . . . 124

3. Isolated locations _. _ _ _ _ _ _ _ _ _ _ _ _ _ _ 125

4. Importance of training $\ldots \ldots \ldots$

XVI. Inspection of properties .

1. Self-inspections

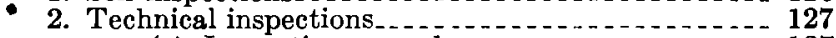

(a) Inspection procedure

(b) Form and contents of report.

XVII. Fire-loss prevention under war conditions.

1. Structural protective measures

2. Control and extinguishment................ 131

3. Arson by enemy action . . . . . 132

4. Protection of records and cultural resources..... 133

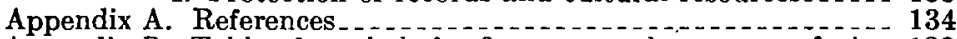

Appendix B. Table of symbols for fire-survey plans....... facing 138

Appendix C. Federal Fire Council blank form for report of fire on Government property

Appendix D. Federal statute on disposition of certain Government records . . . . . . . . . . . . . . . . . . . . 142

Appendix E. Suggested procedure to be observed for combating

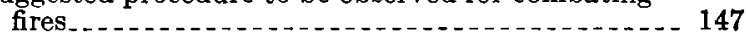

Appendix F. Self-inspection forms

Index................... 156 



\section{MANUAL OF FIRE-LOSS PREVENTION OF THE FEDERAL FIRE COUNCIL}

\section{INTRODUCTION}

\section{SCOPE}

It is aimed to present herein the essentials relating to design, materials of construction, and equipment and operation of buildings, that effectively prevent or abate loss by fire.

In determining the extent of the treatment under the different subjects, consideration has been given to the degree to which information thereon is extant, particularly as incorporated into the sources on which the designer relies for guidance. Where the knowledge on a subject is not in organized form it is aimed to present it to an extent that will enable decision to be made as to the type and degree of the protection that should be provided. Further information can be obtained from the references listed at the end of the manual, the index numbers of which are given in parentheses in the text dealing with the respective subjects.

\section{ARRANGEMENT}

An initial discussion is given of justifiable outlay for fireloss prevention, considering the values and the degree of hazard present. Sections III to VI, inclusive, deal with the fire resistance of building materials, assemblies, and types, control of spread of fire by structural means, and design and arrangement of building to secure exit facilities for occupants in case of fire.

In sections VII and VIII, structural and equipment features having a bearing on safeguarding hazards incidental of heating, lighting, and power supply are discussed as also those pertaining to lightning protection, fire hazards during construction, and special occupancy hazards. In section IX protection of records is treated from the standpoint of construction and equipment and in section XIII from the standpoint of business routine and general fire prevention. 
Sections $\mathrm{X}$ and $\mathrm{XI}$ deal with equipment for detecting and extinguishing fire.

In section XII general methods for decreasing the ease of origin and initial spread of fire are outlined, and in sections XIV to XVI inclusive, the effective use of equipment in case of fire by prior training for emergency, and the systematic inspection of property to enable unnecessary fire hazards to be promptly eliminated and defects in construction and equipment remedied.

In a final chapter are outlined protection measures for Government activities and property under war conditions.

\section{CONDITIONS DETERMINING OUTLAY FOR LOSS PREVENTION}

\section{FIRE-LOSS RATIOS}

The general ratio of annual fire loss to value of buildings and contents subject to fire loss is near 0.002 , or $20 \phi$ per $\$ 100$ value, for the range of property insured by stock fire-insurance companies, most of which would have the benefit of public fire protection in addition to some degree of private protection. Farmers' mutual fire-insurance companies have experienced a similar loss ratio on farm and town property having in general little public fire-department protection and practically no protection supplied by the owner. Compared with this, the loss ratio on industrial property, all but a small portion of which is under automatic-sprinkler protection combined with other fire-prevention measures of comparatively high degree of effectiveness, has been only about 0.1 of this figure or near 0.0002 , or $2 \phi$ per $\$ 100$ value subject to loss by fire. It is apparent that at least a part of the saving represented by this difference in loss ratio is offset by the cost of the protection measures employed.

The loss ratio is not known as well for Government property as it is for private property, but considering construction generally of good types from the fire-resistance standpoint, the presence in general of at least fair public and inside protection, good housekeeping conditions, and occupancies generally presenting only light or moderate fire hazard, it apparently should be lower than the general average. Since differences such as those indicated above have a decided effect on the fire loss, it may be justifiable to assume a loss ratio on Government property of no more than 0.001 
and it may even be considerably lower than this figure, to judge from the incomplete available data.

\section{JUSTIFIABLE EXPENSE FOR PROTECTION}

The expense incurred for protection should be proportioned with respect to the reduction in the fire loss that can be produced thereby, and where property loss alone is concerned, it should not exceed the expected saving. While safety to life and uninterrupted functioning of the activities concerned may justify a higher cost, its comparison with a conservative estimate of the property loss to be prevented is of value in such cases also. The annual cost of loss-prevention measures can be taken as the sum of annually recurring items not included under cost of equipment, such as for fire-brigade and watchman service, plus approximately 10 percent of the total initial investment in equipment.

The 10 percent annual charge against equipment can be distributed as 4 percent interest on investment, 4 percent depreciation, and 2 percent for maintenance. In estimating possible reductions in fire loss, consideration must be given to the degree of effectiveness of the measures provided and an annual expense equal to the fire loss expected if the protection were not provided, is justified on the score of property value, only if these measures can be relied upon to reduce the loss to a relatively small amount.

The expense that can, with economy, be incurred depends on the physical value of the property, its value from the standpoint of continuous use and occupancy, and the degree of fire hazard presented, the latter as represented by the loss ratio. High values and hazards may justify an outlay not otherwise warranted. The increase or decrease in hazard with type of occupancy, character of materials, and method of housing are quite marked and the probability of loss can vary from twice to one-half of the general average for no very outstanding differences in such conditions.

As an example, take a four-story and basement fire-resistive building having a contract or present value of $\$ 1,000,000$ exclusive of ground value. The height above basement slab is $65 \mathrm{ft}$ and the area within exterior walls $40,000 \mathrm{ft}^{2}$. The value of contents, including uninventoried values such as records, is $\$ 800,000$. An additional value of building and contents of $\$ 400,000$ is added as representing loss in productive value of the activities housed and increase in cost 
of accommodations that would result in case all portions of the building and contents suffer the maximum expected fire damage. This gives a total for the purpose of determining justifiable cost of fire protection of $\$ 2,200,000$.

The contents, taken in conjunction with the building design, finish, and occupancy, are deemed to present a low fire hazard. The property has the benefit of good public fire protection with hydrants and alarm boxes located near the building. Under the circumstances a loss ratio without any inside protection, of 0.001 might be assumed, which gives a justifiable annual expense of $\$ 2,200$ for fire-loss prevention, if the measures provided are such that they will reduce the loss to only a small portion of what would otherwise occur. The portion of the watchman service chargeable to fire protection is taken at $\$ 1,000$ leaving $\$ 1,200$ for the annual charge against equipment, which is 10 percent of an initial investment of $\$ 12,000$. A watchman's clock with key stations, a manual fire-alarm system of the generalalarm type, hand fire extinguishers, and standpipe system with small hose might be installed for about one-fourth of this amount. Neither automatic-sprinkler protection nor automatic fire-alarm equipment can be installed over the whole building for the balance. Some of it may be profitably applied to protect hazardous areas of minor extent, such as by wet-pipe automatic sprinklers where applicable. While a considerable decrease in fire loss can be effected with the protection applied, some loss should be expected and, accordingly, the total annual expense incurred should in general be somewhat less than the fire loss that would be experienced with no inside protection.

As another example, take a building of the same size and cost intended for the handling and storage of combustible stocks, the value of which will be taken as $\$ 1,500,000$. There will in general be an increase in fire hazard because of larger accumulations and a fire-loss ratio of 0.002 for this property without inside fire protection will be assumed. On this basis for a total value of $\$ 2,900,000$ the average expected annual fire loss without inside protection would be $\$ 5,800$. Taking cost of watchman service chargeable to fire protection at $\$ 1,500$, the maximum justifiable investment for fire-protection equipment would be $\$ 43,000$. This will usually be found more than sufficient to cover the cost of fire-alarm and watchman's supervisory equipment, hand 
fire extinguishers, standpipe or other connections for small hose, and automatic-sprinkler protection for the whole building.

\section{COORDINATION OF PROTECTION MEASURES}

By combining elements of protection entering into the design and materials of construction of buildings and their equipment and management, a high degree of protection can be obtained at lower outlay than if attempted with one of them alone. Nor is it necessary to charge the full cost of all measures effecting a decrease in the fire hazard to fire-loss prevention. The fire-resistive type of building construction meets a number of other requirements than resistance to fire, including relatively low depreciation, greater strength for given sizes of members, and greater resistance to wind and earthquake shock. Inclosure of vertical and horizontal openings and subdivision of large areas to limit the spread of fire do not introduce a large added element of cost. A decided increase in fire resistance of building members can be attained by proper choice of materials and methods of application at little or no additional cost. Water-supply systems both inside and outside of buildings can in many cases be designed to meet the combined demand from domestic consumption and fire service at a considerable saving as compared with the cost of separate systems. In equipping buildings, incombustible filing equipment, furniture, and shelving, while effecting a decided increase in fire safety, cost little more than equipment of combustible materials. Other examples of equipment serving the dual demands of ordinary service and protection against fire will be given in subsequent sections.

Measures under the general designation of fire prevention, intended to prevent or decrease the frequency of occurrence of fire and restricting initial spread thereof, are known to be effective if consistently applied. While dependent on the human element with possibilty of lapses, they form an important and necessary part of any fire-loss-prevention program. Establishing conditions that are not conducive to the origin and rapid spread of fire, may not be more difficult than continually contending with a less satisfactory state of affairs and added advantages accrue in greater orderliness and better general maintenance of property. 
The relative importance of type of building construction, interior arrangements of building and occupancy, and of protection measures, will vary considerably with occupancy conditions and environment. In a light-hazard occupancy such as an office building, arrangement and construction are clearly of prime importance. For places of public assembly and institutional buildings, arrangement to afford ready means of exit and to prevent initial spread of fire and smoke should receive first consideration. In buildings housing hazardous processes and storage, effective means for discovering and extinguishing fire must be applied if large losses are to be avoided. Next in importance may be proper subdivision of the building, with inclosure of vertical and horizontal communications. The fire-resistive type of building construction usually affords a basis for subdivision into areas restricting spread of fire and smoke, does not itself contribute materially to the spread of fire, and prevents the spread of fire to neighboring construction.

An appreciation of the value of fire-prevention measures and sustained interest therein is essential, beginning with the inception of a building project and extending through the planning, construction, and subsequent use periods. Protection measures are best incorporated integrally into the building and its general equipment with special fire-protection equipment provided where necessary. However, such measures cannot be even moderately effective unless supplemented by subsequent management to give conditions favorable to preventing fire origin and promptly extinguishing any fire that does originate, with well-maintained equipment, automatically actuated or effectively handled by personnel instructed and trained in its use.

\section{FIRE-RESISTANCE C L A S S I F I C A T ION OF BUILDING MATERIALS, MEMBERS, AND ASSEMBLIES}

\section{FIRE-TESTING PROCEDURE}

There has been developed during the past 3 or 4 decades a basis for classifying, from the fire-resistance standpoint, component construction parts such as floors, walls, partitions, columns, and fire doors, fire windows, insulated safes, 
and other protection devices (1). ${ }^{1}$ The classification is based on resistance to exposure from a furnace fire of controlled intensity, the time limit of performance being determined by criteria such as failure to support applied working load, transmission of flame or of hot gases or temperatures hazardous to combustibles in contact with or near the unexposed side or within the inclosure defined by the assembly. The fire exposure is regulated to obtain as nearly as possible the furnace-temperature indications given in table 1 , as determined by prescribed methods.

TABLE 1.-Furnace temperature control schedule for fire tests

\begin{tabular}{|c|c|c|}
\hline Tíme after start & \multicolumn{2}{|c|}{ Temperaturo } \\
\hline $\begin{array}{l}5 \text { min } \\
10 \text { min } \\
30 \mathrm{~min} \\
\mathbf{1} \mathrm{hr} \\
\mathbf{2} \mathrm{hr} \\
\mathbf{4 h}\end{array}$ & $\begin{array}{l}{ }^{\circ} F \\
1,000 \\
1,300 \\
1,550 \\
1,700 \\
1,850 \\
2,000 \\
2,300\end{array}$ & $\begin{array}{r}\text { - C (approxi- } \\
\text { mately) } \\
538 \\
704 \\
843 \\
927 \\
1,010 \\
1,093 \\
1,260\end{array}$ \\
\hline
\end{tabular}

An average temperature rise above initial of $250^{\circ} \mathrm{F}, 139^{\circ} \mathrm{C}$, or a maximum rise at any point of $325^{\circ} \mathrm{F}, 181^{\circ} \mathrm{C}$, as measured under asbestos pads placed on the side not exposed to fire, determines the ultimate fire-resistance period for floors, walls, and partitions and for finish protecting combustible members. Qualification based on the hazard created by burning of contained combustible materials is a part of the classification. Somewhat higher temperature limits are taken to apply for fire doors, vault doors, and other opening protectives. For insulated safes a temperature in specified locations on the inside of $350^{\circ} \mathrm{F}, 177^{\circ} \mathrm{C}$, must not be exceeded.

Ability to resist the impact and eroding effects of hose streams is also required for floors, walls, partitions, and opening protectives. The pressure at the hose nozzle and duration of water application is varied with the fire-resistance classification of the assembly, the more severe requirements applying for the higher classifications.

Materials such as those used in roof coverings and in sound and heat insulations are subjected to special tests to

${ }^{1}$ Figures in parentheses here and elsewhere in the text refer to the references given on p. 134 to 139 . 
determine susceptibility to ignition from flame or brands, and the hazard to the surroundings when burning.

\section{FIRE-RESISTANCE CLASSIFICATIONS}

Based on procedure outlined above, classifications expressed as ultimate resistance in time, to the conditions of the fire test have been established for some types of building constructions in a range of design and materials. As tested according to the 1926 and later revisions of the testing procedure, considerable information is available on columns $(2,3,4)$ and on walls and partitions $(5,6,7,8,9,10)$. Results of fire tests conducted largely according to earlier American procedure or that used abroad are also informative $(11,12$, 13). Fire tests made according to the later procedure and covering the whole field of building constructions have, however, not been made and the fire resistance for some types and materials must be estimated, using the best information available.

Summaries of classifications based on results of tests have been made (14). While the publications to which reference is made (see titles in appendix corresponding to numbers given above) should be consulted for the necessary information on fire-resistance ratings, the following is given as indicative of the range in protection obtainable. All values given are based directly on results of tests.

\section{(a) COLUMNS}

Unprotected structural-steel columns of section corresponding to that required to support a design load of a little over $100,000 \mathrm{lb}$ fail under load after 10 to $20 \mathrm{~min}$ as subjected to the fire test (2). Cast-iron columns of comparable load capacity will withstand the same test for about 30 min. The fire endurance, however, is greatly increased by the application of suitable coverings. In thickness of 2 in, portland cement concrete coverings will give increase to the range $11 / 2$ to $7 \mathrm{hr}$. The lower results are obtained if highly siliceous (quartz, chert) aggregates are used for the concrete, on account of the cracking induced by them as subjected to the sudden temperature rise, effects that can be offset to some extent by embedding metal mesh in the covering. Progressively better results obtain with sandstone, granite, cinders, and trap rock. The highest fire resistance 
obtains with crushed limestone or calcareous pebbles. AImost any fire resistance required can be obtained by increase in thickness within practical limits, combined with proper choice of aggregates and details of application.

The fire resistance of reinforced-concrete columns depends also largely upon the mineral composition of the aggregates used. With the more unfavorable aggregate combinations a fire endurance of between 3 and $4 \mathrm{hr}$ obtains for columns of $18 \mathrm{in}$. outside diameter including a 11/2-in. concrete thickness outside of the steel. By the use of metal mesh near the surface, application of plaster, or choice in aggregates, any needed fire resistance can be obtained with very moderate thickness of material as protection for the portion assumed to carry the load (3). Metal binder for concrete protections should have 2- to 4-in.-wide mesh and weigh not less than $11 / 2 \mathrm{lb} / \mathrm{yd}^{2}$ of fabric. With the given sizes of mesh, no considerable obstruction to the placement of the concrete is presented.

With hollow-clay tile applied to steel and cast-iron columns, fire-endurance limits from $11 / 2$ to $4 \mathrm{hr}$ obtain, the degree of protection depending more on the type of clay, anchorage of tile, filling of the interior, and other details of application than on the gross thickness of the tile (2). Metal mesh in the horizontal joints holds the tile in place much more effectively when exposed to fire than ties around the outside of the covering. Plaster that remains in place during fire exposure increases the effectiveness of all types of fire-protective coverings by giving added heat insulation and decreasing the disruptive fire effects. Lime plaster generally falls off soon after exposure to fire. Such spalling of gypsum plaster occurs occassionally but can generally ke traced to improper preparation of base or plaster of unduly long time of set. Positive anchorage, such as by U-shaped cramps, spanning between holes in ends of adjacent blocks, and embedded in the horizontal mortar joints, is needed for unplastered gypsum-block coverings if their full fire resistance is to be developed. So applied to steel columns, unfilled coverings of 2 -in. solid or 3-in. hollow gypsum blocks givo ultimate fire-endurance limits of $2 \frac{1}{2}$ to $23 / 4 \mathrm{hr}$ and if plastered, between 4 and $5 \mathrm{hr}$. Similarly, plastered protection of 2 -in. gypsum wood-fibered concrete gives ultimate fire resistance of $t \mathrm{hr}(4)$. 
For fireproof buildings unlimited as to height and unsubdivided area, fire resistance for columns of not less than $4 \mathrm{hr}$ has been recommended and where height and area limitations are imposed, not less than 2 or $3 \mathrm{hr}$. It is, however, generally advisable to design the protection for the severity of fire to be expected as outlined herein in a subsequent paragraph. By proper choice of materials and details this can usually be effected with moderate thickness of protective coverings.

Unprotected timber columns (12 by 12 in.) with exposed steel or cast-iron caps fail under load as exposed to the fire test after 35 to $50 \mathrm{~min}$, the immediate cause of failure being softening of the wood in contact with the metal bearing (2). With caps of reinforced concrete the fire-resistive value of the 12 -in. column shaft of about $11 / 2 \mathrm{hr}$ is developed, the wood species included in the tests being long-leaf pine and Douglas fir (15).

\section{(b) WALLS AND PARTITIONS}

The fire resistance given by walls built of brick, structural (hollow) clay tile, and concrete blocks ranges from a little over $1 \mathrm{hr}$ for 4 -in. brick walls to $10 \mathrm{hr}$ or more for 12-in. brick walls or 16-in. walls built of heavy structural clay tile $(5,6,8)$. The fire-endurance limit as determined by temperatures developed on the unexposed side, varies approximately with the 1.7 power of the wall thickness, not including air spaces (law of times) $(14,16)$. Plaster on one or both sides adds more to the fire endurance than would be expected from the increase in thickness.

Solid plaster partitions 2 -in. thick built on metal studs and lath give fire-endurance limits for $1 / 2 \mathrm{hr}$ for $1: 21 / 2$ portland-cement plaster, to $2 \mathrm{hr}$ for neat wood-fibered gypsum plaster, with intermediate values depending on the ratio of cementing materials to sand in the mix (10). Hollow partitions of metal or wood studs covered with gypsum plaster on metal lath or perforated plaster board classify as $3 / 4 \mathrm{hr}$ or better, depending on the thickness and proportions of the plaster (10). Partitions of hollow gypsum block 3-in. thick, plastered, apparently qualify for the 2 -hr rating $(7,13)$. Other classifications can be determined with fair reliability from tests made according to the earlier testing methods $(11,12,13)$, or calculated from results with the same material in a different thickness, applying the "law of times" $(14,16)$. 
Fire and party walls are generally required to have an ultimate fire resistance of not less than $4 \mathrm{hr}$ and inclosures for stair and elevator shafts or partitions with openings that are a part of the exit requirements, 2 to $3 \mathrm{hr}$, with reduction in some instances for light-hazard occupancies. It is desirable to design fire and party walls for the full severity of the fire to be expected with the building contents. Room and corridor partitions in fireproof buildings subdividing areas of $5,000 \mathrm{ft}^{2}$ or more, are usually required to have fire resistance of not less than $1 \mathrm{hr}$ as an aid in restricting the spread of fire.

\section{(c) FLOOR BEAMS, GIRDERS, AND SLABS}

Classifications for floors must be based largely on tests conducted here and abroad before the present testing procedure was adopted $(11,12,17)$, although some from recent tests have been published (14). Estimates based on performance of similar materials applied for walls and columns can be made if material subject to cracking and spalling on exposure to fire is adequately anchored. Fire resistance as limited by temperature on the upper surface can be increased by increasing the thickness of fill over the floor as well as by adding to the protection beneath.

For use in fireproof buildings, particularly if no limitations on height or unsubdivided area are imposed, $21 / 2$ - to 3 -hr fire resistance is generally recommended for floor beams and slabs $(14,19)$. This can be attained with $11 / 2^{-}$to 2 -in. protection thickness on the steel shapes or bars in the beams with portland-cement concrete floor slab 5 to 7 in. thick, depending on the aggregates used, or a poured-gypsum slab 4 in. thick, plastered. For protections placed under and above steel or concrete beams or joists, a suitably anchored soffit covering $11 / 2$ to 2 in. thick, combined with a concrete slab over the beams not less than 2 in., and for the thinner soffit coverings, not less than $2 \frac{1}{2}$ in. thick, will give the required fire resistance. Little information is extant on the fire resistance of brick and hollow-tile arches, but with a concrete fill above and plaster beneath the given fire resistance should obtain with the thickness of arch required to support the floor load. It is, however, desirable and generally feasible to design for the full severity of the fire to be expected in the given location.

For another type of fire-resistive building, limited as to height and floor area, fire resistance of floor members of $11 / 2$ 
to $2 \mathrm{hr}$ has been recommended. This can be attained with a portland-cement concrete slab 4 to $5 \mathrm{in}$. thick or $3 / 4$ to 1 in. of plaster on metal lath beneath steel or concrete joists combined with a top reinforced-concrete or gypsum slab not less than 2 in. thick.

\section{(d) OPENING PROTECTIVES}

Classifications up to the present have been based most generally on the requirements for different types of openings (18). These comprise mainly, A, openings in fire or party walls; $\mathrm{B}$, openings in shafts; $\mathrm{C}$, openings in corridor and room partitions; and $\mathrm{D}, \mathrm{E}, \mathrm{F}$, openings in exterior walls subject, respectively, to severe, moderate, and light fire exposure. Fire doors, windows, and shutters are classified according to performance in tests indicating suitability for the different types of openings $(7,11,12)$. Fire doors to be effective as fire barriers should be self-closing and normally remain in the closed position. Where doors, windows or shutters must be open continually or for portions of the day, means should be provided for closure in case of fire, with heat-actuated devices. The following classifications and requirements follow those used by the fire underwriters.

1. Class $A$ openings.-For class A openings the protectives are required to be mounted on both sides of the opening with hardware and other fastenings found satisfactory in tests. The general limitations in size depend on the type of door and are given as 8 to $12 \mathrm{ft}$ in height and in width, 4 to $6 \mathrm{ft}$ for swinging single doors, 8 to $12 \mathrm{ft}$ for swinging double doors or sliding doors, and $12 \mathrm{ft}$ for rolling doors. The types listed as satisfactory include hollow metal especially designed for this use, sheet metal, steel rolling, and tin-clad, 3-ply wood-core doors. The openings in fire walls should be as few as is consistent with the requirements of the occupancy.

2. Class $B$ openings.-For class B openings the protectives are mounted on one side of the opening, the limitation in dimensions of openings being within the range indicated for class A openings. The same type of doors adapted for the particular purpose can be used, the tin-clad door being required to have only a 2-ply wood core. Others listed as satisfactory for this type of location are metal-clad paneled doors and steel counterbalanced elevator doors.

3. Class $C$ openings.-The protectives for class $\mathrm{C}$ openings are mounted in the opening and may be of the general type 
listed for class B openings, adapted for the purpose and subject to approximately the same limitations in size. Doors may have panels of $1 / 4$-in wire glass, individual glass lights not to exceed $1,296-$ in. $^{2}$ in area.

4. Class $D$ openings.-For class $\mathrm{D}$ openings in exterior walls, swinging doors and shutters, single or in pairs, of the hollow metal, metal-clad with panels, sheet metal, and tin-clad, 2-ply core types, are regarded as satisfactory, as also the rolling steel shutter. Sliding shutters are not recommended for installation on the outside of buildings since snow and ice may accumulate on the track. At least 1 shutter in 3 above the first story and below the seventh must be hung so it can be operated from both inside and outside and marked for identification by the fire department.

5. Class $E$ and $F$ openings.-For classes $\mathrm{E}$ and $\mathrm{F}$ openings in outside walls subject to moderate or light fire exposure, the same types are recommended as for class $D$ openings, with the addition of metal window casements. The limit of size for metal frames containing glass or sash is given as 7 by $12 \mathrm{ft}$, the area of any wire glass light not to exceed 720 in. $^{2}$ for class $\mathbf{E}$ openings and for both this class and class $F$ openings the maximum dimension of glass recommended is 54 inches.

6. Openings into vaults and record rooms.-Doors in openings into fire-resistive vaults are rated as 2-, 4-, or 6-hr doors as based on performance in fire tests (20). In order to qualify for these ratings insulation thicknesses from 2 to 5 in. are required in addition to proper details of door jambs and frames. A lighter door qualifying for a $1 / 2$-to-1-hr rating is recommended for openings into record rooms. The uninsulated type plate steel vault door that was used almost exclusively until within the past $10 \mathrm{yr}$, has in a fire test given a performance qualifying it for a $1 / 2$-hr rating.

\section{(e) ROOFING MATERIALS}

The classification of roofing materials is based on performance in tests designed to determine resistance to ignition from flying brands, flames, and radiated heat, and the extent to which fire will spread over the surface of the roofing. Whether or not flying brands are given off when burning is also a criterion. The classes outlined below, give a range in fire resistance as defined by the testing procedure.

Under class A roofings are included the heavier (3- or 4-ply) built-up asphalt and asbestos, asphalt and rag felt, and 
tar rag-felt roofings, surfaced with slag, crushed stone, pebbles, or asphalt cement. Of the prepared roofings it includes slate, clay and cement roofing tile, and rigid cement-asbestos shingles laid with suitable head lap.

Under class B are included medium weight (2- or 3-ply) built-up asphalt and asbestos, asphalt and rag felt, and tar rag-felt roofings, surfacings with slag, etc., being required for the rag-felt roofings only. Under prepared roofings are included cement-asbestos shingles laid according to the diagonal or French method, heavy asphalt-saturated asbestos felt sheets, and copper, steel, and tin-coated steel sheet roofings and shingles suitably designed and applied.

Under class $C$ roofings are included the lighter built-up asphalt and rag-felt roofings (2- or 3-ply) on which top surfacing of slag, pebbles, etc., is not required. Among prepared roofings, the medium weights of asphalt-saturated asbestos felt sheets, and all but the lighter weights of asphalt-saturated rag felt sheets and shingles, are included in this class. The sheet roofings may be either smooth-surfaced or covered with mineral granules. The shingles are all granular surfaced. Class $\mathrm{C}$ also includes zinc sheets and zinc shingles and sheet-steel roofing not qualifying for class $B$.

The other roofing materials as a class would be more combustible or give less protection than those in class $\mathrm{C}$.

According to another classification (14) roofing materials are grouped into five classes, the first two being substantially the same as respective classes $A$ and $B$ above. Class 3 comprises mainly the built-up roofings under class $C$, the thinner asphalt-asbestos sheet roofings, some metal roofings, and asphalt-rag-felt individual and strip shingles. In class 4 are asphalt-rag-felt roll roofings and some wood shingle roofings having comparable resistance to ignition by brands.

It may be noted that the requirements for roofing materials outlined above are concerned largely with the protection needed for a combustible roof deck beneath them. Where the roof deck is incombustible, any exposed covering material applied should be incombustible or fire retardant and if burning under severe exposure no brands should be given off. The location of the building with reference to other buildings and the spacing of the construction in the district concerned are also factors that may determine the choice in roofing materials. State and city buildings codes generally require greater fire resistance for roofing in the 
congested districts than in the outlying sections where buildings are lower and less closely spaced.

\section{SEVERITY OF BUILDING FIRES}

In order that building members, protections, and equipment, may be designed to have fire resistance adequate for the location, information on the severity of fire to be expected with given amounts of combustibles in the building and contents is required.

\section{(a) FIRE SEVERITY IN FIRE-RESISTIVE BUILDINGS}

As concerns buildings with fire resistance such that a complete burning-out of combustibles will not result in collapse of main structural members, the severity in temperature and duration of fires in combustible contents can be related to the amount of combustibles present, assumed distributed uniformly over the included floor area (22). For ordinary combustibles such as wood and paper having calorific values in the range 8,500 to $6,500 \mathrm{Btu} / \mathrm{lb}$ the equivalents in hours of exposure to the furnace test defined above can be taken as given in table 2 (14).

TABIE 2.-Equivalent durations for fires in fireproof buildings with calorific value of combustibles assumed in the range for wood and paper

\begin{tabular}{|c|r|c|c|}
\hline \multicolumn{2}{|c|}{ Combustibles } & \multicolumn{2}{c|}{$\begin{array}{c}\text { Equivalent } \\
\text { fre duration }\end{array}$} \\
\cline { 1 - 3 }$l b / f t^{2}$ & Btu/ft ${ }^{2}$ & $h r$ & $\min$ \\
5 & 40,000 & 0 & 30 \\
10 & 80,000 & 1 & 00 \\
15 & 120,000 & 1 & 30 \\
20 & 160,000 & 2 & 00 \\
30 & 240,000 & 3 & 00 \\
40 & 320,000 & 4 & 30 \\
50 & 380,000 & 6 & 00 \\
60 & 432,000 & 7 & 30 \\
\hline
\end{tabular}

The periods contain an addition for increase in severity due to fires in adjacent buildings that may be sufficient to cover all but exceptional cases.

In computing combustible contents the calorific value of cotton, wool, silk, straw, grain, sugar, and similar organic materials can be taken as coming within the range for wood and paper. Considering their higher heating values, the 
weight of animal and vegetable oils, fats, and waxes, petroleum oils and other petroleum products, asphalt, bitumen, paraffin, pitch, and alcohol, should be multiplied by 2 to determine combustible contents.

Little difficulty is involved in estimating combustible contents for a given building or even a given occupancy. Typical pieces of furniture and units of contents can be weighed and the weight of finish, flooring, and trim computed. The total weight for a given or typical floor bay divided by the pertaining floor area gives the measure of the distributed combustible contents. Office and residential occupancies give the lighter combustible contents, the average for a building even with a combustible finish floor being seldom more than 10 to $15 \mathrm{lb} / \mathrm{ft}^{2}$ although spaces given to storage of records or other material will generally be more heavily loaded. Where such concentrations occupy only one floor bay or less that is not partitioned off, the dissipation of heat to the surrounding space would decrease the fire severity. For concentrations covering greater areas, the general building design would have to take them into account if they may occur anywhere within the building. If segregated to given portions thereof, the necessary protection can be applied at relatively low expense. If such concentrations are housed in fully enclosed incombustible containers, such as filing cabinets, enclosed shelving and similar equipment, the hazard is reduced to a point where it would require no greater protection than the general average for the building.

Stores and storage present in general the heaviest combustible contents. While the average for such a building may not exceed 20 or $30 \mathrm{lb} / \mathrm{ft}^{2}$ in a considerable portion thereof, concentrations of 60 or more $\mathrm{lb} / \mathrm{ft}^{2}$ may be present. Some building codes set a maximum of 3 - or 4-hr fire resistance beyond which building members need rot be designed, partly on the assumption that fire extinguishment will keep the fire severity within limits. It is, however, preferable and generally feasible to design the building or portions thereof for the full severity to be expected. Also, all main members such as columns, floors, walls, should be designed to have the required fire resistance since the effects on them of the exposing fire and their relative importance from the standpoint of prevention of building collapse are approximately the same (14). 
(b) FIRE-EXPOSURE CONDITIONS IN NONFIRE-RESISTIVE BUILDINGS

The fire exposure to be expected in buildings with combustible or unprotected interior construction is less determinate than for the fire-resistive type nor does it have equal interest from the standpoint of design. Collapse of interior construction is expected from an uncontrolled fire. Masonry walls are required from the standpoint of stability to be of thickness such that fire-resistance demands are generally met even where combustible building members project into them from one or both sides. The main interest concerns exposure conditions for safes and vaults which may be buried in the hot debris. An approximate measure of the hazard is represented by the sum of the weights of combustible building members and contents within the outside walls in all stories (21). Where this is less than $25 \mathrm{lb} / \mathrm{ft}^{2}$ of ground area of building, indications are that 1-hr safes may preserve their contents if impacts are not severe. Otherwise, 2 -hr safes or vaults should be used. These are required where combustibles exceed the above limit, and above $50 \mathrm{lb} / \mathrm{ft}^{2} 4$-hr safes and vaults are required, except that above the basement or ground story 2 -hr vaults may be sufficient. For contained combustibles over $100 \mathrm{lb} / \mathrm{ft}^{2} 6-\mathrm{hr}$ vaults are required in the basement or ground story, with possible decrease to $4 \mathrm{hr}$ for the story next above and to $2 \mathrm{hr}$ for other stories. For combustibles over $150 \mathrm{lb} / \mathrm{ft}^{2}$ it is preferable to avoid the basement location for the vault on account of possibility of prolonged heat exposure from the hot debris.

\section{FIRE-RESISTANCE CLASSIFICATION OF BUILDING TYPES}

By fire resistance in the present connection is meant the ability to withstand fire exposure from without and within, with no collapse of structural members and minimum amount of fire damage. It also pertains to such properties of the different building types as tend to prevent the origin and spread of fire within and also such as will make the building a fire barrier in case of a general conflagration.

\section{FIREPROOF}

The fireproof type includes buildings, the essential structural members of which consist wholly or mainly of incom- 
bustible materials, so proportioned or protected as to resist without collapse the whole severity of an uncontrolled fire consuming combustible building contents, finish, and trim.

\section{(a) CLASSES}

The two main classes from the structural standpoint are skeleton and bearing wall construction. For the former the loads from the stories above the ground story are supported on columns or on beams or girders supported on columns. For the latter the floor loads are supported wholly or partly on bearing walls. From the standpoint of fire resistance there is no preference as between the two classes.

(b) RANGE IN FIRE RESISTANCE ATTAINABLE

Features of general design, such as subdivision of large areas,and protection of vertical and horizontal openings, have a decided effect on restriction of fire spread as outlined in a subsequent section.

By proper design and choice of materials for structural members a fire resistance sufficient to withstand a complete burning-out of combustible contents can usually be attained with moderate proportions of members and protective coverings. By the same means the fire damage can be greatly decreased. This refers to choice of aggregates for concrete, type of clay and design of units for clay products, and methods of application. Plaster can be chosen of types likely to remain in place as exposed to fire, and thus increase the fire resistance of the member and decrease the fire damage. Plaster furred out from the surface of members such as walls and columns has been found particularly effective in preventing fire damage. All other factors being equal, hollow members suffer more damage from fire exposure than solid members, the damage extends farther in from the surface and is more difficult to repair. Hollow members of building units may, however, be preferable in sufficient degree from other standpoints, such as heat insulation and lower weight and cost, as to offset any disadvantage from the standpoint of resistance to fire.

The amount of combustible materials in exterior and interior finish and trim has an influence on the ease with which fires can originate and spread. Incombustible or fireretardant material for frames and sash is an aid in preventing communication of fire from floor to floor at exterior 
openings. They should be glazed with wire glass where needed from the standpoint of exposure from other buildings, other portions of the same buildings, or storage in the open of combustible materials in sufficient amount to create a hazard to the building. Increase in fire resistance for the building is obtainable with incombustible or fire-retardantfinish flooring, wainscoting, partitions, doors, frames, and sash. If wood is used, a considerable gain in fire safety is obtainable, particularly for interior use, by impregnation with chemicals to decrease flammability $(23,24)$. Incombustible or fire-retardant heat-insulating and sound-absorbing materials applied as boards, felts, or loosely as fills, are obtainable and should be preferred to the combustible types in locations where the latter would add appreciably to the general fire hazard otherwise created by the building and its occupancy (25).

\section{MASONRY WALLS WITH INTERIOR WOOD OR UNPROTECTED-METAL FRAMING}

\section{(a) CLASSES}

Subdivision within this type is based on difference in interior floor, column, and partition construction. In heavy timber or mill construction, floors consist of solid planking, tongued and grooved, splined, or laminated, not less than 3 in. in nominal thickness with a finish wearing floor of 1 in, or thicker boards. Roof planking is required to be not less than $2 \frac{1}{2}$ in. thick. Beams, girders, and columns must have minimum nominal thickness of 6 in. (26). In this as in other classes within this type, suitable means must be provided for anchoring floor beams into exterior masonry walls with provision for release when collapsing in fires. The main feature for this class is solid wood construction with absence of hollow spaces, this applying also for wood partitions. Portions thereof may have metal or reinforcedconcrete framing for which a fire resistance of not less than $1 \mathrm{hr}$ is generally required.

Interior unprotected metal framing will in general collapse sooner, as subjected to comparable fire exposure, than timber framing with members of 12-in. minimum dimensions, although cast-iron columns failed in tests only a few minutes earlier than timber columns with unprotected steel caps. Filling reentrant portions of structural-steel columns with 
concrete will increase the fire resistance to the range obtaining for wood members of comparable strength.

Unprotected wood-joist interior construction affords in general lower fire resistance than the heavy timber framing on account of the smaller size of members and the presence of hollow spaces that contribute to fire spread and make extinguishment more difficult. However, with suitable fire protective materials applied as a ceiling on the joists and firestopping of hollow spaces, fire resistance comparable with what is attainable with the heavy timber framing can be obtained.

\section{(b) EFFECT OF DETAILS OF DESIGN AND FINISH}

Subdivision of areas by means of self-supporting fire walls extended a few feet above combustible roof construction is one of the most effective means for restricting fire spread. Protection of vertical and horizontal openings is also effective, particularly during the initial stages of the fire. Finishes such as plaster on metal lath, gypsum lath, or wood lath, and plaster wallboard are effective in retarding fire in approximately the order named. Asbestos paper placed between the finish and base wood flooring will act as a smoke and fire stop. Filling hollow spaces at intersections of floors, roofs, partitions and walls, with incombustible materials, assists in checking the spread of fire through the hollow spaces in the framing. Protection of metal bearings in timber construction or substitution of bearing details of materials of lower heat conductivity such as concrete will increase the time before collapse of heavy timber construction occurs in fires (15).

\section{INCOMBUSTIBLE CONSTRUCTION}

This construction comprises buildings which have exterior walls, bearing walls, floor and roof construction, and other structural members, of incombustible materials, with or without fire-protective coverings, such coverings not necessarily preventing failure for other than relatively light fire exposures.

\section{(a) CLASSES}

The subdivisions within this type are largely defined by the materials used and their thickness, since this will determine the fire resistance of the construction. With incom. 
bustible exterior siding and roof sheathing, metal sash, and wire glass, this type of buildings gives fair resistance against exterior exposure, particularly with light interior contents not stored against the walls. Subdividing partitions and floors should be of incombustible materials.

\section{(b) EFFECT OF SPAN LENGTH, HEIGHT, AND LOADING}

As used in roof construction on spans of not over 30 or 40 $\mathrm{ft}$, the dead-load stress will not be large in comparison with the total design stress, which usually includes provision for resisting wind and snow loads. Since at the time of a fire the latter may not be present in significant amounts, the stress will be relatively low and the members can attain a higher temperature without collapse, than if loaded to have the full design stress. For the longer span lengths, the deadload stress will constitute a larger part of the total design stress. Hence the adaptability of this type for 1-story buildings with roof supported on moderate spans. Where combustible contents are light and heights above floor relatively large, such as in auditoriums, gymnasiums, and hangars, such roof construction using incombustible roof sheathing or slab, may withstand considerable fire in the contents without collapse. Height of unprotected members decreases the possibility of collapse from fire although not to the extent reflected in some building regulations that permit omission of protection on trusses with lower chord $20 \mathrm{ft}$ or more above the floor below. Such protection should be applied to structural members in multi-story buildings, irrespective of height above floor.

\section{WOOD CONSTRUCTION}

In this building type, the supports for the exterior wall construction, as well as those for the interior, are of wood.

\section{(a) CLASSES}

Different degrees of resistance against exterior fire exposure can be obtained, depending on the exterior facing used, the range being defined by brick or masonry veneer, stucco on metal or wood lath, cement-asbestos sheets or shingles, sheetmetal facing, and exterior wood board or shingle facing. When the building itself burns, however, the hazard to the surroundings is not greatly different for the several classes. 
(b) EFFECT OF MATERIALS AND DETAILS

As for type 3, a considerable increase in fire safety is obtainable with incombustible fire-resistive finishes for partitions and ceilings and fire stopping of hollow spaces (26). The fire-resistive properties of the roof coverings used are also important for this as for buildings of similar type, in protecting against exterior exposure and preventing undue hazard to neighboring construction if the building burns.

\section{STRUCTURAL CONTROL OF FIRE SPREAD}

\section{HEIGHT LIMITATIONS}

From the standpoint of fire hazard, no height limitations are generally applied to buildings of construction sufficiently fire resistive to withstand a fire consuming combustible building contents and trim, with a fixed requirement according to some building codes of not less than 3 to 4 hours fire resistance. In New York City such buildings over 150 $\mathrm{ft}$ in height are required to have incombustible or fire-retardant finish floors and interior trim. For buildings of this type having fire resistance in the range $11 / 2$ to $2 \mathrm{hr}$ for the flcor construction, height limitations ranging from 50 to 100 ft have been applied depending on the occupancy and occasionally on the area $(14,19)$. Buildings housing occupancies deemed to have the higher fire hazards are limited to lower heights than those presenting lower hazard.

For buildings of non-fire-resistive interior construction, height limits are lower since the building constitutes a greater hazard when it burns, fire-fighting operations must be conducted largely from the ground, and less-dependable measures can be realized for the exit of occupants in case of fire. For heavy timber interior, height limits up to $80 \mathrm{ft}$ have been recommended for business and residential buildings. For public buildings, height limits have been placed in the range 20 to $55 \mathrm{ft}$ or 1 to 3 stories, mainly to enable proper provision for exit to be made. For wood joist interior construction, limits ranging from 20 to $65 \mathrm{ft}$ or 1 to 4 stories, depending mainly on occupancy, have been applied, and for buildings with exterior and interior framing of wood, limits from 20 to $35 \mathrm{ft}$ or 1 to 2 stories. Unprotected metal buildings are generally limited to 1 story. Mezzanine floors or galleries not exceeding in aggregate area 25 percent of the area of the building, have been allowed. 
While reflecting a considerable variation due to differences in judgment and also possibly in local conditions, the above can be taken as indicative of the range in restrictions on height imposed with the object of attaining greater fire safety. Height limitations are also imposed on the score of city plan. ning and zoning, requirements for light, and resistance to earthquake shock.

\section{AREA LIMITATIONS}

While the building having fire resistance for structural members of 3 to $4 \mathrm{hr}$ or more is generally unrestricted as to area from the standpoint of State and municipal regulations, subdivisions to the practical limits dictated by occupancy requirements and cost is desirable. For buildings of the fireresistive type but with no more than $11 / 2^{-}$to $2 \mathrm{hr}$ fire resistance for interior construction, area limitations of 7,500 to $25,000 \mathrm{ft}^{2}$ have been applied or recommended for buildings facing on 1 street. For interior heavy timber or wood joist construction, these limits have been placed in the range 3,000 to $20,000 \mathrm{ft}^{2}$, depending on occupancy and also on building, height, and for wood frame construction, in the range 2,500 to $5,000 \mathrm{ft}^{2}(14,19)$.

The area limitations apply to sections sub-divided by fire walls or to the building as a whole if no fire division is present. For business buildings, garages, and hangars protected by automatic sprinklers, the area limits are generally increased by 100 percent. Increases in permissible area of 50 percent are generally allowed if the building fronts on 2 streets and up to 100 percent if fronting on 3 or more streets. The same allowances are made for buildings not located on a street line but directly accessible to fire apparatus on 2 or more sides.

\section{PROTECTION OF VERTICAL AND HORIZONTAL COMMUNICATIONS}

The inclosure of stair and elevator shafts and other vertical communications is a recognized means for restricting the vertical travel of fire and protecting avenues for egress of occupants. The inclosure can be directly at the shaft opening or by means of a room or lobby in front of the opening or openings. Stairs should preferably be continucus from first or street exit floor to roof. Where this is 
not the case, connecting hallways or passages should be inclosed in walls or partitions which with their supports through the structural frame of the building, should have fire resistance at least equal to that of the stair inclosure. For other than fire resistive buildings, the inclosing walls should be self-supporting from the ground up. In case of main entrances, objection is frequently made to the inclosure of stairs and sometimes elevators on the street-entrance floor. If the interior communicating openings to the entrance lobby on the same floor and to the floor below are fully protected, no considerable objection exists to the omission of such inclosure.

'To reduce the ease with which fire can be communicated from floor to floor on outside of light-court walls, a minimum distance of $3 \mathrm{ft}$ vertically between windows is desirable. For this and closer spacings, metal frames and sash preferably glazed with wire glass will give added protection.

Information relating to the protection of vertical communications and openings in walls and partitions is given in a previous section on opening protections. Emphasis might be placed on the desirability of utilizing as a fire barrier any wall in a favorable location by providing suitable doors at the openings, which can be done at the time the building is constructed or when existing door assemblies are due for replacement, at moderate added cost.

\section{PROTECTION AGAINST EXTERIOR EXPOSURE}

\section{(a) SPACING OF BUILDINGS}

As an aid in preventing communication of fire, building regulations are requiring wood frame buildings to be spaced not less than a distance of 3 to $10 \mathrm{ft}$ from the lot line or 10 to $20 \mathrm{ft}$ from the nearest building. Some codes permit closer spacing if the wall is filled with brick or similar material, finished with plaster on metal lath, or both. Such construction is generally allowed for the party wall in double frame dwellings although some codes require all party walls to be of masonry. For fireproof buildings and those with exterior masonry walls and interior wood framing (types 1 and 2), no restrictions are imposed and an exterior wall may be built on the lot line if conforming to the requirement for party walls. From the standpoint of code requirements, type 3 or unprotected metal buildings are in some codes unrestricted and according to others restricted in loca- 
tions the same as wood frame buildings. Considering heighi restrictions for this building type, it appears that no greater fire hazard is presented than for type 2 buildings. Party walls should, however, be of masonry.

According to the Public Buildings Act of May 25, 1926, Federal buildings constructed under the supervision of the Public Buildings Administration are required to be spaced $40 \mathrm{ft}$ from any line upon which other construction can be built, this distance to include bordering streets or alleys, unless by ruling of the Secretary of the Treasury a closer spacing is deemed safe and permissible in specific cases.

Other spacing restrictions may be imposed because of needed light, ventilation, hazardous occupancies, and means for egress. The spacing required from the standpoint of fire protection to the structure cannot be assumed as assuring that communication of fire will not take place. They should rather be regarded as aids in preventing spread of fire from building to building and make less probable a general conflagration, considering the fire-fighting facilities available.

\section{(b) PROTECTION OF EXTERIOR OPENINGS}

Building regulations require openings in exterior walls of incombustible construction to be protected where within 30 to $50 \mathrm{ft}$ from a wood frame building or an opening in any other building. Private dwellings and garages, churches, and show windows in the first and occasionally in the second story, are as a rule exempt from such requirements. Openings in walls in the same plane, or in parallel planes and facing in the same direction, are not regarded as mutually exposing. Protection is also required for openings distant not more than $50 \mathrm{ft}$ above a roof of combustible construction. As in the case of spacing of buildings, such requirements cannot be considered as assuring that fire will not be communicated to buildings with unprotected wall openings spaced more than the 30 or $50 \mathrm{ft}$ away from the exposing source. Fire has been communicated to fireproof buildings located $100 \mathrm{ft}$ from burning non-fireproof construction of considerable height and area. The hot blast created by a conflagration may create a hazard at much greater distances. With the protections required and the spacings for unprotected openings, it may be possible with available fire fighting within and without the exposed building to prevent fire from entering $651704-45-3$ 
under other than conflagration conditions. The type of construction of the exposing buildings is important as determining the degree of hazard as also their height and individual or aggregate area. The fully fire-resistive building with moderate size of wall openings presents a mild hazard compared with buildings of combustible interior, or interior and exterior construction. Full or partial collapse of exterior masonry walls may occur when interior construction is consumed and in any case the volume of flame and heated gas is not restrained by floor and roof construction that remains in place throughout the fire. The exposure is more severe to the portion of the exposed building a few stories above ground than to the lower stories.

The designer should, therefore, not be guided solely by current building-code requirements in providing opening protection. Tabulations, necessarily based largely on judgment, have been prepared, giving recommended protections for spacings from buildings within given height and area ranges of the different construction types, that might be considered as approximating full protection, particularly if some degree of fire fighting can be assumed within the exposed building. (See appendix to reference 28.)

The types of window protection include automatic-rolling shutters, swinging shutters, and metal window frames and sash glazed with wired glass. Where the exposure is very severe it may be necessary to supplement wired-glass window protection with some form of shutter. Outside sprinklers might also be used under some conditions to supplement other opening protectives. If the wall area to be protected is large the outside sprinkler will require a heavy draft of water that may at the time be needed for other extinguishing purposes within or outside of the building. Also the exterior details must be such as to direct the water over the window sash. Exterior sprinklers appear, however, well adapted for the protection of buildings of moderate height and area with wood exterior, the details of which have been designed and the sprinklers located to obtain flow of water over the whole exposed surface.

The cost of exterior window protection can be reduced for the larger openings where occupancy and location permit, by glazing marginal panels with obscure wire glass, using the clear glass only in the central panels: The cost of the combination would be little if any more than plate 
glass. The heavier frames and wire glass would have a longer life and offer greater resistance to high winds, hailstorms, and also to intrusion, than plain-glass windows.

\section{MEANS FOR EGRESS}

The source material for the following recommendations relating to egress requirements consists mainly of the building-exits code sponsored by the National Fire Protection Association (29) and results of studies on the same subject by the National Bureau of Standards (30).

Means for prompt egress may be required because of smoke or of panic not attributable to the presence of fire or actual peril therefrom. Hence such means should be provided even where the building and its contents may present only a very low degree of combustibility or fire hazard.

\section{GENERAL REQUIREMENTS AND ASSUMPTIONS}

\section{(a) DETERMINATION OF POPULATION}

The capacity of exits for different occupancies should be based on the actual number of persons to be evacuated and the allowance of time that may be given them to reach an area of refuge without being subjected to too great hazard. A guide to the minimum number of persons to be accommodated in different occupancies is given in table 3 . In many buildings provision must be made for larger numbers.

TABLE 3.-Assumed population density for typical occupancies

\begin{tabular}{|c|c|}
\hline Occupancy & $\begin{array}{l}\text { Gross floor } \\
\text { area per } \\
\text { person }\end{array}$ \\
\hline $\begin{array}{l}\text { Places of public assembly. } \\
\text { Places of public assembly, seating space. } \\
\text { Stores, street floors and sales basements } \\
\text { Stores, other floors. } \\
\text { Schools, court rooms, restaurants, etce } \\
\text { Office, factory, and workrooms.s. } \\
\text { Hotel and apartment } \\
\text { Institutional } \\
\text { Warehouse, storage, and garage. }\end{array}$ & $\begin{array}{r}f+2 \\
15 \\
6 \\
30 \\
60 \\
40 \\
100 \\
125 \\
150 \\
300\end{array}$ \\
\hline
\end{tabular}

(b) NUMBER OF EXITS

E'very floor area or room should have not less than 2 exits as remote from each other as practicable except rooms oc- 
cupied by less than 100 persons. Places of assembly or areas therein accommodating 600 persons or less should have not less than 2 exits. Those accommodating from 600 to 1,000 should have not less than 3 exits and above 1,000, not less than 4 exits.

The maximum area that may be safely served by a given type of exit will depend upon the fire safety of the building, its occupancy, and the course traveled before reaching a place of refuge. At least 2 exits should in general be provided from all floors. More will be required for large areas.

Floor areas of $3,000 \mathrm{ft}^{2}$ or less in buildings of fireproof construction and used for residential or business purposes or as garages, hangars or barns may under some conditions be safe with only 1 exit, although some requirements call for not less than 2 . The same applies for area limits of $6,000 \mathrm{ft}^{2}$ in fire-resistive buildings devoted to office occupancy and in which the maximum distance to an exit does not exceed $50 \mathrm{ft}$. This presupposes in multi-storied buildings, fully-inclosed stairways and adequate elevator service. The same rule would apply to areas in manufacturing buildings of the same class only when the building is fully equipped with automatic sprinklers.

\section{(c) LOCATION OF EXITS}

Exits should be located so that no point in a floor area, room, or space is more than $100 \mathrm{ft}$ distant from an exit, measured along the course of travel, except that in fireresistive office buildings and in buildings fully equipped with automatic sprinklers the distance may be $150 \mathrm{ft}$. Areas subdivided into small rooms and having corridors leading to exits, as in hotels and apartments, may have the exits located so that the travel distance from the room or apartment door along the corridor to an exit does not exceed the distance specified.

Every area or room housing a steam boiler, gas generator, or apparatus using gas or steam likely to be dangerous to the occupants should have not less than 2 exits, 1 leading directly to the outside.

(d) UNIT OF EXIT WIDTH

The width required for the free movement of a file of persons is $22 \mathrm{in}$. and has been chosen as the unit of exit width. Exit ways exceeding in width multiples of 22 in. by $12 \mathrm{in.}$ or more may have such excess counted as half a unit. 
Doorways used for exits should be not less than $30 \mathrm{in}$. wide and stairs, enclosed passages, or hallways, not less than 36 in., except that for the use of not more than 15 persons stairs of 30 -in. width may be used. The width of stairways should not decrease in the direction of exit travel.

\section{DOORS AND DOORWAYS}

\section{(a) EXIT CAPACITY OF DOORS}

The capacity of doors for exit purposes for alert and able-bodied persons may be considered as 60 per min per 22 -in. unit of width: A limit of 100 persons per unit for the period of evacuation seems justified, since part of the exits may not be available in an emergency. If only half are available this would correspond to an exit time of $31 / 3 \mathrm{~min}$. The capacity of exit doors from sleeping quarters and for institutions housing incapacitated persons may be considered as half that for alert and able-bodied persons, or a total of 50 per unit of width. All doors should be open in the direction of exit travel.

Narrow doors are readily congested in emergency and very wide doors appear to have lower capacity rates than those of 4 units or less width. Doorways 2 to 4 units in width are to be preferred to those outside this range where likely to be utilized to their capacity.

\section{(b) MOUNTING AND HARDWARE FOR DOORS}

Outward-swinging hinged doors are to be preferred for outside exits. Revolving doors, although used for outside exits, are given credit for not more than one-half of a 22in. unit of width. They should be supplemented by swinging doors adjacent to them. Rolling doors cannot be credited as exits and sliding doors only as entrances to elevators and at other locations with attendance.

Two doors at the same location in an exit, such as an inner door and a screen door or a detention grill and an outer door, should be provided with a vestibule or sufficient space between them so both can be hung to swing in direction of exit travel.

For interior doorways preference should be given to hinged doors swinging with exit travel in all exits used by by more than a few persons. Doors entering stair shafts should swing with exit travel and should be located so as 
not to interfere with those using the stairway for exit. Doors to elevator shafts, whether serving as means of exit or not, should be reasonably smoketight and fire resistive.

The fastenings of exit doors should be such that egress of occupants is not prevented or unduly impeded. Exit doors from places of assembly accommodating 500 or more persons should be equipped with exit bolts (panic hardware).

For types and fire resistance of doors for the difference locations see section III 2 (d).

\section{(c) HORIZONTAL EXITS.}

Horizontal exits consist of swinging doors through or around fire division walls or partitions. Horizontal exits through fire walls should have vestibules with 2 class $A$ doors in the line of egress. Doors leading to balconies for passage around fire walls may be class $\mathbf{B}$ doors.

Horizontal exits are credited with the same capacity for exit purposes as other doors, but augment by 50 percent the credits allowed other exits leading from protected areas on the side of the wall to which exit is made.

\section{STAIRWAYS, RAMPS, AND ELEVATORS}

\section{(a) EXIT CAPACITIES}

Stairways for buildings housing institutional or residential occupancies are considered as affording egress for 30 persons per 22 -in. unit of width and for other ordinary occupancies, including schools, 60 persons per unit of width. The required number of units of stair width is determined by dividing the greatest number of occupants on a tributary area on any floor above the stairway by this figure. Winding and spiral stairs are not desirable for general exit purposes and should be credited with not more than half the capacity of straight run stairs of the same width. Ramps are credited with the same exit capacity as stairs. Elevators are given little direct credit as exits and in the aggregate may serve for not more than 10 percent of the required exit capacity. However, the capacity allowed for stairs is set somewhat higher than it would be if elevators were not assumed present to carry a considerable portion of the exit load in high buildings.

\section{(b) CONSTRUCTION OF STAIRS}

The risers of stairs should not exceed $73 / 4$ in. in height and the treads should have not less than 9-in.-width exclusive 
of nosings, and should be proportioned so that the sum of the height of 2 risers and the width of 1 tread exclusive of nosings is not less than 24 and not more than 25 in. Stairs less than 2 units in width require a hand rail on 1 side only, other stairs require hand rails on each side and if more than 88-in. wide, intermediate hand rails are required so that the spacing of rails is not more than $88 \mathrm{in}$. Preferably there should be not more than a 3 -unit or 66 -in. width between hand rails.

Runs of stairs should have not less than 3 risers and should have a total rise between landings of not more than $8 \mathrm{ft}$ in public buildings and $12 \mathrm{ft}$ elsewhere. Antislip wearing surfaces should be provided for stairs or ramps exposed to the weather or slippery from other causes.

\section{(c) EXITS FROM STAIRS}

The exits from stair enclosures should be planned and marked so as to be unmistakable and should lead either directly to the outside or have short well-protected passages leading to the outside. It is allowable to have half of the required number and width of stairways empty into firstfloor areas of stores if such areas are sprinklered, and into the first floor corridors of office buildings having no large unprotected openings communicating with adjacent hazardous spaces, such as unsprinklered stores or similar occupancies. Floor areas into which stairways discharge should have exit doors of aggregate width not less than three-fourths the aggregate width of such stairways in addition to the doors required for the population of such floor area. The exit capacity of the stairs will not be appreciably decreased by this narrower aggregate width of the doors.

\section{OUTSIDE STAIRS, FIRE ESCAPES, LADDERS, AND CHUTES}

\section{(a) LOCATION AND LIMITATIONS}

Outside stairs and fire escapes in protected locations and under favorable climatic conditions form acceptable means of egress, otherwise they are looked upon as inferior to enclosed stairways and fire towers. Ladders are acceptable only as means of egress for the use of not more than 3 or 4 able-bodied men from boiler rooms or similar locations, and as means for firemen to retreat from the roof of a burning building to the top landing of outside stairs or fire 
escapes. Chutes or slide escapes are acceptable as 1 to 2 or more required means of egress from elevated floors or areas of industrial works housing processes of high hazard and under some conditions from institutions whose occupants are under constant supervision and control, such as school buildings, orphan asylums, hospitals, sanitariums, and corrective institutions. This assumes that they are regularly used in drills to familiarize the occupants with this method of exit and to maintain the surface of the chute in proper condition. Chutes together with entrance ways and discharge areas should be protected from fire and accumulations of snow and ice.

\section{(b) EXIT CAPACITY}

With farorable design and location, the exit capacity of outside stairs can be computed on the same basis as for iriside stairs. The capacity of chutes or slide escapes can be taken as 30 persons per min for each slideway, except that for schools, orphanages, etc., the inmates of which are under close supervision and where fire drills are practiced frequently, 50 percent additional credit may be allowed. If a required exit time of $21 / 2 \mathrm{~min}$ is taken, the latter figure would require 1 slideway for each 112 occupants. For hazardous occupancies exit time of less than 1 min may be required.

\section{(c) CONSTRUCTION}

Outside stairs, fire escapes, ladders, and chutes should be fire resistive to the degree needed by the service intended. Unless conforming with the requirements for inside stairs in point of general limiting proportions of heights and width of runs, platforms, risers, and treads, their use should be limited to existing buildings. Chutes should be designed to retard acceleration and to avoid congestion or interference at the discharge outlet. Openings in walls should have class $\mathrm{E}$ or better protectives where within $10 \mathrm{ft}$ of an outside exit way and be of fixed type or automatically closed.

\section{LIGHTING AND MARKING OF EXITS}

Buildings of public character or occupied by persons not ordinarily familiar with the exits should have lighted exit ways and exit signs visible from the exit approach. Exit ways, the direction of egress in which is not readily apparent, 
should have direction signs. Luminous or well-illuminated signs should be provided for the exit of places of public assembly.

Green to correspond with other traffic signals is suggested for exit ways rather than red which in most signal systems indicates "danger" or "stop".

Story designations should be marked inside of stair and elevator shafts and the landing at the exit leading to the outside should be marked in such a manner that persons cannot inadvertently pass it.

The floors of exit ways from places of public assembly should be illuminated at intensities of not less than $1 \mathrm{ft}-\mathrm{c}$ at principal points, such as corridor intersections and angles, passageways, stairways, stair landings and exit doorways, and at other points to intensities of not less than $0.5 \mathrm{ft}$-c. The latter intensity should be used for exit ways of buildings of other occupancies.

\section{ENCLOSURE OF EXIT WAYS}

Inside of buildings, stairs, elevators, ramps, and exit corridors should be inclosed with constructions having fire resistance as outlined in section III 2(b), and the openings in the enclosures suitably protected (sec. III 2(d)). Ramps, bridges, stairs, and chutes outside of buildings are generally not required to be enclosed if exposing adjacent openings are protected.

\section{SAFEGUARDING COMMON HAZARDS}

\section{HEATING AND VENTILATION}

In fireproof buildings fire hazards from heating equipment can generally be safeguarded with little added detail. Fire-resistive inclosure for the heating equipment and fuel storage is usually required with protectives in the openings. Rooms housing oil or gas heating equipment or storage should, in addition, be vented to the outside and the enclosure should be as fully gas-tight as can be practically attained. Fires have been communicated through fire-resistive floors unduly exposed from beneath by heating equipment. Proper insulation of furnaces and boilers decreases not only heat loss but also the fire hazard. Where furnaces are supported on a floor not directly on the ground, an air space should 
be provided between the equipment and the floor, as materials such as mortar and concrete are disintegrated by prolonged heat exposure even if of moderate degree. Wood piling in dry soil under concrete slabs 3 -ft thick has been charred from a boiler setting supported on it without an air space. Wood forms left in place under concrete basement slabs or arches under fireplaces have been ignited in a similar manner.

Exhaust ventilating systems present little possibility of causing spread of fire or smoke. Plenum systems are best safeguarded by locating inlets and unprotected ducts at points where fire or smoke is unlikely to enter. The fire shutters actuated by fusible links that are installed in the ducts may not function until after communication of a considerable volume of smoke and heated gases. Fan rooms should be designed to accommodate no other materials or equipment and provision should be made to prevent accumulation of oil and dust.

Combustible interior and exterior building construction must be safeguarded by proper protections and spacings for heating equipment and accessories. A 4-in. thickness of brick plus flue lining or equivalent, is generally considered the safe minimum for chimney walls (31). Ceilings above furnaces and fuel rooms generally need protection with incombustible finishes. Smoke pipes should not pass through combustible floors or roofs and if passing through partitions, ventilated thimbles of 8-in. larger diameter than the pipe should be used or of 4-in. larger diameter if filled with incombustible insulating material. Long runs of horizontal metal pipe are undesirable unless of heavy gage with riveted joints. Stoves and uninsulated furnaces of the size used in residences generally require a spacing of not less than 24 in. from combustible walls or partitions unless protections are applied (27) (32).

High-pressure steam should be reduced to the low pressures required for heating before the pipes are passed through combustible constructions and metal sleeves provided around the pipes passing through floors and partitions. Proper pressure-relief valves and fusible plugs are required for heating boilers. In installations where a check valve is placed in the water supply line to prevent back flow through the water meter, all heater equipments, such as water heaters, supplied through the connection should be 
equipped with pressure-releasing devices. In addition there should be provided a separate connection from the heater with a check valve in it set to release into the supply line at a point sufficiently remote to prevent damage to the meter from the back flow of hot water.

\section{ELECTRIC LIGHTING AND POWER}

The electric circuits and equipment of a building present a possible hazard that on account of the extent of their distribution and continuous presence of potential, justifies safeguards that otherwise might be considered excessive. The fire and life or accident hazard are in general inseparable, and the electric installation should be designed to safeguard them. General requirements covering both have been formulated $(30,31)$.

\section{(a) CONDUCTORS AND THEIR PROTECTION}

Safe current-carrying capacities of conductors are given in tables 1 and 2 with supplements of reference (33) and the fuse or other overcurrent protection should be of the same rating as the rated capacity for the given size of wire unless otherwise provided for equipments such as motors that may be connected. Ordinarily Nos. 14,12 , or 10 AWG wires are used for lighting or small appliance branch circuits, fused with 15-, 20-, and 25-amp fuses, respectively. Regardless of the size of wire, lighting circuits with fixtures wired with No. 18 or 16 should be fused for no more than 15 amps. The rules of the Supervising Architect of the Public Buildings Administration require not smaller than No. 12 AWG gage for lighting branch circuits and where the distance from the lighting panel to the first outlet exceeds $75 \mathrm{ft}$, No. 10 wire is to be used to the first outlet. Careful consideration must be given the power demands of equipment such as banks of elevators.

Rubber wire insulation conforming with Federal Specification No. J-C-103, for type RP, performance grade, or RH, heat-resistant grade, is preferable to type $R$, code-grade rubber insulated wire. Where dampness may occur, Type RW, moisture-resistant insulation as defined in the above specification should be used. Requirements for lead sheath are covered in the given specification as also for conductor and braiding. Portable cord with rubber outer sheath of type 
POSJ is designed for light duty, type SJ for hard usage, and type $\mathbf{S}$ for extra hard usage (33). Type $\mathbf{A}$, asbestos insulation, should be used in hot dry places and where wires are bunched as on the back of a large switchboard or in a wire tower. Where exposed to oil or oil vapors, Type SN, synthetic insulation (33), gives good performance and for use in corrosive atmospheres proper choice should be made of types best suited for the conditions.

Overcurrent protection may be afforded by the use of fuses or circuit-breakers. Approved fuses are available in the plug type up to 30 amperes and in the cartridge type to 600 amperes. Nontamperable plug fuse bases not only insure the nontamperability but also prevent insertion of a fuse of improper rating. Nontamperable adapters may be used in ordinary plug-fuse cut-out bases. Renewable type cartridge fuses are generally limited to buildings where a competent electrician is employed. Approved circuitbreakers are available in the usual current ratings for branch circuits and feeders or incoming mains.

Overcurrent protection should be provided for all branches of smaller size than the main from which they are tapped. Overcurrent protective devices should always be enclosed in metal cabinets or boxes with hinged covers. All switches accessible to other than qualified persons should be of the enclosed type operative from the outside. Switches controlling branch circuits should preferably be grouped within a metal cabinet. Switchboards supporting exposed switches and conductors should not be used where accessible to other than qualified persons and in general are being abandoned in favor of dead-front switchboards having all current-carrying parts enclosed in steel.

\section{(b) OIL-FILLED APPARATUS}

Oil-filled apparatus comprises in general transformers, oil switches, and induction regulators. Transformers and oil switches for important buildings should be installed preferably outside. If located within buildings they should preferably be on the ground floor (basement), structurally segregated from the rest of the building and from each other, with vents to the outside. Transformers of $25 \mathrm{kva}$ or less rating are not generally required to be structurally enclosed. Curbs at door openings and floor drains with traps serve to carry away spilled oil to a suitable location. Fire extinguish- 
ment of suitable type, preferably automatic, provided for the enclosure, will increase the safety of the installation. If transformer oils presenting low fire hazard are used, such as chlorinated petroleum oils, automatic fire extinguishing equipment would not be needed but means must be provided for venting or other safeguards provided against toxic fumes that may be given off.

In the case of oil switches protection must be provided against scattered burning oil. No wiring not essential to the transformer installation and the space occupied, nor pipes for water, steam, gas, sewers, or other purposes, accessories such as faucets and sprinkler heads, and ducts for ventilating other parts of the building, should be installed in transformer vaults, even if concealed in furred ceilings. Conduits housing the power leads to transformers should be sealed to prevent entrance of water and gases. While precautions along the lines indicated above should be taken, it should not be inferred therefrom that transformers present any extreme fire hazard as this is not warranted by their comparatively good fire record.

\section{(c) MOTORS}

Motors, motor bearings, resistors and reactors for starting, and the bearings of motor-driven machines should be treated as sources of heat in their installation and separation from flammable material. This applies especially to motors which start or stop automatically or which may operate while unattended. Unless the motor is of a fully enclosed type, fire in the windings augmented by electric ares may emit sufficient radiant heat to ignite exposed flammable material at considerable distances. A thermal protector that cuts the current off when the motor temperature reaches a given limit serves to prevent such incidents and also serious damage to the motor.

\section{(d) GROUNDING}

When alternating current is used the comparatively low voltage supply of the building is usually derived through transformers from much lighter potential transmission circuits. By connecting one of the low-voltage circuit conductors to ground through a low-resistance, high-currentcarrying path, the potential of the ungrounded conductor may be fixed with respect to ground so that accidental crosses between the low-voltage circuit and high-voltage circuits outside of the building cannot increase the life and 
fire hazard by increasing the potential impressed on circuits and appliances within the building.

The combination of grounding one conductor of the building circuit and the non-current-carrying parts of electrical equipment will insure the immediate disconnection of a faulty circuit from the supply by the operation of an automatic over-current protective device in case a breakdown of insulation occurs between an ungrounded conductor of the circuit and an exterior metallic part. Portable appliances should, where practicable, operate on 110 to $120 \mathrm{v}$ and preferably have outside surfaces either of insulating material or connected to ground if of metal. The grounding may be obtained by the use of a three-wire portable cord, one wire being used for the grounding conductor. This will require a special form of receptacle and plug. In damp locations rubberjacketed cord with insulated lamp sockets should be used.

\section{(e) HAZARDOUS LOCATIONS.}

Any location in which the atmosphere may be explosive because of flammable gases or vapors, the suspension of flammable dusts or flyings or where it is impracticable to prevent combustible dusts from collecting on motors or other electrical devices in such quantities as to interfere with normal heat radiation, or any location where ignitable fibers or materials producing combustible dust are handled, is classified as a hazardous location. In such locations, sparks and heating, that may be harmless in ordinary locations, must be avoided. This is possible by the use of electrical equipment designed for use in hazardous locations properly installed $(33,34)$.

Electric-light sockets less than $8 \mathrm{ft}$ above the floor in damp locations or in those where persons can contact them and grounded building parts, fixtures, or equipment, should be of porcelain or other nonabsorptive insulating material, or grounded if of metal. Droplights should not be used in such locations. Currents of $0.01 \mathrm{amp}$ or more passing through the human body are considered dangerous. The dry skin gives contacts a resistance from 5,000 to $100,000 \mathrm{ohms,}$ but when moist this may be reduced to less than 1,000 ohms.

\section{GAS INSTALLATIONS}

As in the case of electrical installations, in safeguarding against the fire hazard, life and accident hazards from asphyxiation, burns, and explosion must also be considered. 
Venting through a fire-resistive flue to the outside is generally required for manually controlled gas appliances, except domestic gas ranges, using in excess of $50,000 \mathrm{Btu} / \mathrm{hr}$, or if all equipment within a room consumes 30 or more (Btu/hr) $/ \mathrm{ft}^{3}$ of room space. Automatically controlled appliances are required to be vented unless equipped to shut off the gas supply if the pilot light is extinguished and the gas consumption is less than 5,000 Btu/hr. Recommendations covering general requirements for safe installation are available $(35,36)$. Appliances such as domestic gas ranges should be spaced 6 in. from a combustible wall or partition unless tested and found safe with a closer spacing. In appliance installations, flexible tubing should be avoided and in lighting installations, swinging gas fixtures.

Liquefied gases present inherently greater hazard in transportation, storage, and use than gases at ordinary pressures and most flammable liquids. The boiling point at atmospheric pressure being below ordinary room or outside temperatures, evaporation of the free liquid will take place rapidly with formation of explosive mixtures with air. Where large quantities are involved, spacing within reasonable limits, of storage or operations from other buildings and occupancies does not afford a sufficient safeguard, and dependence must be placed on containers constructed and protected to prevent rupture, and valves and other safety devices arranged to prevent accidental discharge. Those handled in large quantities comprise mainly liquefied petroleum gases (37).

Fixtures and burners must be adapted to burn the gas concerned. Care need be taken to prevent deterioration at joints, metal-to-metal contact being preferred. Scenting the gas to enable detection of leaks is advantageous.

\section{LIGHTNING PROTECTION}

The principal damage done by lightning arises when it traverses nonconductors, in which case it may cause fire and may do mechanical injury. The type of building, therefore, is of major importance in determining the need for protection against lightning and the type of protection, although the nature of the contents must also be considered. Wherever the building or its contents are highly combustible, special attention should be given to protection against lightning. 
Buildings which are metal-covered or which have a steel or metal-reinforced frame need attention at points where the discharge of lightning may enter or leave the building. Such buildings sometimes have terra cotta or other embellishment or superstructure, which, being nonconductors, should be provided with metal air terminals bonded to the steel frame, if considered of sufficient value to require protection. The steel frame should also be thoroughly grounded, preferably to buried water-supply piping outside of the water meter. Metal roofing which is electrically continuous (not discrete metal shingles), grounded through downspouts or other metal having adequate joints and ground electrodes, serves acceptably as lightning protection.

Buildings of stone, brick, or frame construction can be protected by a complete system of lightning rods. Detailed specifications for such a system are available (38). It has been general experience that where buildings that do not differ greatly in height are spaced closely over a considerable area, such as in the built-up portions of cities, there is less probability of lightning striking than for isolated buildings. Monumental buildings, because of their character and sometimes also because of their height and isolated location, are in special need of protection against lightning.

Steel flagpoles on buildings should be grounded on the steel of the building by a structural connection or by means of a copper conductor large enough to withstand mechanical damage and corrosion that may affect it. Wooden flagpoles should be provided with a bare copper conductor, fastened directly against the wood extending from the top of the pole to an effective junction with the structural steel or the ground connection.

\section{SAFEGUARDING SPECIAL HAZARDS}

Among special hazards can be named packing and shipping operations, storage of hazardous liquids or chemicals, woodworking, painting, and similar hazardous processes, and showing, handling, or storage in quantity of nitrocellulose photographic, X-ray, and motion-picture film.

\section{GENERAL PROTECTION MEASURES}

Where located in the same building with other occupancies, special hazards are generally safeguarded by struc- 
tural subdivision, automatic fire-extinguishing equipment, or both. Where the activity or storage is of considerable extent or extra hazardous, a separate building may be required. In any large building designed for general oflice, residential, or institutional occupancy it may be desirable to provide one or more ventilated vaults for the storage of hazardous materials, not including flammable liquids other than in small containers. Such vaults should preferably be located on the roof or in the upper story to enable ready venting to the outside $(39,40)$. If located in lower stories the vent should preferably be placed so that no windows, doors, or other wall openings are within $50 \mathrm{ft}$. The wall, roof, and floor constructions of such vaults should be designed to resist moderate pressures that may result from the burning of hazardous materials within them even if vented according to recommended standards.

\section{HAZARDS DURING CONSTRUCTION, DEMOLITION, AND ALTERATION}

Many disasters have occurred during the construction or alteration of buildings due to fires in combustible false work and building materials (41). The Fall River, Mass., conflagration of 1928 started in a building that was being demolished and from which automatic-sprinkler protection had been removed.

The use of incombustible materials as far as possible in form work, or of wood treated to reduce flammability, would assist materially in decreasing construction hazards. The fire protection of structural members should follow erection as closely as practicable and some stairs, elevators, and standpipes should be carried up with the construction. Heating during construction should preferably be by steam or by other method less hazardous than stoves or open fires. The permanent heating plant might be installed and utilized at an early stage of the construction for this purpose.

\section{STRUCTURAL PROVISIONS AGAINST THE EXPLOSION HAZARD}

For the storage of high explosives underground magazines may be adapted, the required depth underground depending on the amount and character of the explosive. Not only are the destructive effects on the surface of the ground from the 
explosion wave greatly reduced by such location but the probability of sympathetic detonation of nearby magazines in similar subsurface locations is also greatly reduced. This assumes soil, sand, or soft clay formations with absence of rock or hard pan. For manufacture, handling, and storage of explosives in large amounts conducted above ground, the preferable building type would be one of subsantial construction, that is, fire, theft, weather, and bullet resistant. The materials and their assembly should be such that in event of an explosion, scattering of the material will cause the least destructive effects. Practically, it will be found that considerable weight and resistance must be incorporated into the structure to attain the necessary strength and resistance to the elements. The following types of materials have been found satisfactory for surface magazines : medium soft brick; double wood walls, preferably of not less than $2 \mathrm{in}$. thick plank, so as to provide a space of not less than 6 in. to be filled with screened sand, earth, lean concrete ( 1 part cement to 7 parts sand) or other similar material, covered on the outside with sheet iron not less than 26 gage or other fire resistant material; concrete block with the cells filled with materials mentioned previously.

Explosives magazines should be located according to the American Table of Distances (42). Barricades of earthfilled timber cribs or retaining walls built around magazines will decrease the hazard from explosions outside of the barricade and by blanketing flying debris and directing the explosion wave upward, will decrease the damage to neighboring construction from explosion within the barricade. Location in deep narrow valleys has an effect similar to that obtained with barricades. Large trees also will decrease the range of flying debris and assist in breaking up the pressure wave caused by the explosion. With adequate barricades, the distances from inhabited buildings, public railways, and public highways may be decreased by one half according to the American Table of Distances (42).

Small amounts of explosives in excess of immediate laboratory or experimental needs are best stored in vaults on sublevels. Such vaults may be constructed of concrete, brick, steel or other fire-resistant materials. Explosives for uses other than those above mentioned should be stored in external magazines.

If it is necessary to provide protection against explosions of only moderate intensity such as those involving a minor 
amount of explosives or those depending on the combination of a gas or dust with the oxygen of the air, there is considerable advantage in designing buildings which will not collapse under the pressure produced. This can usually be accomplished by providing a strong frumework with vents or openings in the walls or roof through which explosive pressure can be released before it becomes sufficiently high to cause collapse or structural damage. Protection against the elements can be obtained by covering or closing these openings with material which will be easily blown off or readily ruptured by pressure from within or by using light panels, doors, and windows hinged to swing outward. 'The use of vent's for the release of explosion pressure has been specially recommended for buildings subject to dust explosion hazards (43).

The weight or resistance of opening closures and the size and spacing of vent openings required to insure that explosion pressure will not exceed the structural resistance of the building, will depend both on the type of construction and the severity of the explosion. To release the pressure produced in explosions of materials such as certain types of grain dust or coal dust, which have comparatively low rates of pressure rise, 200 to $500\left(\mathrm{lb} / \mathrm{in}^{2}\right) / \mathrm{sec}$, vent areas of $1 \mathrm{ft}^{2} / 80$ $\mathrm{ft}^{3}$ of room volume have been found satisfactory for approximately cubical shaped rooms or inclosures in buildings of heavy mill type construction. Certain types of starch and metal powders produce explosions with much higher rates of pressure rise, 1,000 to $5,000\left(\mathrm{lb} / \mathrm{in} .{ }^{2}\right) / \mathrm{sec}$ and vent areas of $1 \mathrm{ft}^{2} / 25 \mathrm{ft}^{3}$ have been recommended where such materials are handled (43).

Buildings constructed to house operations in which explosion hazards may exist can be built to resist pressures of 500 to $1,000 \mathrm{lb} / \mathrm{ft}^{2}$ at little additional cost over ordinary construction and large window areas can be provided to serve as vents to release explosion pressure at or below $500 \mathrm{lb} / \mathrm{ft}^{2}$. Double strength A quality glass in 14 - by 20 -inch panes will break under dust explosion pressure of $510 \mathrm{lb} / \mathrm{ft}^{2}$. Larger panes will break at lower pressure and scoring the outside surface of the glass with a diamond or cutter has been found to reduce the resistance to about one-fifth that of the unscored pane (44).

The steel frames of large fixed windows will frequently buckle and be forced out of their settings at pressures below the breaking strength of the glass they contain. Special types of steel sash, hinged to swing outward and normally 
held closed by some friction device, have been designed specially for use as explosion pressure vents and are available for installation in plants where explosion hazards exist.

Buildings within which hazards from explosions exist require special precautions appropriate to each type of hazard in the types of mechanical and electric equipment installed with the object that dust accumulations, presence of dust clouds, or ignition thereof, may be prevented. Studies relative thereto as well as general fire-prevention precautions, applicable to a range in hazardous occupancies have been made and recommendations for promoting safety are available $(42,43)$.

\section{CONSTRUCTION AND EQUIPMENT FOR PROTECTION OF RECORDS}

\section{BUILDING CONSTRUCTION AND FINISH}

The prospective content of records of some buildings, particularly Government and office buildings, is of such volume and value as to justify special consideration in the design and finish of the building. This will require fireproof construction, well protected against exterior exposure with little or no combustible interior finish, floors, doors, and trim. Undivided areas should be moderate, preferably less than $10,000 \mathrm{ft}^{2}$, and vertical and horizontal communications well protected. Combined with proper equipment for housing the records and good housekeeping, a good degree of protection is attainable by this method (45). It is well adapted for conditions involving a large volume of records of value high enough to require special protection measures.

\section{RECORD VAULTS}

In nonfireproof buildings and in fireproof buildings where structural and occupancy conditions are not favorable, excellent protection can be obtained for records in suitably constructed vaults having fire resistive doors. This type of protection is particularly adaptable for records not in frequent use.

Record vaults have been clasisfied as 2,4 , and $6 \mathrm{hr}(20)$ but should be constructed to withstand the fire conditions in the location concerned, some general information relative to which is extant (21). In nonfire-resistive buildings they 
must be supported on the ground independent of the building but in fire-resistive buildings, designed to withstand any fires that can occur within them, may be supported on the structure. The most severe fire exposure conditions occur in the lower stories of nonfire-resistive buildings where the vault may be covered with hot debris for a considerable period after the fire has subsided. The wall and floor thicknesses required can be judged from the fire-resistance ratings for the types of wall and floor assemblies that are to be used. The openings into record vaults should be restricted to those required for entry and ventilation.

\section{RECORD ROOMS}

In fireproof buildings records in considerable volume but not of the highest value can be given protection by segregation in rooms enclosed by walls and floors of fire resistance proportioned for the severity of fire to be expected, but not less than about $2 \mathrm{hr}$. The finish floors, and trim of record rooms should be of incombustible materials and all interior and exterior openings properly protected (20).

\section{RECORD STORAGE BUILDINGS}

For large volumes of records that need be consulted only occasionally, considerations of economy as well as fire protection indicate that storage can best be made in buildings constructed and equipped for the purpose. Such buildings can have incorporated in their construction, finish, opening protection, and equipment, the elements most conducive to fire safety, and with proper operation and maintenance, a high degree of protection is attainable.

\section{FILM VAULTS}

Vaults for the storage of nitrocellulose film if located within buildings housing other occupancies should preferably be located on the roof or in the upper story so they can be readily vented to the outside. If vented through the wall of the building, no windows, doors, or other wall openings should be located within $50 \mathrm{ft}$ from the vent $(39,40)$. Experimental studies indicate that the pressure developed by burning nitrocellulose film is dependent on the amount of vent area per unit weight of film. With the vent area re- 
maining constant, the pressure rises slowly as the amount of film is increased until a critical point is reached at about $6 \mathrm{lb}$. of unenclosed film per square inch of vent area above which the pressure rises rapidly. It was also found that under comparable conditions, film enclosed in containers developed less pressure when burning than unenclosed film and it appears therefore that partitions, cabinets, and other means of separation would lower the pressure hazard. If the ratio of $5 \mathrm{lb} / \mathrm{in}^{2}$ of vent is observed, a ratio recommended by the National Archives, the pressures to be expected would be no more than one-half of those obtained with $7 \mathrm{lb} / \mathrm{in}^{2}$ of vent area. In the tests it was also found that with the same ratio of film weight to vent area the pressures decreased with the ratio of film weight to volume of vault.

With reinforced concrete construction sufficient resistance can be built into it without difficulty to prevent failure under the pressure of $5 \mathrm{lb} / \mathrm{in}^{2}$ to be expected with unenclosed film in amount equivalent to $5 \mathrm{lb} / \mathrm{in}^{2}$ of vent. This assumes proper disposition of the reinforcement and design stresses approximating the proportional stress-strain limits of the materials. The rate of pressure rise from the burning of nitrocellulose film in vented vaults is not so rapid that the inertia of the construction can be depended on to offer appreciable resistance to rupture of the enclosing construction, although it would be involved in decreasing the scattering of broken parts thereof. No negative pressure wave, after the inside pressure is spent, is to be expected in the burning of nitrocellulose film in vented enclosures, but pressures approximating those in explosions, with subsequent negative pressures, can be developed if there is no vent, or the vent is obstructed. While automatic sprinkler protection in vaults cannot, under all conditions, be depended on to prevent building up of high pressures from burning film, upright partitions between tiers of film, cabinets or other separations, concentrate the heat on the sprinkler lead, causing it to operate sooner than otherwise, or to delay the spread of fire to unaffected parts of the vault, thereby decreasing the peak of maximum pressure.

\section{EQUIPMENT}

(a) FURNITURE

For record vaults, record rooms, record-storage buildings, and general-occupancy buildings designed to afford the best 
protection, all shelving and other record containers should be of incombustible materials and preferably afford full enclosure. For open shelving, that with solid backs and partitions is preferable. Metal shelving open on all sides gives very little more protection than wooden shelving. In shelving open at the front, the rate at which fire spreads decreases with the size of compartments. Metal filing cabinets supported on incombustible structural and finish floors afford good protection. The contents may, however, be ignited and destroyed by a fire in a finish floor of 1-inch boards (45).

No definite degree of protection can be given by incombustible uninsulated record containers in non-fire-resistive buildings or fire-resistive buildings where fires can attain volume in freely exposed combustible contents, equipment, and trim. For such condition valuable records should be protected in vaults, record rooms, or insulated safes.

\section{(b) PORTABLE RECORD CONTAINERS}

Insulated safes and other portable insulated record containers are adapted for protection of relatively small volumes of records that are in frequent use. Only a small percentage of the records originating in connection with many activities have high value and these can be given protection in portable insulated record containers or, if the fire exposure to be expected is severe, in record vaults, the fire resistance of which is adequate for the locations concerned.

The current classifications of insulated safes, A, B, and $C$, correspond to fire-endurance limits of 1,2 , and 4 hours (46), and of insulated cabinets, 1 hour and 1/2 hour (47). The most severe fire exposure for safes results from contact with the hot ruins of nonfireproof buildings and for some conditions the highest fire resistance afforded by this type of container may be inadequate. For fireproof buildings it is generally possible to select safes and cabinets of classes designed to resist the full severity of the fire that can occur in the locations concerned.

\section{FILM CABINETS}

The standards set for vaults for nitrocellulose film $(39,40)$ assume storage on open racks. If greater protection is desired for film of record character or special value, cabinets can be placed inside such vaults (48). Where vaults 
are not available, cabinets are necessary. Storage in one location of up to 1,000 pounds in cabinets provided with automatic sprinklers and vented to the exterior is considered permissible, each cabinet to contain not more than 250 pounds, preferably less $(39,40,48)$. For films of secondary value in amounts of 100 pounds or less, stored in cabinets vented to the exterior, sprinklers are not generally considered necessary, nor for films of primary value, where the cabinet is so constructed and insulated that each roll of film is in an individual compartment, the contents of which may burn without igniting the film in the other compartments.

It is to be noted that the object of housing of nitrocellulose film is to prevent ignition from extraneous causes, and to prevent the spread of ignition, once started. There is no evidence that such film will ignite from spontaneous heating starting at temperatures within the ambient range obtaining within habitable portions of buildings. This applies for the new film, as well as for film in various stages of decomposition.

Vaults and cabinets equipped with automatic sprinklers require not only water connections of adequate size, but also floor drains. Water supply lines should be located and protected against failure from fire exposure. Vaults in nonfireproof buildings must be ground-supported and constructed and protected, so that collapse of the building in a fire will not destroy or seriously impair their structural integrity and the protection for the contents. Cabinets can give assured protection only in fireproof buildings that can withstand destruction of the contents by fire without floor, wall, or other structural collapse.

\section{FIRE-ALARM AND WATCHMAN'S SUPERVISORY EQUIPMENT}

The principal functions of fire-alarm equipment within a building are to summon quickly and accurately to the trouble those who will extinguish the fire and protect property exposed to fire and water damage and to warn occupants so that exit can be made if necessary. For the performance of its functions, the fire alarm system must provide:

(1) A reliable means continuously present for transmitting the signal. If operated manually, it must be readily accessible and require only the most elementary performance 
on the part of the sender to reduce to a minimum delay or error due to sender's distraction or unfamiliarity with the equipment.

(2) The signal must reach those trained to respond, it must compel immediate attention, and mean "fire" without possibility of misinterpretation; and it should, if necessary, also designate the approximate location of the fire.

The type of building, occupancy, and construction are the determining factors governing the type of the fire alarm system, or the watchman's report system to be iristalled in any building.

Equipment for supervision of watchmen's rounds increases the reliability of this service which would increase the probability of preventing conditions conductive to origin of fires and make more likely their discovery in the early stages. While fire in some materials gain headway rapidly, in furniture and ordinary building contents fires progress more slowly, particularly if no accumulations of loose combustibles are present and the materials in the building do not contribute fuel for the fire.

\section{MANUAL FIRE-ALARM SYSTEMS}

In these systems the alarm is transmitted to a central point by pulling a lever, pushing a button, or breaking a small glass panel or other frangible member in a fire-alarm box. The access to the lever or button is generally protected by a hinged door or by a glass panel that must be broken. Some boxes give the alarm automatically with the breaking of the glass or other frangible panel or member. This may sound a general alarm, or only at certain designated locations from which alarms in the whole or given portions of the building can be initiated. For coded systems, the location of the box pulled is indicated by the ringing code and by the record on the register, if one is provided. If desired, it may be indicated by lamps or drops on an annunciator board. Equipment recording the alarm by perforation of a paper tape or printing of a number can be supplied as also a stamp to record the time it is received.

The minimum size of building in which such equipment should be installed will vary with structural and occupancy conditions. In hotels, dormitories, and apartment houses, some State and city regulations require bells for sounding a general alarm, as a means of notifying the occupants. This 
type of alarm, particularly if indicating the location of the fire, is also of assistance in summoning anyone within hearing to fight the fire. There appears to be no object in providing for reception and recording of signals at one or more central points (presignal feature), unless someone is on duty at one or more of them at all times of the day and night. Careful consideration should be given to the type of system to be chosen for given buildings, considering construction, size, and occupancy. Coded systems in general cost more than those of the uncoded type and central indication, recording and time stamp add to the initial as well as maintenance cost. A common-sense appraisal of the added value for given conditions of these features will often be very informative. Codes if used should be designed to give for the first one or two digits the general location such as story of the building, and the next digit a more specific location within the story. Even so, building occupants and personnel may not memorize ringing codes, but for large fireproof buildings the system can be zoned so that initially only the bells in the section where a box is pulled will ring.

\section{(a) TYPES AND SPECIFICATIONS}

Systems of the noncoded type have considerable merit in their simplicity of operations, ease of maintenance and low initial cost. For smaller buildings and building groups, where an elaborate coded system is not justified from the standpoint of cost or where the use of the system is so infrequent that the coded signal loses its locational value, the noncoded system with an annunciator panel at a central receiving point such as a watch office or a telephone operator's desk, is an alternative for the coded system.

For the smaller buildings requiring fire alarm equipment, the annunciator panel is omitted, the system being of the general-alarm type, in which the pulling of any box will ring all fire-alarm bells within the building or a given fire-subdivision thereof. Such systems can be electrically supervised to indicate continuity of electric connections. Such supervision does not, however, indicate mechanical defects in boxes and gongs, and unless double terminals are used at boxes, it may not even indicate whether the box is electrically connected with the system. Hence periodic tests by operating all boxes and noting performance of all bells are desirable for these as well as the more elaborate coded 
systems. Such tests alone without electrical supervision have been effective in the maintenance of a great number of these simple systems that have served effectively in numerous fires in warning occupants of the impending danger. However, electrical supervision of the wiring gives an added element of reliability and with proper details does not greatly increase the cost or complexity of the system.

Two general classes of coded manual fire-alarm systems can be recognized. One covered by Federal Specification No. W-F-391 (49) is adapted for groups of widely scattered buildings with unreliable power supply. In this system the first box pulled on a circuit sends its signal and the pulling of any other box or boxes while the signal is being transmitted will not interfere with the transmission. The operation of other boxes during this period (average of about 50 sec) will not result in alarms from these boxes. This system is designed for operation by storage battery, the gongs being of the electro-mechanical type operated by a hand-wound spring enabling 250 powerful strokes to be made, or sufficient for about 5 complete fire signals. This system has handwound gongs and uses battery current only for transmitting the impulse that releases the bell mechanism and for supervision. Based on the present generally reliable public power supplies, other types using such power sources for all purposes including bell-ringing, have been developed and are made by several companies, a number of which are covered by Federal Specification W-F-96.

The "shunt" type system described in Federal Specification No. W-F-396 (50) is designed mainly for operation by power from the electrical supply for the building. In this system when two or more boxes are pulled at or near the same time, the box on the circuit electrically nearest to the source of energy will send a complete signal. When there is a short time interval between the pulling of several boxes, fragmentary records of signals from other boxes will be given either before or after the complete signal from the box electrically nearest to the source of power. In case of electrical discontinuity, short-circuiting, or grounding of the circuit, by the operation of a switch manually or automatically, an auxiliary circuit may be established over which fire alarms are received pending the clearing of the trouble on the primary circuit.

In both classes, continuity of all important electric circuits and source of electric power is insured by electrical 
supervision, and an electrical disarrangement is announced by a trouble bell which may be silenced by transfer of the signal of a trouble lamp.

The Army Signal Corps has had in use on military reservations an outside manual fire alarm system based on the use of telephones. With the preferred details it consists of mine-type telephones (conventional telephone in a weathertight cast-iron housing) connected to a switchboard at fire brigade headquarters. The lifting of the receiver from the hook at any fire-alarm station rings a fire gong at headquarters and flashes a red annunciator signal showing the location of the station pulled. A two-way telephone conversation can be established between the station and headquarters which is helpful in determining the assistance needed. In some modifications of the system the boxes connect with the post telephone switchboard, the operator at which dispatches the fire brigade over direct lines reserved for this purpose. Some installations have the usual desk or wall-type telephones installed in wooden boxes. The field circuits required in all cases are a pair of telephone wires from each box to fire headquarters. These lines can be, and in many installations are, electrically supervised so that in the event of an open line a trouble signal showing the disarranged circuit is given on the control switchboard.

\section{(b) LOCATION OF STATIONS}

Manual fire-alarm stations should be located in the path of eccape from fire at readily accessible points which are not likely to be obstructed and preferably so that the distance of travel to reach a box will not average more than $100 \mathrm{ft}$. Location will also depend on the subdivision of the building as determining access to box locations. Some advantage is presented by locating fire-alarm stations, standpipes for hand hose, and hand fire extinguishers near each other, since the location will thus become better known to the occupants and the sender of an alarm will be in position to use the extinguishing equipment with the least delay.

\section{AUTOMATIC FIRE-ALARM SYSTEMS}

(a) TYPES AND OPERATING DETAILS

Fire alarms may be initiated automatically by the fusion of an alloy, expansion of air within a partially closed system, 
expansion of liquid within a frangible bulb, and action of temperature on bimetallic strips, thermopiles, or mercury bulbs. One type extensively used to detect fires in cargo holds of ships, involves a pipe system for sampling the air from the different compartments and means for automatic detection and detection by eye of any smoke present. Adaptations of this type of system have been applied in buildings for purposes such as automatic closing of ducts and shutting down fan motors in ventilating systems.

The fire signal from a zone circuit, which may include as many as 50 to 100 fire-detectors, $1,000 \mathrm{ft}$ of pneumatic tubing, or $1,500 \mathrm{ft}$ of thermostatic wire, is given at one or more central points by the ringing of a bell, and the zone is indicated by a lighted lamp on an annunicator board or a coded signal. Not less than one manual box is usually provided for each zone. Electrical supervision of circuits is generally provided only up to the thermosensitive elements of automatic systems, the contact for most types of thermosensitive elements being normally open. For closed-circuit systems the contacts can also be thus supervised.

The protection given by automatic fire-alarm systems is in general adapted for conditions presenting hazard of a degree that would not require automatic extinguishing equipment and yet such that more protection than can be given by manual fire alarm and extinguishing equipment is necessary. As in the case of manual systems the effectiveness of the protection depends upon the certainty of reception of the signal by someone always in attendance at one or more points at which the alarm is given and the degree to which such person is in position to act on the alarm, summon aid, or initiate fire extinguishment with suitable equipment, which should include hand fire extinguishers and fire hose.

In the absence of a central point for receipt of localized signals continuously attended, an annunciator located at the entrance or outside of the protected building showing the location of the circuit operated or box pulled is a desirable feature where a system protects a relatively large building or area or where prompt response in fighting the fire is very important. The alarm is assumed to ring and give a location indication for the building or area in the public or private fire brigade headquarters. This feature can be included in both manual and automatic fire-alarm systems.

The effectiveness of the unit-type alarm device in which the detecting element and alarm are combined in one assem- 
bly depends entirely on whether an alarm sounded will be heard. It has little or no application in building not occupied at all hours. In residence buildings an alarm unit located at a point such as the basement, to be effective, should rouse sleeping occupants on upper floors.

\section{(b) SPECIFICATIONS AND INSTALLATION DETAIIS}

General requirements for installations in buildings and ships have been issued that are informative $(51,52,53,54,55)$. Fixed-temperature thermo-sensitive elements, considerably more sensitive than the fusion-type automatic-sprinkler head, are in general required to be spaced so that no point on smooth ceilings is more than $10 \mathrm{ft}$ distant. Closer spacings are required for less sensitive elements and for greater sensitivity such as is presented by the rate-of-rise elements, somewhat wider spacings. On ceilings with beams over 12 in. deep it is usual to treat the inclosed space as a separate ceiling.

If electrical supervision is provided it should cover not only the circuits but also the energy supply and at least one firegong circuit. The energy for supervision should be supplied preferably from a reliable source of electrical-current supply. In this case the energy for the trouble circuits is taken from the other side of three-wire circuits.

As for manual systems, many small automatic fire-alarm systems without electrical supervision have been in successful use, the operative condition being checked periodically by operation of the thermosensitive elements and gongs. Such checking is also desirable for electrically supervised systems since this type of supervision has in general the same limitations as for the manual systems. Thermosensitive elements or detectors are generally checked by putting an electric short across their terminals equivalent to that produced by thermal operation. Occasional thermal operation of a few elements is desirable, but may make necessary resetting or replacements of the parts affected by heat, depending on the type.

A reliable general power service or a storage battery on a floating or trickle charge from a general power system, are preferable power sources for operation of fire-alarm systems. Where continuous operative condition of the system is very important, there should be an auxiliary power source with automatic change-over in case of failure of the main source. A general power source with a battery thereon on 
trickle charge serves this purpose. The lines for the operation of fire-alarm systems should preferably be taken off the building service on the supply side of the main service switch to avoid interruption of the fire-alarm service when the main switch is thrown off or the building circuit protective device trips. Small systems can also be operated by power from small transformers on the main current supply, and if such. transformers also supply current to devices in continuous or frequent use, some degree of supervision of the source is thereby obtained.

\section{WATCHMAN'S SUPERVISORY SYSTEMS}

For buildings or groups of buildings in which no central watch station continuously occupied is present, the watchman's portable clock and key stations afford a simple means for checking the watchmen's rounds.

Larger buildings or groups of buildings in which a central watch office is maintained are best adapted for systems of supervisory equipment. One type with which the signal is transmitted by plugging in at each station, with or without use of a portable telephone, is covered in Federal Specification No. W-W-101 (56). Federal Specifications for other types are being developed. General requirements for the systems have been formulated $(53,54)$ : In some systems either separate watch and fire-alarm stations or combination stations are placed on one and the same circuit. Electrical supervision over watchmen's supervisory circuits, while desirable, is not considered as necessary as for fire-alarm circuits, since the frequency of watchmen's signals serves in a measure to discover promptly any circuit trouble. The reporting stations should be located so that, as nearly as possible, all portions of the building to be supervised will be covered by the watchmen's routes.

\section{ADAPTATION OF INTERIOR AUTOMATIC-TELEPHONE EX- CHANGES FOR TRANSMISSION OF FIRE ALARMS AND SUPERVISION OF WATCHMEN}

Interior automatic-telephone exchanges can be adapted for the transmission of fire alarms and supervision of watchmen by introducing modifications employing equipment and installation details in common use in telephone and signaling practice. While the telephone circuits are not electrically 
supervised to check their operative condition, this does not introduce a serious element of the unreliability since they are supervised by normal use.

For transmission of fire alarms or other emergency calls, a call number such as 22 or 222 is assigned for the purpose, instructions for sending such calls being posted at each telephone. This call rings special telephones having loud bells at designated locations, such as the office of the superintendent or warden, the fire-brigade headquarters, and the hospital. These telephones are equipped to receive incoming calls only. In addition, the fire call lights a lamp on an annunciator board, giving by number and label the location of the call, which lamp remains connected until manually released at the receiving end.

For transmitting watchmen's calls another call number such as 33 or 333 is used which rings a special one-way telephone at the annunciator board and lights the location lamp. The lamp circuit is, however, broken when the sender completes the call.

This method of transmitting fire, emergency, and watchmen's signals is adapted for conditions where the telephones are not spaced much closer or greatly exceed in number those required for covering the area concerned for the given purpose. If an insufficient number for the purpose is present, additional telephones can with economy, be provided at required locations, since the added cost of the modification compared with the cost of separate signaling systems is small.

Automatic telephone exchanges are being used for transmission of fire alarm and other emergency calls without the annunciator board or other special features outlined above. One number, such as 22 or 222 , is assigned for such calls, which rings a station that is attended at all hours. The call can be made from any telephone on the exchange.

\section{OUTSIDE CENTRAL STATION SERVICE}

Under some conditions such as for isolated locations or where it is not practical to maintain a central station for receipt of signals within the building or property, arrangements for receipt by an outside agency of signals from firealarm, sprinkler, and other equipments, as well as watchmen signals, can be made where such service is available and where the property protected is adapted for it. This in general 
would also call for maintenance of the systems by the same service and entry of its personnel in response to trouble and emergency calls.

\section{GENERAL INSTALLATION REQUIREMENTS}

The central station for all emergency signalling systems and switching equipment of automatic-telephone exchanges used for similar purposes should be located in a fireproof building or at least the fire hazard in the location chosen should be the minimum possible under the conditions. The equipment should be fully enclosed, and where conditions warrant, the enclosure as well as terminal boxes locked to prevent tampering. Damp locations should be avoided as unfavorable to reliable functioning of the central station equipment.

All wiring within buildings should be in rigid conduits preferably concealed, and outside of buildings, underground in tunnels or terracotta conduits. Wires should be copper, rubber covered, in lead-sheathed cables, otherwise with protective or weather-proof braid, the length of exposed wiring between all outlets and instruments to be kept at a minimum.

\section{MUNICIPAL FIRE ALARMS}

The general means for transmitting fire calls to the headquarters of the public fire brigade include the public telephone and the municipal fire-alarm system where present. Where the general area in which a building is located is covered with a municipal fire-alarm system, a public fire-alarm box should be located adjacent to or at least within a few hundred feet from important Government Buildings. A preferable location is just outside of the main entrance.

Some cities permit operation of public fire-alarm boxes by the alarms from manual or automatic fire-alarm system or sprinkler alarms. Whether this is desirable depends on the freedom of the systems from false alarms and other disarrangements and whether it is desired that those in charge within the building shall ascertain the reason for the alarm and the degree of emergency before calling the public brigade. Where the automatic call is made to the fire department only from the operation of a second or general alarm with a manual fire-alarm system, there should be a minimum occasion for 651704-45-5 
false alarms, and this feature may be justified where the hazards from the building construction of occupancy are high. Generally where a central watch office is continuously attended, automatic connections with the public fire-alarm system are not usually made, the means used being a public box, a manually operated switch by means of which a public box can be operated, or a connection with a public telephone exchange having trunk lines reserved for fire calls to city firealarm headquarters.

Telephones connected with private manual switchboards that are not attended for the full 24 hours cannot thus connected be depended upon for transmitting fire and emergency calls. With such installation, some of the branch lines should be left connected with the public exchange for the periods when the private switchboard is not attended, the location of the connected telephones to be known to the watch force or other personnel on duty.

\section{CONDITIONS REQUIRING INSTALLATION OF GIVEN TYPES OF EQUIPMENT}

Information designed to be useful in determining the need for installation of the various types, special features, and adaptations of equipment for the transmission of fire calls and supervision of watch service is given in the preceding paragraphs. Some further information on justifiable expense for protection is given in Section II. Indications of the extent to which it has been considered necessary to require such installations can be obtained from State and city codes. While legal requirements should be expected to call for the minimum of protection needed for given conditions, they, however, must necessarily assume the presence of the more hazardous conditions associated with given occupancies or types of buildings. In an individual case the hazard may be considerably lower because of incombustible fire resistive building construction, methods of safeguarding the occupancy hazard or other protection measures. The legal requirements do not as a rule recognize such modifying conditions that may have a decided effect on the hazard, particularly as it concerns the building design, subdivision, and materials in structural members and finish. For recommended installation requirements in new Federal buildings, see reference 55 . 


\section{FIRE EXTINGUISHMENT}

\section{GENERAL METHODS OF EXTINGUISHMENT}

The means to be provided for attack on fires depend on the amount, value, and fire hazard of the materials involved, temperatures obtaining where the extinguishing equipment is to be located, and the personnel by whom it will be maintained and operated.

\section{(a) CLASSES OF FIRES}

From the standpoint of extinguishment fires can be divided into three general groups that will be designated as classes $\mathrm{A}, \mathrm{B}$, and $\mathrm{C}$.

1. Class $A$ fires.-Fires in ligneous or cellulosic materials like wood, paper, textiles, and animal and vegetable fibers generally, some in this class, as well as those in solid carbonaceous materials such as coal, coke, starch, sugar, cereals, and in bitumen, asphalts, and waxes that do not melt readily under heat. Fires in materials containing nitrocellulose, such as photographic, X-ray, and motion-picture film and pyroxylin products generally, can be placed in this class.

2. Class B fires.-Class B fires are those occurring in mineral, vegetable, and animal oils. Petroleum oils in the form of crude oil, gasoline, kerosene, fuel oil, transformer oil, lubricating oil and grease, and coal-tar oils such as benzol constitute the bulk of mineral-oil products. Among vegetable oils are the alcohols, acetone, turpentine, linseed oil, coconut oil, palm oil, olive oil, cottonseed oil, tung oil, and soybean oil. Some of them are contained in paints, varnishes, and lacquers. Animal oils include lard oil, oleo oil, red oil, menhaden oil, and whale oil.

3. Class $C$ fires.-Class $\mathrm{C}$ fires are fires in electrical equipment for which the extinguishing medium should be a nonconductor of electricity if applied before the equipment is disconnected from the source of energy supply. Fires in insulation of motors, generators, transformers, switchboards, and electrical wiring generally, are included in this class. Fires in the oil of oil-cooled electrical equipment should be regarded as class $\mathrm{C}$ fires while the equipment is energized, but after it is disconnected they can be regarded as class B fires. 


\section{(b) EXTINGUISHING AGENTS}

1. Water.-The extinguishing effects obtainable from water consist mainly in cooling the burning material to a temperature at which it will not support combustion or reignite, wetting it and surrounding material to reduce the rate of combustion and spread of fire, exclusion of oxygen by surface films of water or steam or by immersion, and, as applied to some flammable liquids, dilution to a point where combustion is inhibited.

Water is well adapted for the extinguishment of class $\mathbf{A}$ fires, and to a limited extent for class $B$ and class $C$ fires. It can be used for extinguishing fires by dilution of liquids that mix readily with it, such as alcohol and acetone. Wateralcohol mixtures containing less than 25 percent alcohol will not burn. Properly applied as a fine spray covering the whole surface, water has application in extinguishing fires in petroleum oils heavier than kerosene, including viscous oils, oils that froth such as asphalt, and fuel, crude, and lubricating oils. Water from automatic sprinklers or hose streams can be used to extinguish fires in relatively small containers of flammable liquids such as in paint rooms and other minor storages of similar materials.

Water should in general be applied to class $\mathbf{C}$ fires only after the equipment is disconnected from the power source. While pure water is a poor conductor of electricity, the impurities normally present materially impair its electrical insulation properties. Damage to the equipment and shock to the operator must also be considered in the use of water on live electrical equipment. The possibility of the latter is confined to the presence of high voltages or application at close range and is eliminated entirely if the equipment is disconnected manually or by the operation of automatic circuitbreaking devices. Water as a fine spray has much lower electrical conductivity than as a solid stream or coarse spray.

After a fire in freely exposed materials is well past the initial stage, extinguishment with water is in general the only practical method. Exceptions include fires in large containers of flammable oils. The limitations of water as an extinguishing medium include its relatively high freezing point, making special precautions necessary where temperatures below $32^{\circ} \mathrm{F}$ obtain. As applied to hot fires of considerable extent water may vaporize before it reaches the burning materials, to prevent which it should be applied progressively in large volume to relatively small areas. 
For fires in materials containing part or all of the oxygen needed for combustion, such as nitrocellulose, the extinguishing action is largely one of cooling them below the ignition temperature. This will require comparatively larger amounts of water than for extinguishment of fire in ordinary combustible materials.

2. Soda-acid.-In some types of portable fire-extinguishing equipment and in a few of those of the fixed type, a solution of sodium bicarbonate is employed that, in the operation of the equipment to extinguish fire, is mixed with sulphuric acid. This results in the formation of sodium sulphate, water, and carbon dioxide gas, the chemicals being proportioned to give an acid-free discharge. As held within a closed container, the gas serves to expel the liquid solution under a pressure calculated to give the desired range and and duration of stream without rupture of the container.

The extinguishing effect is almost wholly from the water in the solution applied in a stream that can be directed at the seat of the fire. It is accordingly adapted for the extinguishment of class A fires. It has lower electrical resistivity than water and should not be applied to charged electrical equipment. The damage from staining, etc., is somewhat greater than for water. The freezing point of the bicarbonate solution is about $-2^{\circ} \mathrm{C}, 28^{\circ} \mathrm{F}$.

3. Hoam.-Foam for extinguishing fire is produced by mixture of solutions of aluminum sulphate and sodium bicarbonate to which a foam stabilizing ingredient has been added, and consists mainly of bubbles of carbon dioxide. In some foam systems the materials in powder form are mixed with water in a foam generator.

Foam is best adapted for the extinguishment of class $B$ fires. It should be applied gently from a point near the surface of the oil and in sufficient quantity to form a continuous blanket over the whole surface. Foam extinguishes oil fires partly by the cooling from the water it contains but more by cutting off the oil surface from the air, flames, and radiant heat. This inhibits or retards the formation of oil vapor necessary for the continuance of the fire. If the oil for a considerable depth below the surface is up to a temperature where vapor is given off freely, the vapor will penetrate the foam and burn above it. Foam is broken down by solvents such as alcohols, acetone, and ether, and is accordingly not effective for extinguishing fires in them. Carbon disulphide is so volatile that the vapor will continue to 
be given off and burn above the foam. Water or carbon dioxide are preferred fire-extinguishing agents for such fluids.

Foam is as effective, weight for weight, on some class A fires as water. However, as applied to finely divided material it will not penetrate the burning mass to the extent obtainable with water. The greater cost, more limited general availability, and lower range of the applied stream of foam must also be considered. It is a good conductor of electricity and causes somewhat more damage to electrical equipment and materials generally than water. The freezing points of the foam solutions are not greatly below $0^{\circ} \mathrm{C}$, $32^{\circ} \mathrm{F}$, and even below $5^{\circ} \mathrm{C}, 40^{\circ} \mathrm{F}$, the quantity of foam produced for given weights of dry chemicals is materially less than for higher temperatures.

4. Carbon tetrachtoride.-Carbon tetrachloride is a heavy volatile liquid with boiling point near $77^{\circ} \mathrm{C}, 170^{\circ} \mathrm{F}$, and freezing point near $-23^{\circ} \mathrm{C},-9^{\circ} \mathrm{F}$. At $38^{\circ} \mathrm{C}, 100^{\circ} \mathrm{F}$, the carbon tetrachloride would constitute 25 percent by volume of the saturated gas-air mixture and at $55^{\circ} \mathrm{C}, 131^{\circ} \mathrm{F}, 50$ percent. This would reduce the oxygen content of the air to 15.75 and 10.5 percent, respectively. However, so many conditions enter in case of fire extinguishment, such as the time required for evaporation, the quantity applied in relation to the room space, and the distribution of the concentration at different levels, that such relations should be taken as only indicative. The vapor is heavier than air, which assists in smothering a fire particularly within a closed space, although retarding evaporation at temperatures below the boiling point.

The pure form used in fire extinguishers is free from water, and together with the other liquids added to depress its freezing point, is a poor conductor of electricity. It can break an electric arc. Hence it is adaptable for class $\mathrm{C}$ fires although it is moderately effective for small class B fires. Its effectiveness on large oil fires is limited since it would in part dissolve in the oil. Any undissolved or unevaporated portion would not float on the surface on account of higher specific gravity.

Carbon tetrachloride is in general less damaging to ordinary materials and equipment than water or foam. On account of its solvent properties it will damage some electrical insulations and the liquid and condensed fumes produce cor- 
rosion of metals. The gas is irritating and toxic and on application to fires the decomposition products contain hydrochloric-acid gas, carbon monoxide, chlorine, and under some conditions, particularly as applied to hot metal, small amounts of phosgene, a highly toxic gas. Hence, manual extinguishment with it in closed spaces should be conducted with caution and rooms within which it has been applied should be well ventilated before being entered.

5. Carbon dioxide.-Carbon dioxide is at normal pressures and temperatures a colorless, ordorless, inert gas which extinguishes fire by smothering. It is nondamaging to most materials, noncorrosive, leaves no residue, is an electrical insulator, and does not deteriorate with age. It is suffocating in high concentrations. For fire extinguishing it is stored at room temperature at pressures up to $1,050 \mathrm{lb} / \mathrm{in}^{2}$ in steel cylinders in liquid form, or in refrigerated containers maintained near $0^{\circ} \mathrm{F}$ at pressure of about $300 \mathrm{lb} / \mathrm{in}^{2}$. Special valves are needed to retain the carbon dioxide without leakage, and also to prevent freezing at the outlet. On emerging from the nozzle, it expands to about 425 times its stored volume. Once liberated, it cannot remain a liquid so that the amount of inert gas produced by a given quantity of liquid is independent of the fire and is governed only by the quantity applied. The discharge is usually a combination of carbondioxide gas and snow at $-79^{\circ} \mathrm{C},-110^{\circ} \mathrm{F}$. Although the main extinguishing effect is from smothering by the gas, the cold snow materially aids in local cooling.

Flame cannot exist in air $-\mathrm{CO}_{2}$ mixtures containing more than 25 to 60 percent $\mathrm{CO}_{2}$, depending on the material burning. This corresponds to a range in oxygen content of the air from 15.75 to 8.4 percent. The higher concentrations of carbon dioxide will also be needed for extinguishing glowing or incandescent combustible materials. Carbon dioxide has little lasting effect and care should be taken to guard against reflash, by discharging sufficient gas to prevent it.

It is recommended for classes $B$ and $C$ fires and is of limited value on class $A$ fires. For other than relatively small class $B$ and class $C$ fires and for class $A$ fires that are past the incipient stage, certainty of extinguishment must be premised on the presence of an enclosure that will enable an inert gas mixture to be maintained for the required period. It is used in built-in systems for flooding spaces containing special hazards, for local application on machines, tanks, 
etc., and in hand and wheeled extinguishers. The portable devices have a relatively short range which, however, is somewhat offset by the cold cloud of the discharge which protects the operator from the heat of the fire.

For maintaining an inert atmosphere within a room or enclosure accommodating hazardous processing or storage, flue gas or exhaust gas from internal-combustion engines is often used. This generally contains, in addition to carbon dioxide and nitrogen, minor amounts of oxygen and carbon monoxide. The latter is frequently present in amounts of 1 percent or more, which are highly toxic concentrations.

Spaces flooded with pure carbon-dioxide gas, such as is obtained from the liquid form, need ventilation to increase the oxygen content to about 18 percent before being entered. Where the oxygen concentration is below 10 percent unconsciousness is likely to result within a short time. Such conditions would require oxygen helmets or air masks.

Where carbon monoxide is present in the inert gas a greater amount of ventilation is generally necessary than for carbon dioxide alone. The maximum safe concentration of carbon monoxide if breathed for periods of over 1 hour is considered to be 0.02 percent or 20 parts per 100,000 . The Davy safety lamp, while indicating the safe limit of oxygen content does not necessarily indicate the required reduction in carbon monoxide. Thus with inital oxygen content of 10 percent 2 air changes will increase the oxygen to a little over 19 percent and decrease a carbon-monoxide concentration of 1 percent to 0.12 percent, a total of about 4 air changes being required to reduce it to 0.02 percent (70). With no oxygen initially present and 2 percent of carbon monoxide, 3 air changes will increase the oxygen content to 19 percent and decrease the carbon monoxide to 0.10 percent, nearly 5 air changes being required to reduce it to 0.02 percent.

6. Steam.-Steam can be used for extinguishing class B fires where the surrounding space, or space above the oil, is enclosed or partly enclosed, provided the amount supplied is sufficient to reduce the oxygen content to the required degree. For fires in petroleum oils this would require raising the air temperature to near $72^{\circ} \mathrm{C}, 162^{\circ} \mathrm{F}$, which corresponds to a water-vapor concentration in the air of nearly 34 percent and oxygen concentration of about 14 percent. For class A fires the vapor concentration must be higher and maintained for a longer period if glowing ma- 
terial is to be extinguished. For this condition an air temperature of $82^{\circ} \mathrm{C}, 180 \mathrm{~F}$, corresponding to a content of saturated water vapor of 51 percent, and reduction of oxygen content to 10.3 percent, should preferably be attained.

The steam may extinguish both by smothering and by wetting. On account of the heat required to raise the temperature of the enclosure a liberal margin over the computed necessary quantity should be allowed. It will generally be advantageous to use steam for fire extinguishment only where a sufficient supply can be obtained from heating, power, or other boilers not supplying steam for equipment, the operation of which is necessary when a fire occurs. For discharge into occupied spaces, low-pressure steam, such as exhaust steam, should preferably be used and the release effected by manual means. Precautions need be taken to avoid accidental discharge and automatic discharge should be applied only for uninhabited spaces.

7. Dry powdered material.-Dry sand, soil, or other incombustible material in fine particles or powder form are moderately effective on small class B fires, such as oil burning on the ground or floor. Heavy material like sand is not effective for fires in oil contained in vats or tanks, but light chemicals applied by means of compressed inert gas as a dust and mixtures of sodium bicarbonate and dry sawdust applied by hand, are moderately effective where the area of the oil can be fully covered. For other than very small fires, such as grease fires in cooking utensils, a much greater quantity than that contained in the usual dry-powder hand fire extinguishers will be required. Without special equipment they must all be applied at relatively close range, which limits their usefulness for the purpose.

8. Freezing-point depression.-The freezing point of some fire-extinguishing media can be depressed by the addition of chemicals and thus enable their use in equipments exposed to temperatures below their normal freezing point. For water, additions of calcium chloride or sodium chloride (common salt) are usually made for this purpose. Common-salt solutions are best adapted for wood containers: If coated on the inside with pitch, asphaltum, or a mixture of paraffin and resin, they will generally also hold the calcium-chloride solution satisfactorily. Common salt has a greater corrosive effect on metal and does not depress the freezing point to the low limit obtainable with calcium 
chloride. One pound of lime added to each 50 gal of calciumchloride solution will make it slightly alkaline and assist in decreasing corrosion. Table 4 gives the quantities in avoirdupois pounds required per gallon of water for depression of the freezing point of water to the degree desired. The quantities are based on pure dry sodium chloride and refrigeration grade calcium chloride. The latter is assumed to consist of 75 percent of $\mathrm{CaCl}_{2}$ and 25 percent water, the quantities required being obtained by modifying the values given in the International Critical Tables (vol. 4, p. 257-8) to allow for the water content assumed.

TABLE 4.-Properties of nonfreezing water solutions

\begin{tabular}{|c|c|c|c|c|c|}
\hline \multicolumn{2}{|c|}{$\begin{array}{l}\text { Freezing temper- } \\
\text { ature of solution }\end{array}$} & \multicolumn{2}{|c|}{$\begin{array}{l}75 \text { percent calcium } \\
\text { chloride }\end{array}$} & \multicolumn{2}{|c|}{ Sodium chloride } \\
\hline $\begin{array}{c}\text { De- } \\
\text { grees F }\end{array}$ & Degrees & $\begin{array}{l}\text { Pounds } \\
\text { per gal } \\
\text { of water }\end{array}$ & $\begin{array}{l}\text { Speciflc } \\
\text { gravity at } \\
20^{\circ} \mathrm{C}\end{array}$ & $\begin{array}{l}\text { Pounds } \\
\text { per gal } \\
\text { of water }\end{array}$ & $\begin{array}{l}\text { Specific } \\
\text { gravity at } \\
20^{\circ} \mathrm{C}\end{array}$ \\
\hline $\begin{array}{r}+20 \\
+15 \\
+10 \\
0 \\
-5 \\
-10 \\
-20 \\
-30 \\
-40\end{array}$ & $\begin{array}{l}-6.7 \\
-9.4 \\
-12.2 \\
-17.8 \\
-20.6 \\
-23.4 \\
-28.9 \\
-34.4 \\
-40.0\end{array}$ & $\begin{array}{l}1.39 \\
1.82 \\
2.23 \\
2.98 \\
3.31 \\
3.65 \\
4.26 \\
4.84 \\
5.37\end{array}$ & $\begin{array}{l}1.090 \\
1.116 \\
1.136 \\
1.174 \\
1.191 \\
1.206 \\
1.232 \\
1.255 \\
1.275\end{array}$ & $\begin{array}{l}0.95 \\
1.30 \\
1.62 \\
2.22 \\
2.49\end{array}$ & $\begin{array}{l}1.072 \\
1.097 \\
1.118 \\
1.156 \\
1.172 \\
\end{array}$ \\
\hline
\end{tabular}

No chemicals should be applied for depressing the freezing point of sodium-bicarbonate or aluminum-sulphate solutions as used in soda-acid or foam fire-extinguishing equipment. The freezing point of stored liquid carbon dioxide is too low to require any protective measures. The freezing point of carbon-tetrachloride fire-extinguishing liquid is required according to specifications (57) to be not higher than $-45.5^{\circ} \mathrm{C},-50^{\circ} \mathrm{F}$. Different chemicals are used by individual manufacturers to depress the freezing point of the carbon-tetrachloride base. The additions should not decrease appreciably the electrical insulating or fire-extinguishing properties of the liquid nor increase its toxicity.

(c) GENERAL TYPES OF FIRE-EXTINGUISHING EQUIPMENT

The general types of fire-extinguishing equipment comprise portable fire extinguishers, manually operated fixed equipments, and automatically operated fixed equipments. 
The choice in types will depend largely on the relation of cost of protection to the value of the property protected and the degree of fire hazard presented, as discussed in section II. It will also depend on particular structural and occupancy conditions and the environment. An occupancy unduly exposing or exposed by its surroundings may need a higher degree of protection than if its own hazards alone were considered.

Portable fire extinguishers are here taken to comprise hand and wheeled extinguishers, exclusive of motor-propelled equipment. The manually operated fixed equipments include mainly standpipe and hose systems arranged with small hose for the use of occupants or with outlets for the larger hose used by organized fire brigades, and outside systems of water mains and hydrants. Fixed equipments for discharging inert gas or foam by manual means would be included also. Automatically operated fixed equipments discharge the extinguishing fluid through the medium of heat-actuated devices and comprise automatic sprinkler systems discharging water, and automatic carbon-dioxide and foam fire-extinguishing systems.

\section{PORTABLE FIRE-EXTINGUISHING EQUIPMENT}

The points in favor of portable equipments include relatively low cost, portability, which enables them to be carried to the vicinity of the fire, and ease of obtaining an extinguishing medium best adapted for particular conditions. Their effectiveness is limited by the small volume of extinguishing fluid that can be contained and the close range at which it must be applied. Hence, for all but the larger units on trucks, they must be regarded as effective only on fires in their initial stages. To serve effectively as protection, the personnel within the space covered must be informed as to the location and use of the equipment.

\section{(a) RATING OF HAND FIRE EXTINGUISHERS}

As a convenience in rating and spacing hand fire extinguishers, a "unit of first aid" has been adopted, each unit consisting of one to five duplicate appliances, depending on their effectiveness on the different classes of fires. The ratings for the more usual types, as applied by the Underwriters' Laboratories (58), together with other information, are given in table 5. The tabulation indicates the classes 
of fires for which given extinguishers are adapted and the number required for each unit of first aid. Information on types of fires and extinguishing action of the different media is given in section XI-1. The extinguishers listed are suitable for first-aid use generally except where women are depended on to use the extinguishers, in which case those with a weight of $30 \mathrm{lb}$ or under should be available.

\section{(b) TYPES OF PORTABLE EXTINGUISHERS}

1. Soda-acid type.-In the loose-stopple type (59) the sulphuric acid is discharged into the solution by inverting the extinguisher. In the break-bottle type, used mainly only by fire brigades, the top must be bumped against the floor to liberate the acid. The range of the stream is from 30 to $40 \mathrm{ft}$ and the time of discharge about $1 \mathrm{~min}$ for the $21 / 2^{-}$ gal size. The stream should be directed at the base of the flame on the burning materials.

TABLE 5.-Application of hand flre extinguishers

\begin{tabular}{|c|c|c|c|c|c|c|c|c|}
\hline \multirow[b]{2}{*}{$\begin{array}{l}\text { Kind of extin- } \\
\text { guisher }\end{array}$} & \multirow[b]{2}{*}{ Capacity } & \multicolumn{4}{|c|}{ Application } & \multirow[b]{2}{*}{$\begin{array}{l}\text { Weight of } \\
\text { (approx.) } \\
\text { each }\end{array}$} & \multirow[b]{2}{*}{$\begin{array}{l}\text { Protect } \\
\text { from } \\
\text { freezing }\end{array}$} & \multirow[b]{2}{*}{$\begin{array}{l}\text { How } \\
\text { oper- } \\
\text { ated }\end{array}$} \\
\hline & & $\begin{array}{l}\text { Class } \\
\text { of fire }\end{array}$ & $\begin{array}{l}\text { Num- } \\
\text { ber } \\
\text { per } \\
\text { unit }\end{array}$ & of fire & $\mid \begin{array}{c}\text { Num } \\
\text { ber } \\
\text { per } \\
\text { unit }\end{array}$ & & & \\
\hline Soda-acid & $11 / 4$ or $11 / 6 \mathrm{gal}$ & A & 2 & & & Pound & Yos & \\
\hline Do & $21, \mathrm{ggl}$ & $\hat{A}$ & 1 & & & 35 & Yes... & $\frac{\hat{x}}{\mathbf{X}}$ \\
\hline $\begin{array}{l}\text { Water, stored } \\
\text { pressure car- }\end{array}$ & $21 / 2 \mathrm{gal}$ & $\mathbf{A}$ & 1 & & & 35 to 40 & Yes -. & $\mathbf{x}$ \\
\hline Loaded stream. & 1 gal .......... & $\mathbf{A}$ & 2 & & & & No.... & $\mathbf{X}$ \\
\hline Do & $18 / 4$ or $21 / 2 \mathrm{gal}$ & $\vec{A}$ & 1 & $\cdots$ & & 35 and 40 . & No.... & $\hat{\mathrm{x}}$ \\
\hline Pump tank... & $21 / 2 \mathrm{gal}$ & $\bar{A}$ & 1 & $\cdots$ & & $35 \ldots$ & Yes:- & P \\
\hline Tank contain- & 25,35 , or $40 \mathrm{gal}$ & $\mathbf{A}$ & 1 & & & 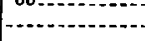 & Yes :-. & $\mathbf{T}$ \\
\hline $\begin{array}{l}\text { Wug onre-pals. } \\
\text { Cask with } 3 \text { pails. }\end{array}$ & $50 \mathrm{gal}$. & $\mathbf{A}$ & 1 & & & & Yes 6 & $\mathrm{~T}$ \\
\hline Fire pail & $12 \mathrm{qt}$ & $\vec{A}$ & $\dot{5}$ & & & & Yes $\mathrm{B}^{-}$ & $\frac{1}{\mathrm{~T}}$ \\
\hline Foam & $11 / 4$ or $11 / 2 \mathrm{gal}$ & $A$ & 2 & $\mathbf{B}$ & 2 & 19 to 25 & Yes... & $\overrightarrow{\mathbf{x}}$ \\
\hline Carbon tetra: & $1,11 / 4,11 / 2$, or $2 \mathrm{qt}$ & $\mathbf{B}$ & 2 & $\stackrel{\mathbf{0}}{\mathbf{C}}$ & 2 & 7 for $1 \mathrm{qt}$. & $\begin{array}{l}\text { Yes...- } \\
\text { No.... }\end{array}$ & $\underset{\mathbf{P}}{\mathbf{X}}$ \\
\hline Carbon dioxide. & $73 / 5$ or $10 \mathrm{lb}$. & B & 2 & C & 1 & 35 for $71 / 21 b$ & No_... & $\mathbf{S}$ \\
\hline Do-........-. & $4 \mathrm{lb}$ & $\mathbf{B}$ & 2 & $\mathbf{C}$ & 2 & 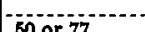 & No...- & $S$ \\
\hline Dry compound. & 12 or $20 \mathrm{lb}$ & $\mathbf{B}$ & 1 & $\mathrm{C}$ & 1 & on or 71 & No.... & $\mathbf{S}$ \\
\hline
\end{tabular}

- $\mathbf{P}=$ hand-operated pump; S=stored pressure; $\mathbf{X}=$ internally generated pressure; $\mathrm{T}=$ by throwing.

"Yes" for plsin water; "No" for nonfreezing solution. The nonfreezing solution will add $6 \mathrm{Ib}$ to the welght given in the preceding column for $21 / 2$-gal extinguishers and $12 \mathrm{lb}$ for the 5-gal capacity. 
2. Water type (self-propelled).-The charge, $21 / 2$ gal of water, is propelled by a special cartridge containing sufficient carbon dioxide to produce the necessary pressure to propel the water. It has a range of 30 to $45 \mathrm{ft}$ and a discharge time of about 50 sec. It is operated by inverting and bumping.

3. Loaded stream extinguishers.-The method of operation is similar to that for the soda-acid extinguisher but the solution is nonfreezing.

4. Water tank with pump.-These should be constructed to withstand corrosive effect of nonfreezing solution.

5. Water pails, tanks, and casks.-Five 12-qt fire pails are taken as a unit of first aid. The range and effectiveness of the application are less than for discharge by means of internal pressure or pump, but little or no training is required for fairly effective use.

6. Foam extinguishers.-The design and method of operation are similar in essentials to those for the soda-acid type (60). The extinguisher discharges a foam made up largely of carbon-dioxide bubbles, in volume about 7 times that of the original solution. This will float and spread over the surface of a burning liquid and extinguish the fire by excluding the air needed for combustion. The range is about $25 \mathrm{ft}$ and the time of discharge about three-fourths of a minute for the $21 / 2$-gal size. On oil fires, to avoid agitation, direct discharge on side of container at the liquid level, not into the liquid.

7. Carbon-tetrachloride extinguishers.-The liquid pump type is covered by Federal specifications (61), the limit of size for other than very specialized purposes being $2 \mathrm{qt}$. The effective range of the pump type is about $20 \mathrm{ft}$ and the rate of discharge about $1 \mathrm{qt}$ in 45 sec. In extinguishing in oil, the discharge should be directed at the side of the container, at or a little above the liquid level, and not into the liquid. Hand grenades, usually containing colored carbon tetrachloride in a glass bulb and intended to be thrown at the fire, are not considered effective fire-extinguishing appliances.

8. Carbon-dioxide extinguishers.-The carbon dioxide is contained in liquid form under pressure and liberated largely as a gas by puncture of a disk with a hand-driven pointed tool or by opening a valve. The fire must be approached as closely as possible for effective operation, the range being rela- 
tively small. The time of discharge for the 4 - and $71 / 2-1 b$ sizes is about $20 \mathrm{sec}$ and for the $15-\mathrm{lb}, 40 \mathrm{sec}$. Best results are obtained by directing the discharge at the edge or base of the fire, making certain that extinguishment is complete before progressing. Electric wiring and equipment to be given this type of protection should be enclosed at least in part as an aid in obtaining the needed concentration of inert gas for extinguishing a fire in them.

9. Dry-powder types.-The ordinary dry-powder extinguisher consisting of a tube, containing a few pounds of dry powder, usually cooking soda, is of too small capacity to be recognized for rating purposes. Five 12-qt pails of fine dry sand are rated as one unit of extinguishment for small fires in spilled oil. For small areas of heavy oil in vats, a sodaand-sawdust mixture has been used, a unit of first aid consisting of $8 \mathrm{bu}$ of sawdust and $80 \mathrm{lb}$ of soda. The material must be applied to cover the entire surface, as it will not spread like foam. All of the methods employing dry powder thrown by hand are limited in effectiveness by the close approach to the fire that must be made.

In the dry-compound type listed in table 5 , the fire extinguishing agent is a specially treated bicarbonate of soda in dry powder form with a cartridge of carbon dioxide for expelling it.

10. Extinguishers on wheels.-Truck or wheeled extinguishers of the soda-acid, foam, loaded stream, and water selfpropelled types are obtainable in 17 and 33 gal actual capacities. The possible range for the larger size is greater than for the hand extinguishers. Wheeled carbon-dioxide extinguishers are listed with capacities of 50, 75, and $100 \mathrm{lb}$ and the dry compound type with capacities of 150 and $350 \mathrm{lb}$.

\section{(c) RECHARGES FOR PORTABLE FIRE EXTINGUSHERS}

Recharges for soda-acid extinguishers can be bought from the manufacturers or made up from the chemicals concerned. The charge for carbon-tetrachloride extinguishers consists essentially of the purified chemical to which a freezing point depressant has been added, and is covered by Federal specification O-F-380 (57). Recharges for the other types of extinguishers must in general be obtained from the manufacturer of the extinguisher. Inquiry should be made before extinguishers are purchased as to the cost and facilities for recharging as this may determine the type to be installed. 


\section{(d) SPACING OF PORTABLE EXTINGUISHERS}

According to the recommendations of the National Fire Protection Association, for light-hazard occupancies such as office, residential, institutional, and public buildings, units of first-aid fire protection should be provided so that not over $100 \mathrm{ft}$ of travel is required to reach the nearest unit. One unit may be required for each $5,000 \mathrm{ft}^{2}$ of floor area (58).

For occupancies such as stores, warehouses, and manufacturing establishments of average hazard, units are recommended to be spaced so that the travel to reach the nearest unit will not exceed $50 \mathrm{ft}$. One unit may be required for each $2,500 \mathrm{ft}^{2}$ of area. For extra-hazardous occupancies the same general spacing is recommended, with provision of additional units for special hazards.

Where standpipe with hose or other fixed or large-size portable extinguishing equipment appropriate for the hazard concerned is present, concentration of hand fire extinguishers greater than that required for light-hazard occupancies, would not in general be necessary. Where a unit consists of several duplicate pieces, all should preferably be grouped in the designated location for the unit.

\section{(e) LOCATION AND SUPPORTS}

Portable fire extinguishers should be located at points readily accessible and not likely to be blocked. Where standpipes with hose for use of occupants are present, hose rack and extinguisher might be placed within the same cabinet which can be recessed into the wall and fitted with glass doors. Metal doors with locks should be used only where proven to be a necessity, such as at some points in penal institutions and psychopathic hospitals. Where the occupancy of the building and general location of hazards are known when it is designed, the type, size, and location of portable fire extinguishers should be determined and proper supports and enclosures provided during construction.

\section{STANDPIPE AND HOSE SYSTEMS}

The protection given by standpipe and hose systems in buildings below a certain height is augmented by hose streams supplied by street hydrants where public protection is present. For higher buildings, the standpipe system must furnish the whole supply needed for hose streams used in fire extinguishment. This will generally involve 2 systems of stand- 
pipe or standpipe outlets, 1 for small hose to be used by the occupants of the building and the other for the larger hose employed by the public fire brigade. The building height above which standpipe supply for large hose should be provided depends in part on local conditions, such as water pressure in the street mains, fire-department equipment, and its preferred method of fighting fire. The limit can be taken to be in the approximate range 45 to $65 \mathrm{ft}$ height of roof above street level.

The degree of protection that can be given by standpipe and hose designed for the use of occupants or watch force of a building depends on facilities for the discovery of fire and the organization for fire fighting. Where the hazard and values warrant, frequent rounds by watchmen of unoccupied spaces or installation of automatic fire-detecting equipment, will assist in early discovery, and an established procedure to be followed in case of fire by occupants and building personnel will help to achieve prompt extinguishment. For spaces continuously occupied the fire is likely to be discovered in its initial stages by the occupants, and unless highly flammable contents are present, standpipe and hose systems can be used to give very adequate protection.

\section{(a) WATER SUPPLY FOR STANDPIPES}

The usual sources of supply for standpipes with large hose outlets are fire-department pumpers supplying water through outside siamese connections, city high-pressure water mains, pressure tanks, gravity tanks, fire pumps, or combinations of them. For standpipes supplying small hose the sources include city service mains, house booster pumps, pressure tanks, gravity tanks, or combinations of pumps and tanks. The method of supplying water will determine some of the more important details of the systems.

1. Water supplies for large hose.-For standpipe systems supplying large hose (generally 21/2-in. hose with $11 / 8$-in. nozzle) the requirements for water supply can be given as not less than $250 \mathrm{gal} / \mathrm{min}$ for each standpipe riser at a pressure of not less than $50 \mathrm{lb} /$ in. $^{2}$ at the top outlet (not including roof outlet) when discharging at the given ( $250 \mathrm{gal} / \mathrm{min}$ ) rate (62). Allowing for friction loss in pipes of the sizes herein recommended, this will be equivalent to a static pressure at the given outlet of 55 to $60 \mathrm{lb} / \mathrm{in}^{2}$ The minimum capacity of fire pumps used as a main source of supply should be $500 \mathrm{gal} / \mathrm{min}$, pressure tanks $4,500 \mathrm{gal}$, gravity tank 5,000 
gal, the latter with bottom elevated not less than $40 \mathrm{ft}$ above top hose outlet. Gravity and pressure tanks should be considered as sources of supply only until other supplies such as fire-department pumpers or fire pump, can be brought into service. Where water for small hose is supplied from a separate source, pressure and gravity tanks for large standpipes can be omitted if they are supplied by any of the following: A city water system of adequate capacity and pressure; fire pump with duplicate power supply; fire pump supplemented by fire-department pumpers; or the pumpers alone if from a well-organized fire brigade, the response of which is not likely to be delayed by snow or other impediments. The quantity and pressure capacity of the separate sources is assumed adequate for the height and number of standpipes concerned. The standpipes should be kept primed by a small connection under pressure sufficient to keep them filled, with check valve against back flow provided in the connection. Dry standpipes should be used only where protection from freezing cannot be provided.

City water mains and their connections with standpipe systems should be of size and number adequate for supplying the quantity required, and connections should preferably be made outside of water meters. If made inside of the meter, the latter should be of size and type that will not introduce undue friction loss under conditions of maximum domestic and fire demand. Disk meters, while the most accurate, introduce the highest loss of head. Velocity meters of the same size as the connecting main are less objectionable. The fire-service meter is designed so that the friction loss is relatively smaIl. Its cost is greater than that of the others and it should not be specified unless needed. Some cities permit connections for fire protection outside of the meter. A bypass should be provided around the meter in any case. It cannot, however, be premised that this will be opened in emergency to permit flow around a meter of insufficient capacity unless it is in a convenient location with building personnel and public fire brigade fully informed on the necessity of so doing.

If the source of water supply is not adequate or the connection therewith is too small or too long to supply water at the required rate, recourse must be had to gravity or pressure tanks, (63) or suction tanks or reservoirs for a fire pump. The amount of storage needed can be determined only from 
a study of the pertaining conditions. It will depend not only on the extent of the property to be protected but also on the type of construction, subdivision into fire areas, protection of openings, occupancy, and the exterior exposure. The quantity is determined by the number of hose streams estimated as necessary and the time they would need to be applied to control a fire under the more unfavorable conditions. Where an adequate water supply is present within reasonable distance, enlargement of the connection to the required size may be found more advantageous than provisions for storage in large amounts. It is occasionally possible to connect with a main of greater capacity or under higher pressure than that supplying the domestic demand of the building.

Where the city has a separate system of high-pressure fireservice mains, the connection to the standpipe system is made by hose from street hydrants to the fire-department connection on the outside of the building. A length of hose for the purpose might be kept within the building together with some lengths of fire hose on portable reels for use in case for any reason the response of the fire brigade is prevented or delayed.

2. Water supplies for small hose.-For standpipe systems supplying small hose (preferably $11 / 2$-in. linen unlined fire hose with $1 / 2^{-}$or $5 / 8$-in. nozzle) any source giving a minimum flow of $100 \mathrm{gal} / \mathrm{min}$ at a pressure of $25 \mathrm{lb} / \mathrm{in}^{2}$ at the highest hose outlet is considered adequate (62). Allowing for friction loss in piping this would require a minimum static pressure at the highest hose outlets of 30 to $35 \mathrm{lb} / \mathrm{in}^{2} \mathrm{~A}$ more effective hose stream results from nozzle pressure of $40 \mathrm{lb} /$ in. $^{2}$ giving, with a $1 / 2$-in. nozzle, discharge of little less than $50 \mathrm{gal} / \mathrm{min}$. With the friction loss in $75 \mathrm{ft}$ of $11 / 2$-in. unlined hose and that in the pipes added, this represents a static pressure at the hose outlet of 60 to $65 \mathrm{lb} /$ in. $^{2}$, which it would be desirable to maintain at least as an average for the building. The supply of $100 \mathrm{gal} / \mathrm{min}$ can be taken from tanks connected with the domestic supply provided the pumps supplying them have the needed capacity for the combined demand. In this case it may be found advantageous to combine the distributing systems for the two purposes also, if the layout requires approximately the same pipe spacing. This may also assist in securing proper pressure distribution since the maximum and minimum pressures desirable for the domestic supply come within the range required for the hose streams. 
If the area is covered with a wet-pipe system of automatic sprinklers, the supply for small-hose streams can be taken from the sprinkler risers, with the limitations given in the installation rules for automatic-sprinkler equipments.

For supplies that are stored as in gravity or pressure tanks, the minimum carried for all but relatively small buildings should be 3,000 gal, which allows for 2 hose streams for $30 \mathrm{~min}$. If water from standpipes for large hose or from ground hydrants is also available, the above should be sufficient until extinguishment is begun with the larger hose.

3. Location of pressure tanks.-When the water level in pressure tanks can be maintained by the pumps under conditions of maximum demand, the tank can generally be located at the most convenient point within the building unless the latter is of such height that the basement location would require excessive pressures to be carried. For moderate heights, the cost of providing support for them above the basement may exceed the added cost for a heavier tank construction in the basement location. Where pressure tanks are used for storage, location on the roof will generally be found necessary, since for the same pressure on the upper outlets with the tank empty, those in a lower location would be required to carry an excess pressure equal to three times the head due to the difference in elevation. This assumes that when filled, the water occupies two-thirds of the tank volume.

Constant water level and pressure can be maintained by automatic regulation of air and water supply. Generally it may be sufficient to regulate only the pressure automatically by controls on either the air or the water supply. Alarm devices indicating low water level and pressure may under some conditions' serve the purpose of automatic regulation.

4. Fire pumps.-The usual sizes are 500, 750, and 1,000 $\mathrm{gal} / \mathrm{min}$ with discharge pressures from 100 to $175 \mathrm{lb} / \mathrm{in}^{2}$, (44) the centrifugal type being generally preferred. Any suction head from pressure in the supply main is generally neglected in rating the discharge capacity although it should be considered in providing pressure-reducing devices at hose outlets and other points. A relief valve should be provided at the pump with drainage for the discharge.

Where there will be an immediate demand on the pump in case of fire, the pump should have a combined manual and 
automatic starting panel, so that it can be started by the ringing of manual or automatic fire alarms, pressure drop in the standpipe system, or by manual switches. Where the initial demand is supplied from tanks, automatic start for the pump is less necessary. The relative cost and reliability of the two methods should be considered for each installation.

5. Enclosures.-Fire pumps and pressure tanks should be placed within fire-resistive enclosures having curbs at door openings and floor drains.

\section{(b) SPACING AND LOCATION OF STANDPIPES}

Standpipes for large hose should be located in enclosed stairways. With adequate pressure, hose lengths of $200 \mathrm{ft}$ or more can be employed, but generally the spacing of stairways required for exit of occupants will enable shorter lengths to reach all portions of the building.

Standpipes for small hose should be spaced so that all portions of the building can be reached by a stream of 25-ft range at the end of not more than $75 \mathrm{ft}$ of hose. Where pressures are adequate the hose length might be increased for isolated locations to $100 \mathrm{ft}$ although this length is less easily handled.

Standpipes or standpipe outlets for small hose should be located in corridors in preference to stairway enclosures, to prevent obstruction of stairways and admission of smoke during the initial stages of the fire,fighting when the stairs are used for exit of occupants. Shorter lengths of hose will also then be required. When standpipe risers supply both small and large hose, the riser should be located in the stairway, and connections for the small hose with shut-off valve inside of stairway, taken off to points outside of the stairway enclosure. However, where no location presenting low fire hazard, such as a corridor, is present, it may be necessary to locate outlets for small hose in stairways, since otherwise it might not be possible to use them on account of fire in adjacent combustible materials. Standpipes may also have to be located with reference to protection against exterior fire exposure. Large standpipes should be extended to an outlet on the roof, portions exposed to freezing to be kept dry by means of a valve inside of the building. Standpipes outside of stairways should preferably be covered by the building construction to prevent direct exposure to fire, or be otherwise insulated. 
(c) RANGE OF HOSE STREAMS OF RESTRICTED HEIGHT

The range of hose streams to be expected when the stream height is restricted, as would be the case in most locations in buildings, is given in table 6 for heights of stream of 6,8 , and $10 \mathrm{ft}$ above ground or floor level. Values are given for $1 / 2$-in. and $11 / 8$-in. nozzles. The tests on which the table is based were conducted out of doors but the results are reasonably free from wind effects.

TABLE 6.-Range of hose streams for different heights of stream above ground

[Tip of nozzle $2 \mathrm{ft} 4$ in. above ground]

RANGE IN FEET FOR /6-IN. NOZZLE

\begin{tabular}{|c|c|c|c|c|c|c|c|c|c|c|c|c|c|}
\hline \multirow{3}{*}{$\begin{array}{c}\text { Pressure at base } \\
\text { of nozzle } \\
\text { lb/in.? }\end{array}$} & \multirow{3}{*}{$\mid \begin{array}{c}\mathrm{Gal} / \\
\text { min } \\
\text { (com- } \\
\text { puted) }\end{array}$} & \multicolumn{12}{|c|}{ Height } \\
\hline & & \multicolumn{4}{|c|}{6 feet } & \multicolumn{4}{|c|}{8 feet } & \multicolumn{4}{|c|}{10 feet } \\
\hline & & $\mathbf{A}$ & B & C & D & $\mathbf{A}$ & $\mathbf{B}$ & C & $D$ & $\mathbf{A}$ & $\mathbf{B}$ & C & D \\
\hline $\begin{array}{l}10 \\
15 \\
20 \\
250 \\
35 \\
30 \\
45 \\
50 \\
60\end{array}$ & $\begin{array}{l}24 \\
29 \\
33 \\
37 \\
41 \\
44 \\
47 \\
50 \\
53 \\
58 \\
62\end{array}$ & $\begin{array}{l}16 \\
17 \\
19 \\
20 \\
22 \\
23 \\
25 \\
27 \\
28 \\
31 \\
33\end{array}$ & $\begin{array}{l}29 \\
35 \\
40 \\
44 \\
48 \\
51 \\
54 \\
67 \\
60 \\
64 \\
68\end{array}$ & $\begin{array}{l}34 \\
40 \\
46 \\
50 \\
54 \\
57 \\
60 \\
63 \\
65 \\
68 \\
73\end{array}$ & $\begin{array}{l}38 \\
47 \\
52 \\
57 \\
62 \\
66 \\
69 \\
72 \\
75 \\
80 \\
85\end{array}$ & $\begin{array}{l}17 \\
19 \\
21 \\
23 \\
25 \\
27 \\
29 \\
31 \\
32 \\
35 \\
37\end{array}$ & $\begin{array}{l}30 \\
38 \\
44 \\
48 \\
53 \\
57 \\
61 \\
64 \\
67 \\
72 \\
76\end{array}$ & $\begin{array}{l}35 \\
43 \\
49 \\
54 \\
58 \\
62 \\
66 \\
70 \\
73 \\
77 \\
81\end{array}$ & $\begin{array}{l}40 \\
48 \\
65 \\
60 \\
65 \\
70 \\
74 \\
78 \\
81 \\
87 \\
93\end{array}$ & $\begin{array}{l}17 \\
18 \\
20 \\
22 \\
24 \\
27 \\
30 \\
32 \\
35 \\
38 \\
41\end{array}$ & $\begin{array}{l}36 \\
44 \\
50 \\
56 \\
61 \\
65 \\
69 \\
72 \\
75 \\
80 \\
85\end{array}$ & $\begin{array}{l}39 \\
48 \\
54 \\
60 \\
64 \\
68 \\
72 \\
76 \\
79 \\
84 \\
89\end{array}$ & $\begin{array}{r}44 \\
53 \\
60 \\
67 \\
72 \\
77 \\
81 \\
85 \\
88 \\
94 \\
100\end{array}$ \\
\hline
\end{tabular}

RANGE IN FEET FOR 116-IN. NOZZLE

\begin{tabular}{|c|c|c|c|c|c|c|c|c|c|c|c|c|c|}
\hline \multirow{3}{*}{$\begin{array}{c}\text { Pressure at base } \\
\text { of nozzle } \\
\text { lb/in.? }\end{array}$} & \multirow{3}{*}{$\begin{array}{l}\text { Gal/ } \\
\text { min } \\
\text { (com- } \\
\text { puted) }\end{array}$} & \multicolumn{12}{|c|}{ Height } \\
\hline & & \multicolumn{4}{|c|}{6 feet } & \multicolumn{4}{|c|}{8 feet } & \multicolumn{4}{|c|}{10 feet } \\
\hline & & $\mathbf{A}$ & B & C & D & A. & $\mathbf{B}$ & 0 & $D$ & $\mathbf{A}$ & $\mathbf{B}$ & C & D \\
\hline $\begin{array}{l}10 \\
350 \\
30 \\
30 \\
35 \\
450\end{array}$ & $\begin{array}{l}118 \\
145 \\
167 \\
187 \\
205 \\
221 \\
237 \\
251 \\
265 \\
200 \\
313\end{array}$ & $\begin{array}{l}18 \\
19 \\
20 \\
21 \\
22 \\
24 \\
25 \\
27 \\
29 \\
34 \\
40\end{array}$ & $\begin{array}{l}32 \\
39 \\
45 \\
50 \\
56 \\
61 \\
65 \\
69 \\
71 \\
75 \\
78\end{array}$ & $\begin{array}{l}38 \\
45 \\
51 \\
57 \\
62 \\
67 \\
71 \\
76 \\
80 \\
80 \\
89\end{array}$ & $\begin{array}{l}43 \\
51 \\
58 \\
64 \\
69 \\
74 \\
79 \\
83 \\
87 \\
94 \\
99\end{array}$ & $\begin{array}{l}17 \\
21 \\
24 \\
27 \\
30 \\
32 \\
35 \\
37 \\
39 \\
43 \\
46\end{array}$ & $\begin{array}{r}35 \\
42 \\
48 \\
55 \\
61 \\
67 \\
73 \\
79 \\
85 \\
94 \\
100\end{array}$ & $\begin{array}{r}38 \\
47 \\
55 \\
62 \\
68 \\
74 \\
79 \\
84 \\
90 \\
100 \\
110\end{array}$ & $\begin{array}{r}41 \\
63 \\
63 \\
71 \\
77 \\
83 \\
90 \\
96 \\
102 \\
113 \\
123\end{array}$ & $\begin{array}{l}21 \\
25 \\
\mathbf{2 8} \\
31 \\
34 \\
36 \\
\mathbf{3 8} \\
40 \\
42 \\
45 \\
47\end{array}$ & $\begin{array}{r}39 \\
51 \\
60 \\
67 \\
73 \\
78 \\
84 \\
89 \\
94 \\
102 \\
108\end{array}$ & $\begin{array}{r}43 \\
56 \\
65 \\
72 \\
79 \\
85 \\
91 \\
96 \\
101 \\
111 \\
119\end{array}$ & $\begin{array}{r}60 \\
62 \\
72 \\
80 \\
88 \\
95 \\
102 \\
109 \\
115 \\
126 \\
135\end{array}$ \\
\hline
\end{tabular}

$A=$ Range where stream is nearly solfd with little spray,

$B=$ Range for center of stream about $4 \mathrm{ft}$ above ground.

C-Range for conter of streem where it hilts ground.

D = Range for extreme drops. 


\section{(d) SIZE OF STANDPIPES}

With the maximum demand and the water supply available known, the size of standpipes and distributing mains can be determined so that the quantity and pressures required at outlets will be obtained. Standpipes supplying large hose in buildings not over $75 \mathrm{ft}$ or 6 stories high will generally be adequate if of 4-in pipe. For higher buildings 6-in. standpipes are recommended (62). No increase in size for combined supply to large and small hose will usually be required.

For supplying small hose, standpipe risers and circulating mains should not be less than 2 in. for buildings not exceeding 4 stories or $50 \mathrm{ft}$ in height and $2 \frac{1}{2}$ in. for higher buildings. Where the same pipe system is used as that for the domestic supply, it may be necessary to increase these sizes by $1 / 2$ or 1 in. Generally, considerable economy and increased simplicity can be obtained by this combination of services. It assumes, however, that the water supply provided is adequate for both.

All standpipe risers should be connected through a gate valve with a circulating main of size not smaller than the largest riser.

(e) HOSE OUTLETS, HOSE, NOZZLES, AND VALVES

Hose valves should be of the gate or angle type and have national standard fire-hose thread. If the fire-hose thread for the locality is not according to this standard, adapters should be provided. This is recommended on the assumption that the national standard thread will eventually be adopted. Generally large hose is not provided at the outlets. Small hose should preferably be $1 \frac{1}{2}$ in. linen unlined (64), fittings to have $11 \frac{1}{2}$ threads per in. The necessary length should be stored on racks at each outlet. The discharge side of hose outlet valves and all other outlets for fire hose should have male threads. Semiautomatic or one-man hose racks can be obtained with which water from the open hose valve is prevented from entering the hose until after it is extended, but are not in general considered necessary. Racks for hose should preferably be in cabinets flush with the supporting wall and fitted with glass doors. In correctional and similar institutions, steel doors prominently marked may have to be used in place of glass.

For small hose, nozzles should preferably be $1 / 2$ in. Nozzles with a shut-off device should be provided only for 
locations where prevention of water damage is a prime consideration. Another type of nozzle now coming into use has means of adjusting the discharge from solid stream to fine spray. This has advantages under some conditions, of extinguishing fires with a minimum of water and water dam. age. The spray can also be used to help protect the firemen from the heat of the fire. They cannot, however, be depended on to give the uniformly fine spray or fog adapted for extinguishing fires in certain flammable liquids or the safety in application of water to live electrical equipment, obtainable with nonadjustable nozzles designed for such purposes.

Spray or "fog" nozzles for attachment to hose lines for manual application, especially designed for extinguishing oil fires without scattering the oil, are also available. They have been found effective for limited areas over a limited range for fires in oil of relatively high flash point, such as domestic fuel oil but, in general, not effective for those of lower flash point, as, for example, gasoline. Usually they require a supply pressure in the neighborhood of $100 \mathrm{lb} / \mathrm{in}^{2}{ }^{2}$ They are available for attachment directly to the hose or, where a close approach to the fire is impracticable, are supplied with a play pipe of greater or lesser length.

One gate valve should be provided at the base of each standpipe riser. Where standpipes are exposed to freezing, they can be kept dry with a control valve and drain. The valve may be manually operated or remotely controlled and operated by electrical or hydraulic means. One valve may be used to admit water to several standpipes.

Where standpipe systems or pressure tanks are supplied for initial fire fighting from the domestic or other source at lower pressure than that given by the fire pump or firedepartment pumpers, a check valve should be placed in the connection to the low-pressure supply. Street (siamese) inlets for pumpers or high-pressure fire-service connections, should be provided at one or more accessible points to standpipe systems, where such public protection is provided. For standpipes serving large hose, one such connection must be provided for each standpipe riser where the risers are not interconnected.

(f) ALLOWABLE PRESSURES AND PRESSURE-REDUCING DEVICES

Continuous pressures exceeding $150 \mathrm{lb} / \mathrm{in}^{2}{ }^{2}$ are usually considered undesirable on parts of standpipe systems from 
which hose outlets are taken. At the hose outlets, pressurereducing devices should be provided so that the pressure with the stream flowing will not exceed about $55 \mathrm{lb} /$ in. $^{2}$ immediately outside of the outlet. Nozzle pressures of 40 $\mathrm{lb} /$ in. $^{2}$ should preferably not be exceeded. With a $11 / 8$-in. nozzle at the end of $100 \mathrm{ft}$ of $21 / 2$-in. rubber-lined hose, or $75 \mathrm{ft}$ of $11 / 2$-in. linen unlined hose with $1 / 2$-in. nozzle, 55 Ib/in. ${ }^{2}$ at the hose valve would correspond to the given nozzle pressure. Allowing for friction losses in pipe and fittings, the above rule would require reducing devices at hose outlets where the static pressure exceeds 60 to $65 \mathrm{lb} / \mathrm{in}$ :

Where the standpipe systems for small hose are combined with the domestic water-supply system, the pressure regulation required for the latter may serve the purpose for the hose outlets, depending on the range in pressure obtaining. Pressures can be reduced by the insertion of a disk outside of the hose valve with an orifice " $A$ " square inches in area, that can be determined approximately from the formula,

$$
A=.0425 \frac{Q}{\sqrt{P_{1}-P_{2}}}
$$

where $Q$ is the discharge in gal/min and $P_{1}-P_{2}$ is the difference in pressure on the two sides of the disk in $1 b /$ in. $^{2}$ The actual pressure obtaining on the outlet side of the disk should be determined in representative locations after installation.

Another method consists in placing a brass sleeve over the lower threaded portion of the valve stem immediately above the gate, about $\frac{1}{1}$ in. thick and slightly larger than the thread on the valve stem. Its length is made so that it will stop the movement of the valve at the position giving the desired pressure. For rising-stem valves it is most conveniently determined by measuring the travel of the valve from the full open position to the position giving the desired pressure, the required length of sleeve being equal to this travel. For this type as also for the nonrising-stem type, this movement can be computed in terms of the number of turns required and gate movement per turn of wheel. (See fig. 1.)

Adjustable pressure-reducing valves are obtainable involving restriction of flow through adjustable disks or diaphragms. The cost of the pressure regulation using these 
valves is much greater than with the devices outlined above and it should be considered whether for a given installation the added expense is warranted. One type of location in

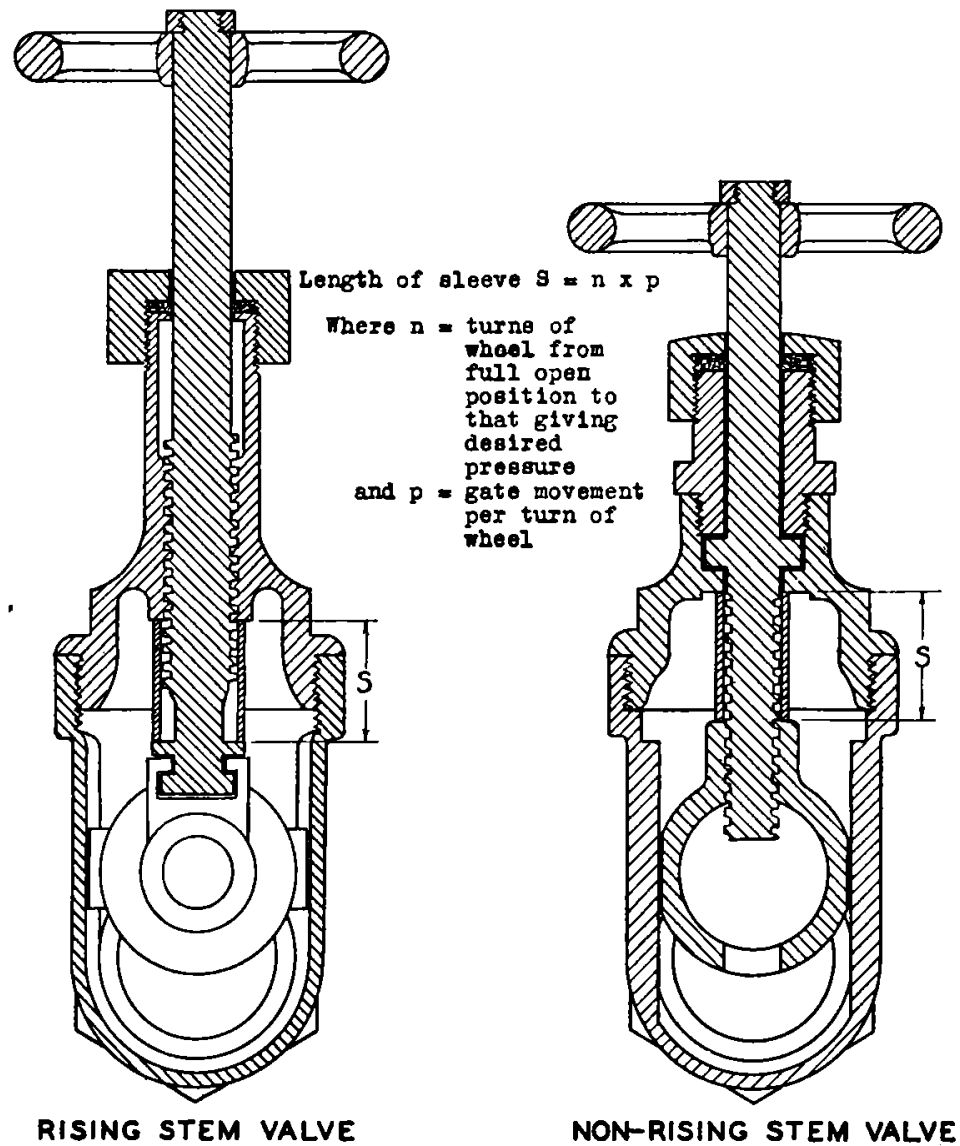

FTaURE 1.-Pressure reducing device for hose outlet valves.

which the adjustable device has advantages is where a standpipe may have to be used to fight an exposure fire requiring water at higher pressure than fires inside of the building. 


\section{AUTOMATIC-SPRINKLER EQUIPMENTS}

\section{(a) SCOPE OF APPLICATION}

Automatic-sprinkler protection employing water is adapted in general for occupancies presenting hazards and values such that the cost of the protection can be justified on the score of expected reduction in loss from fire, as outlined in section II. In determining the cost of protection, items such as any resulting change in the cost of the structural portion of the building, its value from the standpoint of utility, storage capacity, etc., and the expense for operation and maintenance, should also be considered. The effectiveness of this type of protection with properly installed and maintained equipments is high, so that an annual cost equal to a large portion of the average annual fire loss to which given types of property are subject as unprotected can be profitably incurred for this type of protection.

It will, in general, be found that only conditions representative of the higher values or hazards call for such protection. Some areas within buildings may not present values such that the protection is required on that account alone, but a fire in them may cause damage to higher values in adjacent relatively nonhazardous areas to such extent as to justify the installation. Carpenter and paint shops, shipping rooms, and waste paper and miscellaneous storage in fire-resistive public or office buildings are examples. The general types of occupancies for which the protection is adapted include manufacturing, handling, and storage, presenting moderate to high hazards and values, and subject mainly to class A fires. Fires such as those in garages and airplane hangars that come in part under class B, can generally be controlled satisfactorily also on account of the large volume of water applied. Other areas adaptable for automatic sprinkler protection include inaccessible spaces difficult to protect by other means. The absence of other forms of protection and requirements for isolation, such as in penal institutions, may also be determining factors.

The protection cannot, however, control fires in flammable liquids in large containers, in materials subject to flash fires, or those originated by explosions of gases, including vapors from flammable liquids, dusts, and explosives. Spaces subject to class $\mathrm{C}$ fires such as electrical generating, transforming and distributing stations, are also not adapted for this type of protection. Other materials that react with water 
to such extent as to preclude this type of protection where they are present in quantities, include aluminum powder, calcium carbide, calcium phosphide, metallic sodium and potassium, calcium oxide (quick lime), magnesium powder, and sodium peroxide.

Materials of high value subject to water damage might come within a similar classification although storage in suitable containers or on skids will minimize this possibility. Generally, the prospective water damage from accidental operation or opening of heads over a large area because of a localized fire, is overestimated. In some locations the exposed piping and heads may be objectionable on the score of appearance. Concealed piping and pendent heads can be used on wet-pipe systems although at some sacrifice in effectiveness.

The general advantage of sprinklers as an automatic firealarm and extinguishing equipment consists in that the effectiveness is independent of the human element except as concerns response for shutting off water to prevent undue water damage, and proper upkeep. With the types of protection previously discussed, it has been indicated that there must be discovery of fire at early stages and prompt response to alarms with means for initiation of fire extinguishment, if the effectiveness of the equipment provided is to be developed.

Automatic sprinklers compensate to some extent for deficiencies in construction from the standpoint of fire resistance of building members, subdivision into fire areas, and protection against exterior exposure. They cannot, however, be taken as substituting for adequate means for egress, particularly in places of public assembly, although safety to life is promoted by the extinguishment of fire in earlier stages when this equipment is present within a building.

\section{(b) TYPES}

The types of automatic-sprinkler equipments employing water include wet-pipe, dry-pipe, thermostatically operated systems with either closed or open heads, and open systems for protection against exterior exposure.

In the wet-pipe system all portions are filled with water, and without special precautions, such as maintenance of piping filled with nonfreezing solution, is adapted only for areas not subject to freezing. Within this limitation its effectiveness, reliability, and economy, give it preference 
over other types except in areas over which rapid spread of fire can occur. This type can be applied at low cost to minor hazardous areas such as furnace rooms and waste paper storage. The small number of heads would often require no outlay for additional water supply.

In the dry-pipe system, adaptable for areas subject to freezing temperatures, the piping beyond the dry valve is filled with air under pressure. The operation of a head lowers the air pressure which trips the dry valve, admitting water to the system. Exhausters or accelerators are installed to hasten the action of the valve. The air in the system slightly delays the issue of water and the dry valve introduces an element of added initial cost and maintenance and a minor element of unreliability due to possible sticking of the dry valve on its seat. The latter is being largely overcome in recent types of valves.

In thermostatically controlled systems with closed heads, the piping beyond the control valve is filled with air at or near atmospheric pressure. The thermosensitive elements are usually of the rate-of-rise type (see sections $X 2(a)$ and $\mathbf{X}$ (b), and are suitably distributed on the ceiling over the area to be protected. The operation of one or more thermosensitive elements from fire in the area, opens the valve and admits water to the system. No water will, however, issue until a sprinkler head opens. The thermosensitive elements being more sensitive than the sprinkler heads, will give the alarm before the latter opens, which, with prompt response may enable the fire to be extinguished with first-aid equipment before the sprinkler head opens. On opening of the heads water will issue a little more promptly than in systems controlled by dry-pipe valves because of the lower air pressure initially present in the pipes. A small difference in air pressure may be maintained between the atmosphere and the piping system as a means of detecting leaky or accidentally opened heads.

In thermostatically controlled systems with open heads, the water is admitted to the system when the control valve operates and issues through the full number of heads controlled by the valve, the heads being standard sprinkler heads with the thermosensitive element and cap removed. These are restricted by accepted regulations $(65,66)$ to 75 per valve compared with 1,000 permitted for closed heads.

Both types of themostatically-controlled systems are adapted for areas subject to freezing temperatures. The 
type with open heads can control fires that spread rapidly better than the other types. Possibility of water damage from both accidental operation and the excess applied in case of fire, must, however, be considered. The contents of buildings such as garages and airplane hangars are not likely to be damaged by water.

Open sprinklers used for protection against exterior exposure were discussed briefly in section $V 4(b)$. They are usually manually controlled but may be operated automatically by heat-actuated devices.

\section{(c) HEADS FOR AUTOMATIC-SPRINKLER SYSTEMS}

Heat-actuated heads for controlling the flow of water in automatic-sprinkler systems have been the subject of intense development and testing during the past $50 \mathrm{yr}$ with the result that present recognized models have a high degree of reliability if properly installed.

There are three common types of sprinkler heads. One type depends for operation on the fusion of a solder in a device that controls the issue of water from the head, the temperature of operation being controlled by the characteristics of the solder. A second type depends for operation on the fusion of a solid chemical in a similar device, the temperature of operation being controlled by the use of different solid chemicals for the fusible element. The third type operates by the fracture of a liquid-filled bulb, the temperature of operation being controlled mainly by varying the relation of the volume of liquid to that of an air bubble within the bulb. All three types can be obtained in models designed to operate at various temperatures which can be recognized by the color of the frame. The temperature ratings of the various heads and the corresponding frame colors are indicated in table 7.

TABLE 7.-Temperature ratings of automatic sprinklers

\begin{tabular}{|c|c|c|c|}
\hline $\begin{array}{l}\text { Rated operating tem- } \\
\text { perature of heads } \\
\left({ }^{\circ} \mathrm{F}\right)\end{array}$ & $\begin{array}{l}\text { Max permissible } \\
\text { temp at ceiling } \\
\text { where sprinklers } \\
\left.\text { to be used ( }{ }^{\circ} \mathrm{F}\right)\end{array}$ & Designation & Color of frame \\
\hline $\begin{array}{l}135 \text { to } 165 \\
175 \text { to } 212 \\
325 \text { to } 286 \\
320\end{array}$ & $\begin{array}{l}80 \text { to } 100 \\
101 \text { to } 150 \\
151 \text { to } 225 \\
226 \text { to } 300\end{array}$ & $\begin{array}{l}\text { Ordinary } \\
\text { Intermediate........ } \\
\text { Hard } \\
\text { Extra hard }\end{array}$ & $\begin{array}{l}\text { Unpainted bronze. }{ }^{1} \\
\text { White.2 } \\
\text { Blue. } \\
\text { Red. }\end{array}$ \\
\hline
\end{tabular}

1 The $135^{\circ}$ nonmetallic (chemical) type has partial black marking on sides of frame.

The $175^{\circ}$ chemical and silica bulb types have yellow frames. 
The sensitivity of a sprinkler head, expressed in terms of the time before it operates and subjected to a given temperature rise, depends on its design and temperature of operation. The air temperature surrounding a sprinkler when it operates due to rise in temperature as from a fire, is likely to be considerably higher than its rated operating temperature, since the temperature of its thermosensitive element lags behind that of the surroundings.

For locations subject to corrosion, wax-coated heads can be obtained that afford considerable added protection. The wax melts at temperatures below that at which the sprinkler operates and hence does not materially delay operation. Heads completely enclosed in a sealed glass flask can also be obtained, but they are less sensitive than the heads with bare elements. Painting or kalsomining of heads is undesirable as it decreases sensitivity and causes sticking of moving parts.

The life of sprinkler heads as of sprinkler systems generally will vary considerably with the exposing conditions. In computing the cost of the protection, annual depreciation of 4 percent will probably cover for most conditions both deterioration and obsolescence of the equipment as such. It may not cover loss on the investment due to change in occupancy or termination of the useful life of the building. Loss on the latter score is avoided by installing automatic sprinklers in buildings that have assurance of longer life than the protection equipment.

\section{(d) GENERAL INSTALLATION DETAILS}

Installation requirements for automatic sprinkler systems have been given careful consideration and systems installed according to accepted standards $(65,66)$ should give good performance. These include such details as spacing of heads for different types of buildings or ceiling constructions, clearance above heads, size of branch lines, risers, distributing mains and connections, types of fittings, types and general locations for valves, gages, drains, test pipes, and fire-department connections.

In the recommendations of the National Fire Protection Association details of automatic sprinkler systems are outlined for three general occupancy classifications-light hazard, ordinary hazard, and extra hazard, differing mainly in spacing of sprinkler heads, size of supply lines, and capacity 
of water supply (66). The light-hazard group includes apartment houses, dwellings, hotels, schools, churches, hospitals, and office buildings, occupancies which ordinarily are not given automatic sprinkler protection. Under ordinary-hazard occupancies are listed mercantile establishments, warehouses, factories, and others not coming under the high or extra-hazard groups. The extra-hazard class includes occupancies that because of the type disposition, or amount of combustibles to be protected require greater rate or amount of water flow or quicker response than for ordinary occupancies. The rules of the Associated Factory Mutual Fire Insurance Companies are designed for the ordinary and extra-hazard occupancies as outlined above (65).

A brief summary of requirements of interest to the designer of the building and its equipment may be pertinent. Check valves are required in connections to multiple sources of water supply to prevent back flow through one source from another source at higher pressure. A gate valve is generally required on each side of the check valve to enable inspection and repair of the valve, except in street connections for fire-department pumpers. 'The water supply to the whole system or portion thereof served should be controlled by one gate valve in an accessible location. Floor valves should be used for shutting off portions of the system only where areas, heights, number of building subdivisions, or number of tenants served are large or where contents are very susceptible to water damage. This is to reduce possibility of shut valves. The types of valves, their supervision, and protection should be adapted for the location. This will need special consideration where tampering or similar interference is possible in order that the protection may be in operative condition at times when it may be most needed. Provision must be made for carrying off water from drains for standpipe risers and from test pipes.

Proper structural details will assist materially in increasing the effectiveness of the installation. A clear space of 24 in. between ceiling and top of permanent equipment and 10 to $12 \mathrm{in}$. between sprinkler piping and ceiling is desirable. This should be considered in fixing story heights. While smooth ceilings give the best distribution of water from sprinkler heads, beams or draft stops 12 in. or more deep at intervals not exceeding $100 \mathrm{ft}$, assist in preventing the opening of heads beyond the area affected by a fire and in- 
crease the sensitiveness of the heads above the fire. This is particularly important where a floor or roof is supported on deep open trusses. At least some of the latter should be made solid by fireproofing or other method. For fire-resistive floor or roof construction, the best arrangement from the standpoint of class A sprinkler protection is attained by making panels 20 by $20 \mathrm{ft}$ to correspond with the $10-\mathrm{ft}$ spacing required for the sprinklers, with beams at all margins of the panels projecting 10 to $12 \mathrm{in}$. below the floor slab.

Vertical communications must be protected to prevent opening of heads on floors not affected by the fire and exterior openings should be protected for similar reasons. Small enclosures and concealed spaces in walls and ceilings of combustible construction are undesirable since they enable fire to originate and spread through channels that cannot be reached by the sprinklers. Segregation of portions of building not covered by the protection from those that are protected is required by the regulations. Floors should be watertight and slope on a grade of not less than 1 in. in $20 \mathrm{ft}$ toward scuppers or floor drains.

\section{(e) WATER SUPPLIES FOR SPRINKLERS}

The sources of supply include public water mains, the same reinforced by booster or fire pumps, fire-department pumpers and gravity and pressure tanks. There should preferably be two sources of supply. A public main giving adequate capacity and pressure is a satisfactory source of primary supply. Hydrant tests should be made at the building site to determine the available pressure with water flowing at the required rate. A static pressure of $25 \mathrm{lb} / \mathrm{in}^{2}$ on the top line of sprinklers or 10 to $15 \mathrm{lb} / \mathrm{in}^{2}$ minimum at this point with water flowing at a rate representative of the consumption when all heads subject to one fire are opened, represents minimum requirements. The connection should be made outside of the meter or a meter placed in the connection that will not cause undue loss of head.

Gravity tanks are considered satisfactory primary supplies if the bottom of the tank is 20 or $25 \mathrm{ft}$ above the top line of sprinklers. Capacity of tank has been recommended as not less than the consumption of 25 percent of the sprinkler heads within one undivided area for 20 minutes. Assuming $20 \mathrm{gal} / \mathrm{min}$ per sprinkler, this is equivalent to $100 \mathrm{gal}$ for each sprinkler within the area. For 50 or more heads within 
one area the minimum capacity should be 5,000 gal. The above assumes the presence of a secondary supply such as a public main supplying water through a fire pump or firedepartment pumpers. If an elevated tank supplies private hydrants also, the bottom should have an elevation above the highest buildings of not less than $25 \mathrm{ft}$ and have capacity of not less than 30,000 gal.

Pressure tanks generally, carry only about $1 / 2$ of the water specified for gravity tanks. The static pressure on the top line of sprinklers with the tank empty should not be less than $15 \mathrm{lb}$. Unless acting merely as a cushion tank for a fire pump, the pressure tank or tanks should be placed on the roof or other elevated position to avoid excessive pressure in the basement location as explained in section XI 3 (a) 3 above. A secondary supply such as was indicated for gravity tanks would be needed with the pressure tanks.

Fire pumps should preferably be provided with automaticstarting panels even where an initial supply in gravity or pressure tanks is present. Fire-department connections on outside of buildings should be made to all sprinkler equipments where public protection is present.

For further details relating to water supply and watersupply equipment, reference is made to section XI 3(a) above.

(f) FIRE-ALARM AND SUPERVISORY EQUIPMENT

Means for giving an alarm at locations where it will receive attentiton at all hours in case of water flow from opened sprinklers or other cause, tripping of alarm valve, low air pressure, or operation of thermosensitive elements, should be provided. Exceptions to the rule might be made for small wet-pipe systems where provisions have been made for preventing decided water damage.

Sprinkler supervisory equipments checking position of supply valves, operative condition of alarm circuits, pressures at dry-pipe valves, and water level, pressure, and temperature in supply tanks, are obtainable. The necessity for such equipment can be determined only with reference to the conditions surrounding each installation.

\section{FIXED CARBON-DIOXIDE FIRE-EXTINGUISHING SYSTEMS}

Fixed carbon-dioxide extinguishing equipment is adapted mainly for fires in materials and equipment in enclosed spaces $651704-45-7$ 
that can be controlled by the reduction of the oxygen content of the air to a point where combustion will not continue. The limit varies for different materials as indicated in table 8.

TABLE 8.-Reduced oxygen concentrations of the air required to prevent or extinguish fire in different materials

[Taken from Proceedings of the Thirty-fifth Annual Meeting of the National Fire Protection Association, p. 123, 1931]

\begin{tabular}{|c|c|c|}
\hline Material & $\begin{array}{c}\text { Maximum } \\
\text { permissible } \\
\text { oxygen } \\
\text { percentage }\end{array}$ & $\begin{array}{l}\text { Required } \\
\text { carbon- } \\
\text { dioxide } \\
\text { concentration }\end{array}$ \\
\hline $\begin{array}{l}\text { Pittsburgh coal dust. } \\
\text { Pyrethrum flower dust. } \\
\text { Acetone } \\
\text { Cotton lint or dust in suspension in air } \\
\text { Ethyl alcohol }\end{array}$ & $\begin{array}{l}16 \\
15.5 \\
15 \\
15 \\
15\end{array}$ & $\begin{array}{l}23.8 \\
26.8 \\
28.6 \\
28.6 \\
28.6\end{array}$ \\
\hline $\begin{array}{l}\text { Gasoline vapor } \\
\text { Kerosene vapor } \\
\text { Methane } \\
\text { Cork dust-. } \\
\text { Wheat, corn, or oat elevator dust }\end{array}$ & $\begin{array}{l}15 \\
15 \\
14.5 \\
14.1 \\
14\end{array}$ & $\begin{array}{l}28.6 \\
28.6 \\
31.0 \\
32.9 \\
33.3\end{array}$ \\
\hline $\begin{array}{l}\text { Ground oat hulls } \\
\text { Ether } \\
\text { Hard rubber dust } \\
\text { Wheat sterch } \\
\text { White dextrine }\end{array}$ & $\begin{array}{l}13.7 \\
13 \\
13 \\
12 \\
12\end{array}$ & $\begin{array}{l}34.8 \\
38.1 \\
38.1 \\
43.9 \\
43.9\end{array}$ \\
\hline $\begin{array}{l}\text { Ethylene } \\
\text { Sulfur } \\
\text { Carbon disulphide } \\
\text { Cotton in bulk-to prevent smoldering and reignition } \\
\text { Jute. }\end{array}$ & $\begin{array}{l}10 \\
8.5 \\
8 \\
8 \\
8\end{array}$ & $\begin{array}{l}52.4 \\
59.6 \\
61.9 \\
61.9 \\
61.9\end{array}$ \\
\hline $\begin{array}{l}\text { Carbon monoxide. } \\
\text { Hydrogen. }\end{array}$ & $\begin{array}{l}5.9 \\
6.9\end{array}$ & $\begin{array}{l}71.9 \\
71.9\end{array}$ \\
\hline
\end{tabular}

This method is adaptable for the prevention or extinguishment of class $A$, class $B$, or class $C$ fires where an inclosure is present sufficient to maintain the inert gas mixture for the required period. Application of the gas locally to the fire without presence of any inclosure is confined mainly to portable equipment, although some fixed installations for direct application to machines and relatively small tanks, vats, and similar equipment have been made.

Two general conditions from the standpoint of application obtain. One condition requires the continuous presence of the gas within the space to prevent fire or explosion and for the other the gas is admitted after the fire has started. For both conditions the gas can be released by manual or automatic means (67). Provision can also be made for both 
immediate and delayed automatic release. Distributing valves, manually or automatically controlled, can be installed to direct the discharge to any one of several separate spaces, thus reducing the amount of 'inert gas that need be stored.

The carbon dioxide gas is usually contained in $50-$ or $75-1 \mathrm{~b}$ cylinders, $9 \mathrm{ft}^{3}$ of gas at atmospheric pressure and temperature being assumed to weigh 1 pound. Flue gas and exhaust gas from internal-combustion engines have also been applied for maintaining continuously an inert atmosphere within an inclosure. Thorough ventilation of flooded spaces before entry is required, especially when the latter gases are used. When applied automatically, alarm devices actuated by the thermo-sensitive elements that release the gas or by the initial discharge should be installed to enable occupants to make exit. Openings in inclosures to be flooded, other than those needed to relieve the pressure built up, should be closed by the same means, and forced ventilation shut off. The discharge into closed spaces should be made through suitably spaced nozzles designed to prevent undue agitation that would accelerate combustion, and, also, stoppage from freezing at the point of discharge.

The room space to be allowed per pound of carbon dioxide applied as protection depends mainly on the reduction in oxygen content required for extinguishment of fire in the materials concerned. For oxygen content reduced to 15 percent, $27 \mathrm{ft}^{3}$ of room space per pound can be allowed, while for reduction to 10 percent, $1 \mathrm{lb}$ of carbon dioxide will be needed per $12 \mathrm{ft}^{3}$ of room space. Some excess should be allowed. for a further discharge by manual means if found necessary to extinguish the fire. The size of the room must also be considered, the larger rooms being allowed a greater space for a given amount of inert gas. The recommended range is from $15 \mathrm{ft}^{3} / \mathrm{lb} \mathrm{CO}_{2}$ for up to $800 \mathrm{ft}$ room space, to $22 \mathrm{ft}^{3}$ for rooms of over $50,000 \mathrm{ft}^{3}(67,68,69)$.

\section{FOAM FIRE-EXTINGUISHING SYSTEMS}

Foam fire-extinguishing systems are adapted for class $B$ fires, such as occur in storages of flammable liquids, with exceptions as noted in section XI 1 (b) 3. The foam-producing materials are generally kept separated, until mixed in the foam-generating equipment. The foam can be applied by either manual or automatic means. It should be applied 
in a manner that will produce the least agitation of the burning liquid.

The capacity of generating and distributing equipment can be determined approximately on the basis of delivery of not less than $10 \mathrm{ft}^{3}$ of foam per minute for each $100 \mathrm{ft}^{2}$ of liquid surface of the largest unit to be protected (71). The supply of foam-producing materials kept on hand should be sufficient for 5 to $10 \mathrm{ft}^{3}$ of foam per square foot of liquid surface of the largest unit to be protected, the amount depending on the volatility of the liquid and the method of application of the foam.

\section{WATER-SPRAY SYSTEMS}

The water is applied in finely divided form by means of special type spray nozzles and is recommended for conditions where the usual methods of applying water may be ineffective or undesirable such as on live electrical equipment or certain oils (See par 1 (b) 1 above). The control may be either manual or automatic. While it is recommended that the electric supply be cut off in advance of application of water, certain distances of all portions of the equipment from live electrical apparatus are required, varying from $6 \mathrm{in}$. to over $10 \mathrm{ft}$. depending on the voltage (72). There should be full information on the electrical resistance of the spray with the equipment and water pressure concerned if it is to be applied to live electrical apparatus.

\section{OUTSIDE PRIVATE PROTECTION}

(a) WATER SUPPLY

Where a building or group of buildings is located beyond the range of protection from a public water supply, or where the latter is inadequate for the purpose, the installation of water mains covering the property may be necessary. The distance to the public or other supply beyond which this is necessary will depend on the extent of the property and the equipment of the public fire brigade. With good accessibility, fire engines in series can pump water through $1,000 \mathrm{ft}$ or more of $21 / 2$-in. hose, rubber-lined, to deliver streams at the required pressure on the fire, although operating at a decided disadvantage. Where the property is of considerable extent and the distance of any portion thereof from public fire hydrants is more than a few hundred feet 
it is preferable to provide an underground distributing system.

Where a satisfactory distributing system for domestic supply is present and large extensions of the property are not expected, it may be best to make any new system for fire protection separate from other supplies. The advantage consists in fewer connections, less deterioration and obstruction within the piping, less possibility of drainage from connections broken by fire, and in some cases lower cost of water service. The latter would be true in general where no charge or only a nominal one is made for the fire-service connection. For new installations of any considerable extent, the universal practice of towns and small cities of combining all water service in one system will probably in general be found preferable. Where unpotable water must be used for fire protection, separate systems are required. While the requirements for fire protection may necessitate a larger quantity in storage than for domestic purposes, the actual amount consumed over a period of years is very small as compared to that for domestic consumption, which may make it economical to use the potable supply in preference to the construction of a separate system. The combined system has a reliability feature in its favor in that the domestic demand serves to assure open position of supply valves. However, piping could be partly obstructed by sediment and incrustation without the fact becoming apparent until the higher demand for fire extinguishment is imposed. Water systems supplying the combined domestic and fire-service demand should have supervision and maintenance comparable with that of a municipal water system, thus minimizing possible impairment of the fire service incidental to repairs or extensions of the system and its connections. No underground pipe that is a part of the system should be smaller than 6 in. and valves should be provided for shutting off the domestic connection outside of all buildings served. A separate fire-service system should be provided where the supply for fire extinguishment is from a gravity tank or other limited source or where the pressure required is in excess of that suitable for domestic use. Separate systems should be employed also where an economy results from the avoidance of a meter installation, lower annual rate, service charge or meter rental, the use of a less expensive, nonpotable water supply, or like con- 
ditions. In computing relative costs, interest on investment in the water systems, depreciation, and maintenance costs should be considered.

The amount and head of water required in storage, and capacity of connections and pumps, is determined by the maximum flow required for fire extinguishment and the length of time it would be needed under the more extreme conditions. This can be determined only from a study of local conditions. In general, the protection of an individual dwelling or a building of corresponding size requires 500 gal a min. Where dwellings are exposed within distances of $20 \mathrm{ft}$ the requirement would be $1,000 \mathrm{gal} / \mathrm{min}$, and where a district is closely built or buildings approach the dimensions of hotels, warehouses or other structures 2 and 3 stories high or of large area, approximately $3,000 \mathrm{gal} / \mathrm{min}$ is required. Densely built sections of 3-story buildings or extensive warehouses, pier sheds, and manufacturing sections, require up to $6,000 \mathrm{gal} / \mathrm{min}$.

\section{(b) DETAILS OF THE SYSTEM}

The details of the layout should follow accepted practice, the design to be based on a full study of present and possible future requirements. A complete plan of the installation and all subsequent additions and changes should be made and filed for reference. Supply and distributing mains should be cast-iron pipe preferably not less than 6 in. Distributing mains should be looped. Where buildings in considerable size or number are involved, a minimum size of mains used for hydrant supply should be 8 in. Six-inch mains should be used only where they complete a good gridiron, and their length without a cross-connection should not exceed $600 \mathrm{ft}$. Hydrants should be located to enable not less than 2 hose streams to be concentrated on any point in buildings without standpipe protection. No hose line should be required to be more than $500 \mathrm{ft}$ long where streams are taken direct from hydrants nor more than $700 \mathrm{ft}$ where pumpers are used (73). The average length of hose required should be much less. Hydrants in cold climates should be designed, installed, and drained to prevent freezing. Two $21 / 2$-in. outlets, with national standard fire-hose thread, are usual for private hydrants. 'They should be placed not nearer than $50 \mathrm{ft}$ to non-fire-resistive buildings and be located on two or more sides thereof. Where supplying pumpers they 
should have a suction connection of size and thread to fit the suction hose used and should be located not more than $20 \mathrm{ft}$ from driveways or other location accessible to the fire engine. Where hydrants are on a system of mains supplying large automatic-sprinkler or standpipe systems, no suction connection for pumpers should be provided.

\section{(c) HOSE}

The amount of hose to be carried depends on the equipment of the public fire brigade and the degree of certainty and promptness of the response. With a trained private fire brigade, an amount of hose should preferably be carried sufficient to control all but very severe fires, even where. outside aid is available. Cotton rubber-lined hose, $21 / 2$-in. with standard couplings (74), is best for the use of a trained force. Untrained personnel have difficulty in using this size of hose. The hose can be carried on portable reels, trucks, or stored in hose houses provided over the hydrants. Hose houses should be built to keep out rodents, vermin, etc., that would damage the hose, and racks should be provided to keep the hose dry. They should be arranged so two hose connections can be made readily and enable hydrant valve and hydrant to be replaced. A motor-driven hose wagon or hand-drawn reels may for many conditions be found more practical than storage of hose in hose houses, since less hose would in general be required and less difficulty encountered in maintaining it. A reserve supply of hose should be kept on hand to replace that damaged in fighting a fire. Nozzles should not exceed $11 / 8$ in., and for many conditions a smaller size may be preferable. Detachable reducing tips or shutoff valve for nozzle will reduce the water damage incurred in extinguishing fires in the initial stage.

\section{PUBLIC WATER SUPPLY}

The adequacy of the public water supply is of prime importance in determining the design and cost of private protection. The best possible utilization should be made of it for any form of protection. Its capacity and reliability for any purpose can be determined by flow and pressure tests at the building site and the plan of street mains, the reservoirs, and pumping equipment, will disclose other conditions affecting reliability of the supply. 
Connections with the street mains of adequate size and number can usually be made. Separate unmetered connections for fire-protection purposes are preferable. All credit that can conservatively be allowed should be given to supply of water by fire-department pumpers or high-pressure fireservice mains, to standpipe and sprinkler systems through the street (siamese) connections.

\section{PUBLIC FIRE BRIGADE}

The organization, equipment, location of companies, and the cooperative arrangements that can be effected with the public fire-fighting force have an important bearing on the degree and forms of private protection to be provided. That the fullest use should be made of this service is dictated by considerations of both economy and effectiveness of protection. A procedure should be established for transmitting fire alarms and directing the responding force to the fire. Where considered of mutual advantage, private emergency-signaling systems might be connected directly to the public fire-alarm headquarters.

The building personnel responsible for fire protection should be familiar in a general manner with the equipment and methods of fire fighting used by the public brigade. The latter, by inspections and contacts, can acquire a familiarity with the buildings and occupancies to be protected that will be very helpful when called to extinguish fires in them.

\section{FIRE CAUSES AND THEIR ELIMINATION}

\section{THE FIRE WASTE}

The fire loss on buildings and contents in continental United States, based on reports by subscribing companies to the Actuarial Bureau of the National Board of Fire Underwriters is given in Table 9. This is the aggregate estimated total property loss, as distinguished from the insurance loss, and includes an addition prior to 1935 of 25 percent and thereafter 30 percent, to cover losses not reported to the Actuarial Bureau. According to these figures, the aggregate fire loss is now somewhat over $\$ 400,000,000$ per year with an upward trend from the low loss figure of 1935. The trend in terms of relative loss is given in the third column of the table, taking 
the loss figure for 1926 as the base. From the high point for 1926 there is a decline, at first gradual, and then more rapid as the full effect of the business depression beginning in 1929 is reflected in the loss figures.

There are also given in table 9 the relative amount of fire insurance carried by companies on whose reports the fire losses given in the table are based, and the wholesale price index of 800 to 900 commodities, the latter as issued by the Bureau of Labor Statistics. Both the fire loss figures and the amount of insurance would be affected in some degree by the change in price of commodities, although the smaller change in the insurance index as compared with the price index in the period 1929-35 indicates that a considerable portion of the property subject to fire loss, including notably buildings, is less subject to changes in value than commodities in general. The more decided drop in the relative fire loss in the same period, greater than the decline in value of insured property, can be ascribed in part to the decrease in industrial activity, as indicated by the Federal Reserve Board index of industrial production in the last column of the table.

After allowing for such factors, there is apparent a real decrease in the fire loss in relation to values subject to loss, which indicates that the more general use of fire-resistive building construction for major buildings, introduction of fire-prevention measures, and improvements in public and private means for prevention and extinguishing fire, have been effective in reducing the loss. Even so, it constitutes a serious drain on the Nation's resources, considering particularly that the cost of public and private fire protection, and loss in wages and production chargeable to fire, increase the actual loss to a figure estimated to be in excess of 1 billion dollars per year. There is in addition a loss of about 7,000 lives per year from fire and burns, according to the mortality statistics published by the United States Census Bureau. It has been estimated that the loss would be increased to 10,000 lives if it included deaths due directly or indirectly to fire but reported under other classifications, such as those from exposure, nervous shock, and collisions and other accidents involving fire or incurred in connection with fire extinguishment. In addition to the deaths reported there are as many or more serious injuries. 
TABLE 9.-Fire losses and fire-loss trends in continental United States [Fire losses and relative amount of insurance are as reported by the National Board of Fire Underwriters]

\begin{tabular}{|c|c|c|c|c|c|}
\hline Year & Fire loss & $\begin{array}{l}\text { Relative } \\
\text { fre loss }\end{array}$ & $\begin{array}{l}\text { Relative } \\
\text { amount of } \\
\text { fre insur- } \\
\text { ance carried }\end{array}$ & $\begin{array}{l}\text { Wholessle } \\
\text { commodity } \\
\text { price index }\end{array}$ & $\begin{array}{l}\text { Production } \\
\text { index }\end{array}$ \\
\hline $\begin{array}{l}1920 \\
1921 \\
1922 \\
1923\end{array}$ & $\begin{array}{r}\$ 447,887,000 \\
495,406,000 \\
506,541,000 \\
535,373,000 \\
549,062,000\end{array}$ & $\begin{array}{l}80 \\
88 \\
90 \\
95 \\
98\end{array}$ & $\begin{array}{l}80 \\
65 \\
73 \\
86 \\
85\end{array}$ & $\begin{array}{r}154 \\
98 \\
97 \\
101 \\
98\end{array}$ & $\begin{array}{l}78 \\
60 \\
76 \\
92 \\
85\end{array}$ \\
\hline $\begin{array}{l}1925 \\
1926 \\
1928 \\
1929\end{array}$ & $\begin{array}{l}559,419,000 \\
561,981,000 \\
472,934,000 \\
464,607,000 \\
\mathbf{4 5 9}, \mathbf{4 4 6 , 0 0 0}\end{array}$ & $\begin{array}{r}99 \\
100 \\
84 \\
83 \\
82\end{array}$ & $\begin{array}{r}91 \\
100 \\
95 \\
98 \\
103\end{array}$ & $\begin{array}{r}103 \\
100 \\
95 \\
97 \\
95\end{array}$ & $\begin{array}{r}94 \\
100 \\
99 \\
103 \\
115\end{array}$ \\
\hline $\begin{array}{l}1930 \\
1931 \\
1932 \\
1933 \\
1934\end{array}$ & $\begin{array}{l}501,981,000 \\
451,644,000 \\
406,860,000 \\
271,453,000 \\
271,197,000\end{array}$ & $\begin{array}{l}89 \\
80 \\
72 \\
48 \\
48\end{array}$ & $\begin{array}{l}95 \\
89 \\
80 \\
78 \\
85\end{array}$ & $\begin{array}{l}86 \\
73 \\
65 \\
66 \\
75\end{array}$ & $\begin{array}{l}95 \\
78 \\
60 \\
72 \\
78\end{array}$ \\
\hline $\begin{array}{l}1935 \\
1936 \\
1937 \\
1939\end{array}$ & $\begin{array}{l}\mathbf{2 3 5}, \mathbf{2 6 3}, 000 \\
266,659,000 \\
254,959,000 \\
258,478,000 \\
275,102,000\end{array}$ & $\begin{array}{l}42 \\
47 \\
45 \\
46 \\
49\end{array}$ & $\begin{array}{l}87 \\
85 \\
87 \\
84 \\
85\end{array}$ & $\begin{array}{l}80 \\
81 \\
86 \\
79 \\
77\end{array}$ & $\begin{array}{r}91 \\
107 \\
118 \\
93 \\
113\end{array}$ \\
\hline $\begin{array}{l}1940 \\
1941 \\
1942 \\
1944\end{array}$ & $\begin{array}{l}285,879,000 \\
303,895,000 \\
314,295,000 \\
373,000,000 \\
437,273,000\end{array}$ & $\begin{array}{l}51 \\
54 \\
56 \\
66 \\
75\end{array}$ & $\begin{array}{r}89 \\
96 \\
112 \\
110\end{array}$ & $\begin{array}{r}79 \\
87 \\
99 \\
103 \\
104\end{array}$ & $\begin{array}{l}130 \\
169 \\
207 \\
249 \\
245\end{array}$ \\
\hline
\end{tabular}

\section{CAUSES OF FIRES}

The tabulation of causes of fire loss given in table 10 is of interest as indicating relatively the loss attributable to the different types of causes, from which an indication of the extent to which the fire loss is preventable can be obtained. While this gives only the loss from known causes, it is probable that most of the causes enter into the loss from unknown causes and unreported losses in approximately the proportions given in the table. Exceptions might be causes easily identified, such as "exposure", "lightning", and "explosion"; the losses from which would be expected to appear largely under those from known causes.

Examination of the fire loss from the standpoint of the nature of the losses indicates that about two-thirds of the loss is caused by defective construction and installation and lack of knowledge and care with respect to acts and conditions 
that originate or cause spread of fire. Losses from defective chimneys, flues, heating and electrical equipment, and roofing, open lights, petroleum, gas, sparks, explosions, ashes, rubbish, spontaneous ignition, and matches (smoking), are thus largely preventable, and loss of life from fires of such origins could be avoided. A considerable allowance must be made, however, for inability to control the acts of individuals and it has been found that in general for a large and permanent reduction in the fire loss, improvements must be made in construction, protection equipment, and other items not directly dependent on the human element.

\section{TABLE 10.-Fires in the United States resulting from known causes}

[As reported to the National Board of Fire Underwriters for the 10-year period Jan. 1, 1932 to Jan. 1, 1942. Fires, the cause of which was unknown, are not included]

\begin{tabular}{|c|c|c|c|c|}
\hline \multirow{2}{*}{$\begin{array}{l}\text { Number } \\
\text { of claims }\end{array}$} & \multirow{2}{*}{ Cause } & \multirow{2}{*}{$\begin{array}{l}\text { Percent } \\
\text { of claims }\end{array}$} & \multicolumn{2}{|c|}{ Property Loss } \\
\hline & & & Value & Percent \\
\hline $\begin{array}{r}1,238,275 \\
416,866 \\
322,698 \\
300,994 \\
291,181\end{array}$ & $\begin{array}{l}\text { Matches-smoking } \\
\text { Misuse of electricity. } \\
\text { Exposure (fire originating off premises) } \\
\text { Sparks on roofs } \\
\text { Overheated or defective chimneys, flues, } \\
\text { etc. }\end{array}$ & $\begin{array}{r}29.78 \\
10.03 \\
7.76 \\
7.24 \\
7.00\end{array}$ & $\begin{array}{r}\$ 174,979,768 \\
94,84,885 \\
156,560,237 \\
70,208,310 \\
119,985,311\end{array}$ & $\begin{array}{r}15.86 \\
8.60 \\
14.19 \\
6.36 \\
10.87\end{array}$ \\
\hline $\begin{array}{l}259,591 \\
253,382 \\
245,512 \\
221,725 \\
189,111\end{array}$ & $\begin{array}{l}\text { Lightning } \\
\text { Stoves, furnaces, boilers and their pipes.. } \\
\text { open lights. } \\
\text { Petroleum and its products } \\
\text { Hot ashes and coals }- \text { pen fres........ }\end{array}$ & $\begin{array}{l}6.24 \\
6.09 \\
5.90 \\
5.33 \\
4.55\end{array}$ & $\begin{array}{r}50,516,178 \\
100,344,879 \\
24,878,160 \\
77,897,461 \\
26,624,942\end{array}$ & $\begin{array}{l}4.58 \\
9.09 \\
2.25 \\
7.06 \\
2.41\end{array}$ \\
\hline $\begin{array}{r}114,906 \\
68,066 \\
60,058 \\
44,831 \\
33,945\end{array}$ & $\begin{array}{l}\text { Ignition of hot grease, etc. } \\
\text { Spontaneous combustion } \\
\text { Oas -natural and artificial } \\
\text { Sparks arising from combustion } \\
\text { Rubbish and litter }\end{array}$ & $\begin{array}{l}2.76 \\
1.64 \\
1.44 \\
1.08 \\
.82\end{array}$ & $\begin{array}{r}14,316,865 \\
81,109,225 \\
14,370,517 \\
20,889,395 \\
8,235,406\end{array}$ & $\begin{array}{r}1.30 \\
7.35 \\
1.30 \\
1.89 \\
.75\end{array}$ \\
\hline 30,333 & $\begin{array}{l}\text { Miscellaneous-cause known but not clas- } \\
\text { sified }\end{array}$ & .73 & $17,269,461$ & \\
\hline $\begin{array}{l}25,593 \\
25,581 \\
15,233\end{array}$ & $\begin{array}{l}\text { Explosions. } \\
\text { Friction, sparks from running machinery } \\
\text { Fireworks, balloons, etc. }\end{array}$ & $\begin{array}{l}.62 \\
.62 \\
.37\end{array}$ & $\begin{array}{r}21,186,184 \\
26,571,543 \\
2,581,990\end{array}$ & $\begin{array}{r}1.92 \\
2.41 \\
.24\end{array}$ \\
\hline $4,157,881$ & - & 100.00 & $1,103,374,717$ & 100.00 \\
\hline
\end{tabular}

NotE.-These totals are for reported fires where the cause is ascertainable and do not represent elther the total number of fires or the total property loss in the United States. Excluded are all unreported loses as well as the many fires resulting from unknown causes. It is estimated that the aggregate property loss from fire in the United States during this decade was in excess of three billion dollars.

A general grouping of predominating causes of fire, applying particularly to those occurring in major fire-resistive buildings, might include, 1, accumulations; 2, hazardous 
materials, and 3, unattended equipment. Accumulations of ordinary combustibles in undue amounts and for unnecessarily long periods, are responsible for many fires, since they can be ignited by discarded matches, cigarettes, sparks, spontaneous heating, or similar causes. Hazardous materials in solid, liquid, or gaseous form, such as flammable liquids and gases, celluloid, and other hazardous solids, are readily ignited and fires in them are more difficult to control than those in ordinary combustible materials such as wood and paper. Equipment such as burners, ovens, dryers, and gas or electrically heated flat irons, unless well protected or equipped with reliable automatic temperature regulation, are likely to cause fires if left unattended for unduly long periods.

\section{POSSIBILITIES IN FIRE CONTROL}

The above discussion of fire causes has indicated that a large percentage of the loss is preventable with the elimination of defective construction and installation and prevention of acts by individuals that directly or indirectly cause fires to originate and spread. While it is practical to achieve a considerable reduction in the fire loss by such means, it has been the general experience that for a large assured permanent betterment, prevention and protection measures must be provided that are not directly dependent on acts and habits. Fire-insurance experience is informative in this respect. The annual loss experienced for a period of years preceding 1932 by stock fire insurance companies insuring property having a value of over $\$ 200,000,000,000$ was near 20 cents per $\$ 100$ of property value. The types of property and protection provided cover the full range from lowto high-hazard occupancies, combustible to fully fire-resistive construction, and protection ranging from none to supervised automatic-sprinkler installations backed by highly efficient public protection. The experience of dwelling and farm mutual-insurance companies indicates a similar loss in that on a value of over $\$ 50,000 ; 000,000$ annual losses corresponding to about $20 \phi$ per $\$ 100$ of property value have been incurred. The property involved would have little or no private protection and on the average only a moderate degree of public protection. The construction would in general be wood frame or masonry wall with wood interior framing, and the occupancy hazard light or moderate. No large values would 
be subject to a single fire that is confined to the building in which it originates.

Another class of risk includes mainly commercial and industrial establishments having fire-alarm and regular watchman service. Construction would be expected to be above the average from the standpoint of fire resistance. Private protection would consist of hand fire extinguishers and standpipe and hose as a general minimum, with automaticsprinkler protection for a portion approximating one-third of the total. The occupancy hazard would vary from very light for office buildings to high hazard for some industrial occupancies. For these conditions the reported average annual loss for the period 1925 to 1932 was near $5 \phi$ per $\$ 100$ of value, the total value involved being about $\$ 16,000,000,000$.

The experience of fire-insurance companies in writing improved risks gives a further indication of effect of protection measures on the fire loss. The properties covered would involve mainly construction of heavy interior timber framing with exterior masonry walls, or incombustible fire-resistive construction throughout, with occupancy hazards ranging from moderate to high. All but a relatively small portion would be covered by automatic-sprinkler protection backed by fire hose for which connections are provided inside and outside of buildings. The properties would generally have watchman service, suitable means for transmitting fire alarms, and protection against exterior exposure. Inspections of properties by experienced inspectors are made at regular intervals and every inducement is given property owners to prevent loss by fire. For a value at risk of near $\$ 10,000,000,000$, the average loss for the past 8 years has been a little less than $2 \mathrm{c}$ per $\$ 100$ of value.

The loss rates given above are based on full value as distinguished from insured value. The saving in fire loss for the lower rates of loss is offset at least in part by the cost of the protection provided. Methods for estimating justifiable costs of protection, considering the different elements of the risk involved, are given in sections II 2 and XI 4 (a).

\section{GENERAL FIRE-PREVENTION MEASURES}

While fire-resistive construction and fire-protection equipment should be provided to the extent justified by pertaining conditions, many operating practices and details of equipment can be introduced that result in material improve- 
ment without involving any considerable expense over what would otherwise be incurred. The present section deals with such items connected with the construction and equipment of buildings and general management of property.

(a) REVIEW OF PLANS FOR NEW CONSTRUCTION AND EQUIPMENT

Changes in plans cost less than changes in the building and in many cases desirable changes easily effected in the design stage are not possible from a practical standpoint after completion of the building. Submission of plans of major buildings for review by the groups that will carry the fire insurance is general practice for private construction, and many improvements are thus made to the advantage of the owner, since lower insurance rates are thereby obtainable. While liederal buildings are not insured, decided advantage would accrue from a similar review of building plans. The many structural and equipment items requiring attention are outlined in the previous sections of this manual. Mention might be made of requirements for fire resistance of the construction sufficient for the occupancy to be housed, including also the roof construction (sec. III 2,3 ), subdivision into fire areas (sec. V 2) and protection of vertical and horizontal communications to restrict the spread of fire (sec. V 3), protection against exterior fire exposure (sec. V 4), and provision of ample means for exit of occupants in case of fire (sec. VI). Other items relate to materials for partitions, floor finish, interior trim, and fixed and movable equipment (sec. IV), structural and equipment provisions for safeguarding common and special hazards (secs. VII and VIII), and means for discovery and extinguishment of fire proportioned with respect to the fire hazard presented by the building and its occupancy. If fireextinguishing equipment such as automatic sprinklers is to be provided for hazardous areas, the building construction should be designed so it will give the most effective protection, and provisions made for reducing water damage by means of tight floors sloping toward scuppers and drains, curbs around floor openings, and storage of goods on skids, trucks, or shelves (sec. $\mathrm{XI}_{4}(\mathrm{~d})$ ).

(b) TEMPORARY CONSTRUCTION AND INSTALLATIONS

It is possible to offset to a considerable extent the advantages of initial fire-resistive construction by additions, 
partitions, enclosures, and finishes of combustible materials. These generally remain for longer periods than intended. The same applies for temporary electric wiring and gas piping. Such constructions and installations should conform to recognized standards applied in the construction and equipment of buildings.

\section{(c) PLAN OF FIRE-PROTECTION FACILITIES}

An accurate plan of the property, locating and designating the fire-protection systems and equipment provided, should be made and kept up to date. This plan should be drawn to scale and give among others the following details:

Arrow indicating points of compass; size of buildings and number of stories; type of construction including thickness and materials of exterior walls, partitions, fire walls, floors, roofs; type of sash and kind of glass; age of each building; buildings with or without sprinklers; exposing structures and for these, type of construction, size, height, proximity, occupancy, sprinklered or unsprinklered, exterior wall openings and protection, if any; public water mains including size; private water supply and private fire protection including size of mains, hydrants, control valves, location and capacity of fire pumps, location, capacity and elevation of gravity tanks. The plan should be dated. A table of symbols has been developed to show the details mentioned above without crowding the plan and is given in appendix $\mathbf{B}$.

In addition to the general plan outlined above, a schematic diagram should be made of risers for standpipes and hose; gravity tanks, including elevation and capacity; pressure tanks, including capacity; connections to pumps; connections to street (siamese) inlets and control valves. Where sprinklers are installed the distribution system should likewise be shown, together with the accessory equipment.

Where watchman's supervisory and manual or automatic fire-alarm systems are installed, plans should be made showing the wiring, distribution of the stations, thermostats, manual boxes, annunciators, bells, etc., and also a riser diagram showing this distribution in cross section.

Diagrams showing location of exits, posted at suitable locations in large buildings, would increase the effectiveness of the means provided for emergency egress.

The foregoing will afford a starting point for the proper maintenance of fire-fighting equipment and also a basis for 
studies relative to the protection of a project as a whole or in its details.

(d) HEATING, LIGHTING, AND POWER EQUIPMENT

Detached chimneys are to be preferred for other than small installations. Where metal stacks pass through combustible construction, they should be separated by a ventilated space of sufficient width maintained clear of dust and accumulations. The space above, to the side, and beneath furnaces, boilers, stoves, etc., should be sufficient to prevent any heat effects such as browning or scorching from occurring on exposed combustible construction or equipment. Where the space is not sufficient, protections of suitable materials must be applied or floor, wall, or roof construction of incombustible materials provided (27). Careful attention should be given to details of chimney construction (29). The fuel supply, whether solid, liquid, or gas, should be properly safeguarded and frequent inspections made for heating in coal storages and defects in oil or gas lines and tanks.

All loose or broken wiring or fixtures should be promptly repaired. Capacity of fuses or other circuit-protective devices should be checked to determine suitability for the size of wire and type of service, and bridging material removed. Extra fuses should be provided at accessible locations. Accumulations of oil on the base or floor around electrical or mechanical equipment should be prevented. Defective motors and similar equipment should not be allowed to remain in service.

\section{(e) SERVICE EQUIPMENT AND FURNITURE}

A considerable increase in fire safety at little added cost is attainable, particularly in fire-resistive buildings, with service equipment, lockers, desks, filing cabinets, shelving, and receptacles for waste, constructed as far as practical of incombustible materials (45). Information on construction, equipment, and general protection measures for records is given in sections IX and XIII. For receiving oily waste and other materials that may heat and ignite, self-closing waste cans are preferable.

(f) FLAMMABLE LIQUIDS AND OTHER HAZARDOUS MATERIALS

This subject presents so many aspects that a full consideration of each situation with the help of available information 
will be required. The following notes and references may be helpful in indicating the degree of hazard and need for protection measures. In general the amount of hazardous materials at individual points within buildings should be kept at a minimum unless special protection measures are applied. Flammable liquids should in general be limited to 1 or 2 gal contained in safety cans. Suitable cabinets, vented vaults, or separate buildings should be provided for the storage of larger quantities in cans or barrels. Portions of buildings used for such storage should be segregated by means of fire-resistive floors, walls, and protection for openings, and underground tanks provided for large storages in bulk $(75,76)$. Location of tanks above ground is preferred for liquified gases stored under pressure, so that inspection for defects can be made (77). The use of flammable liquids within buildings as in dry cleaning and paint spraying must be carefully safeguarded $(78,79,80)$. Nonflammable liquids or those of relatively low hazard should be preferred for purposes such as dry cleaning of clothing and washing of machine parts. Where volatile flammable liquids are stored, handled, or used, it is essential that ventilation be provided in occupied spaces to prevent the formation of flammable or explosive mixtures of the vapors with air, and that all sources of ignition of the mixture be avoided. For extra-hazardous processes or storage in spaces that are not occupied or into which entry need be made only at infrequent intervals, inclosure may be provided and an inert atmosphere maintained by the use of carbon dioxide, flue gas, or engine exhaust gas. Spaces so flooded must be well ventilated before being entered to reduce the content of inert and toxic gases to safe limits. For other locations provision may be made for manual or automatic release of carbon dioxide in case of fire (sec. XI-5).

Nitrocellulose film, celluloid, or other pyroxylin products in quantities exceeding $25 \mathrm{lb}$ should be stored in vented vaults or cabinets $(39,40,81)$. Scraps and waste of such materials must be kept separate from ordinary waste and burned where the poisonous gases given off will not be objectionable. Acetate cellulose film is preferable to the nitrocellulose type as it presents no greater hazard than wood or paper. Similarly, other articles of cellulose, acetate cellulose, casein base plastics, or phenol-formaldehyde plastics are less hazardous than celluloid. 
Where chemicals or explosives in appreciable quantity are handled, used, or stored, their fire and explosion hazard should be ascertained and proper precautions taken $(82,83$, $84,85)$. Where the quantity or hazard presented warrants it, storage should be in detached buildings, or, for less hazardous materials, in vaults provided with suitable vents. (See sec. VIII.) The preferable location for such vaults is in the upper story or on the roof.

\section{(g) GENERAL MAINTENANCE}

Orderliness and good maintenance conditions are known to be effective in preventing origin and spread of fire. Avoiding unnecessary accumulations of combustible materials within or outside of buildings, prompt collection, safe storage and disposition of waste paper and other refuse, and maintenance of orderliness in locations such as receiving and shipping rooms will prevent many fires. Incinerators, whether within or outside of buildings, should be designed and located so that the hazard to the building and surroundings is reduced to a minimum. Prohibition of smoking in hazardous areas with full compliance therewith as with other fire prevention regulations is another important management detail. Throwing smoking materials out of windows causes awning fires that have involved whole buildings. Provision of ash trays will decrease this hazard.

Prompt repair of roofs, floors, windows, shutters, doors, door hardware, and other building details will assist in preventing origin of fires from flying brands, locomotive sparks, exterior exposure, and those caused by trespassers.

Those in charge of property should be impressed with their responsibility for preventing loss by fire and that conditions or practices recognized as hazardous may result in fires that will be charged to negligence on their part.

\section{(h) REPORTS ON FIRES}

Requiring reports on all fires, large or small, will assist in locating hazardous conditions and practices and in correcting defects in construction and protection equipment. The investigation and report on a fire checked in its initial stage with little or no loss may result in changes in structural or occupancy conditions or in provision of fire-protection equipment that will prevent a much larger subsequent loss. Reports of fires show many instances where substan- 
tially the same cause was responsible for successive fires in the same establishment. As an evidence of their recognition as effective fire-prevention measures, the large outlay of insurance organizations in investigating and reporting on fires can be cited. The necessity for reporting fires engenders a wholesome encouragement for fire-prevention activities.

For Federal property a fire report form has been prepared by the Federal Fire Council that is given in appendix C. Items are included that will give not only information on the fire, but also indicate any needed corrective measures. Copies sent to the Federal Fire Council supply the basis for determining the total fire loss on Government property and predominating causes, the ratio of loss to value subject to loss by fire, comparison of the loss ratio with that on private property, and the trend of the loss and loss ratio.

\section{(i) ORGANIZATION FOR FIRE-LOSS PREVENTION}

For all properties, large or small, there should be effected some degree of organization and inspection to eliminate fire hazards and a procedure to be followed in case a fire occurs. Suggestions for such organization are given in subsequent sections of this manual.

\section{PROTECTION OF RECORDS AND VALUABLES}

\section{VALUE OF RECORDS}

Among the most serious elements in fire-loss is the destruction of records. Because the value of records cannot be easily determined, it is often greatly underestimated. The monetary value of some records is fixed by the cost of reproducing them from other sources (for example, replacing a burned map by preparing a new one from the original survey notes) and can be calculated with some accuracy. If the records cannot be replaced, only a "consequential" value can be placed on them, based on the loss to the Government or its citizens that would result from their destruction. This is most difficult to compute in monetary terms, as it may take the form of lowered operating efficiency of the Government, confusion of land titles, or other misfortunes that represent a real but not easily calculated financial loss. The determination of consequential value becomes especially difficult when elements of contigency enter. The destruction of records relating to a 
particular contract would probably never occasion any loss to the Government for example, but if a claim against the Government should happen later to be filed against which those records were the only defense, the resultant loss might run into hundreds of thousands or even millions of dollars.

The determinable monetary value of records is well indicated in an appraisal of the property of the Department of Commerce made in 1931, in which the value of its buildings was estimated at $\$ 25,387,000$, the inventory value of their contents at $\$ 10,875,000$, and the uninventoried values, consisting almost exclusively of records, at $\$ 189,948,000$. 'The possible fire-loss from the destruction of records indicated by this appraisal would be five times as great as the possible loss from the complete destruction of the buildings themselves and all of their other contents.

The most important values of Government records, however, as distinguished from those of business establishment, cannot be reduced to monetary terms at all. Federal records not only serve the fiscal and operating needs of the Government but also protect the personal and property rights of its citizens. To give but a few examples, the claims to veterans' rights of millions of citizens are based on the service records of the War and Navy Departments; titles to all land formerly in the public domain depend originally on the records of the General Land Office; naturalization records secure the elemental rights of citizenship of millions of persons. The records of the Federal Government are also the principal source of the Nation's history. Because of these values to the public the responsibility of Government agencies for safeguarding their records against destruction by fire far transcends the need for protecting the immediate financial values represented by the records.

\section{CLASSIFICATION BY VALUE}

To provide complete protection against fire for all Federal records is, of course, impossible. Hence the first step in any logically planned program is to classify the records according to their value, so that an appropriate degree of protection can be given to each group. The relative importance of different bodies of records is not easy to determine, since it depends not only upon the importance of the information contained in the records but also upon the availability of the same information elsewhere. The information in any given 
record may be absolutely indispensable to the effective operation of an agency but if the same information is readily available elsewhere in legally acceptable form, the original record is not likely to require any extraordinary protection. Consideration needs to be given to the possible duplication of information not only in other records of the agency itself but also in the records of other agencies as well. The necessity of extraordinary protection of memorandum copies of vouchers of any agency, for example, will be reduced or eliminated if originals of those records are available in the General Accounting Office.

In general, however, records may be divided into the following four classes on the basis of their value: ${ }^{2}$

(1) Indispensable records.-Records that establish or protect the rights and property of individuals or of the Government or that are essential to operations of the Government and that could not be replaced if destroyed.

(2) Important records.--Records essential to the protection of the property and rights of individuals and the Government or to important Government operations that could be replaced only with difficulty if destroyed, and records that have permanent historical or other research value.

(3) Useful records.- Records that could be easily replaced if destroyed or that facilitate but are not essential to Government operations and have little or no permanent value.

(4) Useless records.-Records that are no longer used in the current business of the agency and that do not have sufficient administrative, legal, research, or other value to warrant their further preservation by the Government.

\section{Means of protecting records}

Three principal means of prevention of fire loss among records exist:

(1) Duplication of the records or of the information contained in them and the physical separation of the duplicates from the originals.

(2) Placing the records in specially designed buildings or records storage areas in which fire hazards can be minimized.

(3) Placing the records in fire-resistant vaults, safes, or cabinets.

2 The classiflcation is based on that adopted by the committee on Protection of Records of the National Fire Protection Association (20), modiffed to apply to Federal records. 


\section{(a) DUPLICATION}

In the normal course of operations many records are created in two or more copies for administrative reasons. If the two sets of copies are housed in separate buildings, satisfactory protection is afforded by this means alone. In other cases, although the records themselves are not duplicated, the information contained in them is. For example, the same information may appear in a set of accounts and in the vouchers from which the accounts were prepared. Retention of the vouchers provides a measure of insurance against the destruction of the accounts, although in such instances the cost of reconstructing the one set of records from the other must be considered in determining whether the risk of fire loss has been sufficiently minimized.

The most economical means of reproducing essential records not duplicated in the normal course of operations is afforded by microphotography. Microfilming is most practical with loose papers of uniform size, color of paper and ink, and distinctness of writing. Records of this type can be filmed with high-speed automatic cameras at costs running as low as one to two mills a page. The cost of filming bound volumes or loose papers in which there is a wide variation in the degree of contrast between ink and background runs substantially higher. It should be noted that the use of filmed records in which the documents do not appear in a logical and well-understood order is most difficult, and it is generally undesirable to film records not carefully arranged. Certain precautions must be taken to insure that the film copy will be acceptable as legal evidence in the event of the destruction of the originals. Because of this fact and of the many variable factors that must be considered in connection with a microfilming project, it is generally desirable to seek the advice of the Division of Photographic Archives and Research of the National Archives in planning any large microphotographic undertaking.

It should be emphasized that no significant degree of protection is afforded by any means of duplication unless the original and the duplicate records are separately housed so that both cannot be destrpyed in the same fire.

(b) SPECIAL HOUSING

Arrangements may be made to transfer noncurrent records of permanent value to the custody of the Archivist of the 
United States for storage in the National Archives Building. This building is specially designed to preserve records with the minimum possible fire risk, and the transfer to it of important records not in active use is a practical and economical means of insuring their protection.

Large accumulations of important records that are semiactive and must be at hand for relatively frequent reference should be placed if possible in special records storage rooms of the type described in section IX 3. Extra protection can be obtained in such storage areas not only by their special construction but also by the enforcement of special fire precautions, such as the prohibition of smoking (86).

\section{(c) SPECIAL EQUIPMENT}

Smaller quantities of indispensable or important records in active use that must be kept available for daily reference can be placed in records vaults or insulated safes or cabinets of the types described in sections IX 2 and IX 5. By avoiding storage of valuable records in basement vaults of high nonfireproof buildings, it is generally possible to obtain an assured degree of protection by means of vault storage. The basement location is unfavorable because of possibility of contact of hot debris with the walls and doors for a long period after the peak of the fire and also possibility of water damage (21).

While the volume of records that can be profitably stored in insulated portable containers, such as safes, is limited, and under some conditions the protection cannot be definitely predicted, this type of device is an important factor in record protection. It will often be found that a large proportion of the value of an accumulation of records will be represented by only a small part of the total volume, which can be given this form of protection. The advantages consist in being able to place the container where the contents will be the most readily available. Protection can also be obtained by this means in buildings where vaults were not originally installed and in which their subsequent installation would be impracticable. (See sec. IX $5 \mathrm{~b}$ ). In fireproof buildings they can be selected to have a fire resistance that will enable them to preserve their contents in a fire that would consume the combustible contents of the portion of the building in which they are located. Considerations of weight and portability, however, place a practical limit on the protection that can be af- 
forded, which at present is equivalent to that required to resist the first 4 hours of the furnace test (1).

In a fire-resistive building this will correspond to the severity of a fire consuming the contents of a room having ordinary combustibles distributed over the floor area totalling between 30 to $40 \mathrm{lb} / \mathrm{ft}^{2}$. (See sec. III $3 \mathrm{a}$ ). For locations with higher combustible contents the safes would afford temporary protection and the contents would be preserved in case the severity of the fire is decreased by fire extinguishment or other means to a limit not exceeding the fire resistance of the safe. In nonfireproof buildings the protection afforded by safes is limited by possibility of heavy impacts and prolonged exposure in hot debris of a severity that no such container could be expected to withstand. Safes buried in hot debris should be removed as soon as conditions permit or the adjacent ruins quenched as soon as they can be approached. It is this subsequent exposure rather than the initial high temperature incidental to the destruction of non-fireproof buildings that constitutes the main element of hazard for well-insulated portable containers (21).

A note of precaution might be given relative to damage to photographic negatives and prints, blueprints, and similar records, due to condensation of water within safes, and to lesser extent within vaults, when exposed to fire. The insulation of safes and insulated vault doors contains combined or both free and combined water that is vaporized by the fire exposure and condenses in part within the safe or vault. Storage within tight metal containers would decrease the possibility of damage from this cause.

Nitrocellulose film will begin to decompose at temperatures not greatly in excess of $100^{\circ} \mathrm{C}\left(212^{\circ} \mathrm{F}\right)$ and hence should be given a higher degree of protection than ordinary paper records than can be exposed to temperatures of $150^{\circ}$ to $175^{\circ} \mathrm{C}\left(302^{\circ}\right.$ to $\left.347^{\circ} \mathrm{F}\right)$ without appreciable damage. Containers for individual films need same degree of venting to decrease deterioration with time by the acid fumes given off by the film.

Acetate cellulose film, while requiring from the standpoint of fire hazard, no more protection than paper records is damaged by temperatures much in excess of $100^{\circ} \mathrm{C}\left(212^{\circ} \mathrm{F}\right)$ to an extent that would make it unsuitable for projection or for ready use in the usual types of microfilm reading equipments, although it.might be legible and with careful han- 
dling might be reproduced. As exposed to temperatures higher than $150^{\circ} \mathrm{C}\left(302^{\circ} \mathrm{F}\right)$ the film is likely to blister with full or partial loss of emulsion or legibility.

\section{DISPOSAL OF USELESS RECORDS}

Records are themselves highly combustible, and large accumulations of useless papers constitute a distinct fire hazard to the building in which they are housed and its other contents. A schedule for the retention of records should be supplemented with a coordinated program of destruction of those that have reached the limit of their useful period. This can best be accomplished by classifying records when they originate and providing means for destroying those that are deemed useless after a certain period. Where records of a given class originate in large volume, they may be placed in separate files and marked for permanent retention, retention over a period of years, or destruction within comparatively short periods. By this means the contents of the containers can be destroyed at given intervals without requiring sorting of the contents (87).

The Federal Records Disposal Act of 1943 (Public Law 115, 78th Congress, approved July 7, 1943) simplifies the procedure by which authority may be obtained to destroy records. In particular, agencies of the Government are now required to submit schedules providing for the disposal not only of present accumulations of records without further value but of all future accumulations of records of the same specific kind after the lapse of a stated period of time. Under this provision an agency can clean out all its present bodies of inactive records without further value and can take effective steps to prevent any future accumulations of this kind.

The full text of the Federal Records Disposal Act of 1943 is given in Appendix D. Forms and instructions for obtaining approval for the disposal of records under the Act will be provided upon request to the appropriate records division of the National Archives or to its Director of Records Accessioning and Preservation.

\section{PLANNING AND MAINTAINING A RECORDS PROTECTION PROGRAM}

A well-planned records-protection program will afford to each body of records of the agency a degree and type of pro- 
tection appropriate to its value and to the nature and frequency of its use and will minimize the fire hazards to other property and to persons created by the storage of records. To plan such a program it is necessary first to have detailed knowledge of the agency's records, based on an adequate survey. To avoid duplication of effort, it is desirable to integrate studies of records for the purpose of improving records protection with studies undertaken to improve general records management. By proper planning, the information needed to work out a sound protective program can be collected as a part of the studies needed to prepare the schedules for the disposal of records required by the Federal Records Disposal Act of 1943.

The person responsible for planning the protective program will need to know, for each class of records created by the agency: the approximate present quantity and annual rate of accretion; the period of time during which the records of each class will be needed in the work of the agency; their value during that period (indispensable, important, or useful) ; their value after the period of active use has ended (a record may be indispensable while it is actively used but of no value when its immediate use has ended); the conditions under which they are stored (fire resistance of building, kind of filing equipment); and whether the information in the record is available elsewhere.

With this information at hand, it will be possible to set up a schedule indicating for each type of record the number of years that must elapse before it is retired from active use. With proper authorization, records that have no value should be disposed of promptly at the end of that period; those that are of permanent value should be transferred to the National Archives. In some instances records no longer in active use may not have permanent value but may need to be held for a period of years; in others records not considered active may yet have to be consulted with sufficient frequency to make their further retention by the agency desirable. In such cases records should be transferred to a special storage area and held until they can be destroyed or transferred to the National Archives. The objective of this phase of the program should be to remove. from offices and ordinary unprotected file rooms all records that are not required by the nature and frequency of their use to be kept there. To make this part of the program effective, the schedules of records must 
be kept constantly up to date to take into account changes in the records system and new types of records and a wellestablished procedure must exist for going through the records at stated periods (at least annually, preferably semiannually or even quarterly) and disposing of or transferring to the National Archives or to semicurrent storage all those that have become inactive during the period.

Even if a records retirement program is properly and fully maintained, many records will need to be held in offices or unprotected file rooms for use. These will have been evaluated as indispensable, important, or useful. It is next necessary to devise means of special protection for indispensable and important records and other records that cannot be disposed of as useless. If the records are kept in duplicate or the information contained in them is available elsewhere, and if the originals and the duplicates or other sources of the information are housed in other buildings, protection adequate for most needs has already been given. If not, and if the records are housed in incombustible buildings in which the probable duration of fire does not exceed the rated fire resistance of available insulated vaults, safes, or filing cabinets, the use of such equipment for the storage of indispensable records is probably the most desirable alternative. If such equipment is not available, or if the records are housed in a combustible building, definite consideration should be given to the duplication by microphotography of indispensable records at least, and if practicable, of important records as well.

Precautions intended to eliminate fire hazards should be strictly enforced in buildings and areas in which there are large accumulations of records. Smoking should be prohibited in file rooms. Paints, oils, nitrate film, and other highly flammable materials should not be stored near records, nor should hazardous operations involving the use of heat or flame be carried on in the immediate proximity.

\section{HANDLING OF DAMAGED RECORDS}

It is possible to salvage much of the value of water or firedamaged records by the prompt application of proper measures. Safes, vaults, and file cabinets should be opened as quickly as possible after a fire, provided that the contents have cooled sufficiently to avoid renewed combustion when the records are brought into contact with the air. Sheets 
of water-soaked records should be immediately separated to dry, care being taken to preserve the proper order. Charred records should be handled as little as possible to avoid crumbling. By the use of infrared photography, an adequate photographic reproduction can often be made of the writing on papers charred beyond ordinary legibility (88). The technical advice and facilities of the National Archives are available in handling problems in the repair, preservation and salvage of records (89).

\section{PROTECTION OF OTHER VALUABLES}

The protection of works of art, museum objects, and similar valuables against fire presents highly specialized problems, differing in considerable degree from the problems of protection of records. Because objects of this character are generally on exhibition, and hence cannot be protected by measures that limit their accessibility, protection is to be obtained principally by housing the material in fireproof buildings and enforcing rigid fire precautions (90). The National Museum might be consulted on such protection measures.

In general the same methods outlined above for the protection of records can be applied to the protection of valuables. Precautions must be observed to prevent damage from heat, or heat and moisture combined, at temperatures considerably lower than those causing written or printed records to become illegible, in the case of articles such as watches, optical goods, gems, paintings, stamps with adhesive facings, and articles made of celluloid. Storage within vaults having a considerable margin of fire resistance above that required for the location is preferable. When insulated safes are exposed to fire, temperatures up to $100^{\circ} \mathrm{C}$ with condensation of water obtain within them after fire exposures of comparatively short duration. Airtight incombustible containers are desirable for articles susceptible to damage by moisture.

A higher degree of theft or burglar protection is generally required for valuables than for records. Insulated safes and record vault doors designed for protection against fire have incorporated details such as locks and bolts that give a moderate degree of theft protection. They cannot, however, resist burglar attacks with cutting torch or explosives, nor with mechanical tools if sufficient time is allowed. Where the values warrant it, further protection should be provided 
in the form of burglar-resistive chests, safes, or vault construction, including electric-alarm features. Where the volume to be protected is not large, burglar-resistive chests can be placed inside of insulated safes, or burglar-resistive safes within vaults. They should be well anchored into the safe or vault construction to prevent easy removal. For larger amounts, combined fire-resistive and burglar-resistive vault construction must be used.

Burglar-resistive chests, safes, and vault linings are comparatively tight and would afford good protection against the moisture condensed within insulated safes and vaults when exposed to fire. Being uninsulated they can give as such very little protection against fire.

\section{MAINTENANCE OF FIRE-PROTECTION EQUIPMENT}

\section{GENERAL MAINTENANCE REQUIREMENTS}

Fire-protection equipment requires attention for maintenance in common with all plant equipment. Correction of apparent defects, such as leaks and corroded or defective piping and equipment, can be made as a part of the maintenance routine. Many defects are, however, not apparent until the equipment is called upon to function in case of fire, when, in general, repairs or corrections cannot be made in time to enable effective operation. Accordingly, the maintenance of such equipments must be based on inspections and tests designed to determine their operative condition, since no constant demands of service disclose conditions that need correction.

Valves controlling water supplies to standpipes, sprinkler systems, or hydrants, should be inspected, preferably daily, for open position. It is customary to seal such valves in open position with a leather strap or light wire that can be broken when valve must be closed. This detail is very important since the closed supply valve is the most frequent cause of failure of automatic sprinklers and other fre-extinguishing equipment. (Table 11.) For important systems electrical supervision may be advisable $(51,52,91)$. Control valves should be marked by means of a suitable sign to show the portion of the system served by each.

Valves which have not been operated for long periods may stick and in connection with inspections, all important valves 
should be turned. The operative condition of closed valves can generally be determined without turning them by an amount that would let water into the system.

\section{CARE OF STANDPIPE AND HOSE SYSTEMS}

New standpipe systems should be tested when installed for a period of $2 \mathrm{hr}$ for tightness, at a hydrostatic pressure of 25 percent in excess of the highest normal pressure to be used. Flowing pressure tests should be made at the top hose outlet of each standpipe riser, and repeated annually. For test purposes a separate length of hose with nozzle and pressure gage for connection to the highest outlet is recommended. The discharge can be determined from hose stream tables for the given size of nozzle and flowing pressure at its base.

Control valves and hose outlets should be accessible. At each outlet small hose, usually $11 / 2$ in. unlined linen, should be coupled to the outlet and a rack provided so that the hose may be rolled or folded. Hose is sometimes found detached from the standpipe outlet. The linen hose should not be used for general utility purposes as the light covering is not designed to withstand hard usage. Protection from acid and avoidance of damp locations are necessary as acid will attack the covering and dampness may cause mildew. The hose should be unfolded and refolded at intervals to avoid permanent creases. Renewal of gaskets in couplings at hose valves and nozzles should receive attention.

Hose valves should be kept tight to prevent leakage which will wet the hose near the coupling, a common cause of injury to linen hose. Drip cocks may be placed in the hose valve body for draining any leakage that may occur.

Unlined linen hose usually recommended for inside use should be wet only at time of fire, or when there is doubt as to its condition. After use it should be thoroughly dried to prevent deterioration.

\section{MAINTENANCE OF SPRINKLER SYSTEMS}

The causes of failure of sprinkler systems are shown in table 11. The 2,908 unsatisfactory performances were from about 71,500 sprinkler fires reported, or about 4 percent of the total number. 
TABLE 11.-Summary of unsatisfactory sprinkler performances

[For periods 1940 to 1944 and 1897 to 1944, as published in N. F. P. A. Quarterly, vol 38, No. 4, April 1945, p. 293]

\begin{tabular}{|c|c|c|c|c|}
\hline \multirow{2}{*}{ Cause of failure } & \multicolumn{4}{|c|}{ Failures } \\
\hline & \multicolumn{2}{|c|}{$1940-44$} & \multicolumn{2}{|c|}{$1897-1944$} \\
\hline $\begin{array}{l}\text { Water shut-off } \\
\text { Generally defectlve equipment } \\
\text { Unsprinklered portions. } \\
\text { Defective water supply or supplies. } \\
\text { Slow operation of dry system or defective valve. }\end{array}$ & $\begin{array}{r}\text { Number } \\
122 \\
20 \\
45 \\
32 \\
21\end{array}$ & $\begin{array}{r}\text { Percent } \\
29.2 \\
4.8 \\
10.8 \\
7.6 \\
5.0\end{array}$ & $\begin{array}{r}\text { Number } \\
956 \\
237 \\
237 \\
\mathbf{2 5 8} \\
96\end{array}$ & $\begin{array}{r}\text { Percent } \\
32.8 \\
8.2 \\
8.2 \\
8.8 \\
3.3\end{array}$ \\
\hline $\begin{array}{l}\text { Sprinkler system crippled due to freezing } \\
\text { Slow or defective operation of high-test heads. } \\
\text { Obstruction to distribution............ } \\
\text { Faulty building construction. concealed spaces. }\end{array}$ & $\begin{array}{r}11 \\
1 \\
42\end{array}$ & $\begin{array}{r}2.6 \\
0.2 \\
10.1\end{array}$ & $\begin{array}{r}80 \\
29 \\
191\end{array}$ & $\begin{array}{l}2.8 \\
1.0 \\
6.6\end{array}$ \\
\hline $\begin{array}{l}\text { Fauly oul openg construction, concealed spaces, } \\
\text { vertical openings, etc. } \\
\text { Hazard of occupancy too severe for average } \\
\text { sprinkler equipment }\end{array}$ & $\begin{array}{l}20 \\
18\end{array}$ & 4.3 & 142 & 5.8 \\
\hline $\begin{array}{l}\text { Explosion crippled sprinkler system. } \\
\text { Exposure or conflagration } \\
\text { Plugged heads and clogged piping } \\
\text { Miscellaneous }\end{array}$ & $\begin{array}{r}17 \\
5 \\
13 \\
51\end{array}$ & $\begin{array}{r}4.1 \\
1.2 \\
3.1 \\
12.2\end{array}$ & $\begin{array}{r}140 \\
97 \\
90 \\
185\end{array}$ & $\begin{array}{l}4.8 \\
3.3 \\
3.1 \\
6.3\end{array}$ \\
\hline Total..... & 418 & 100.0 & 2,908 & 100.0 \\
\hline
\end{tabular}

It will be seen that among the most frequent causes of failure are closed valves, defective equipment, insufficient water supply, obstructions to distribution, and faulty building construction.

For new installations, tests required before acceptance are detailed in the sprinkler rules $(65,66)$. Occasional tests of water flow by opening the drain at the top or base of the system and observing the drop in pressure, are recommended. Such tests are of value in indicating whether water is available and also any obstructions in the pipes. A drop in pressure during drain tests of amount greater that normal calls for investigation of the cause.

Inspection should be made for loose pipe hangars, corroded piping, and corroded or painted heads. Sprinkler pipes should not be used for clothes lines or similar purposes and a clear distance of not less than 12 in. should be maintained below deflectors to permit proper distribution of the discharge. Inspection for such conditions should be made at regular intervals, preferably not less than one each month.

Location of high-wattage lamps near sprinkler heads should be avoided and areas where high temperatures may obtain should be watched and if necessary higher-degree 
heads substituted. Locations under skylights and near steam pipes should be considered in this connection. Extra sprinkler heads to the extent of 10 percent of the number in one fire area should be kept in reserve, and in no case less than 25 except for small installations.

Extra precautions are urged during periods of repairs to sprinkler systems or to water-supply systems to make certain that the valves are opened when the work is completed. During repairs to large installations it is recommended that a man be stationed at the valve while it is closed.

Note of the air and water pressures at dry-pipe valves should be made daily, and in cold weather also the temperature of the inclosure. Monthly inspection should include observation of the valve accessories, including testing of alarm valves, although in cold weather water-motor alarms should be tested by means of a test switch. At intervals of 1 or 2 years dry-pipe valves should be tripped, the interior of the valve inspected for corrosion and incrustation, and cleaned before resetting. This may be done without admitting water to the system by nearly closing the water-supply valve, and when the dry-pipe valve trips, closing it completely before water flows into the system. After resetting the dry-pipe valve the supply valve should be reopened and sealed.

\section{MAINTENANCE OF HYDRANTS AND RUBBER-LINED HOSE}

Hydrant stems and caps should be lubricated occasionally with graphite mixed with cylinder oil. Hydrants should be tested annually for static and flowing pressures. In freezing weather they should not be opened; a slight turn of the stem will show whether or not hydrant is frozen. An alternative is to lower a weight into the hydrant and determine the presence of ice by the sound, and water by the wetting of the weight.

In hose houses, the cotton rubber-lined hose used in outside service, should be folded so that it may be pulled out without twisting or kinking. Rearrange the folds occasionally. At least $100 \mathrm{ft}$ of hose should be kept attached to the hydrants. Water should be run through rubber-lined hose occasionally, preferably twice a year, to retard deterioration of the lining. Once a year test the hose, capped, to the highest static pressure available. After use drain all hose and dry the jacket thoroughly before replacing the hose in 
the hose house. The roof and doors of hose houses should be maintained weather tight and the houses kept free of rubbish. The hose houses should be constructed and maintained to keep out rats, mice, and other vermin that may attack the hose.

\section{CARE OF FIRE PUMPS AND TANKS}

For electrically driven centrifugal fire pumps, controlling equipment should be tested at intervals and electrical equipment protected against leakage from the pump. Pumps should be kept lubricated. Two independent sources of current supply are recommended (92). The pump room should be kept clean, heated, and well lighted. Steam pumps should be operated once each week for a period of several minutes. The discharge may pass through the relief valve. At least two employees should be qualified to operate the fire pumps and be fully familiar with all of their details.

Elevated steel and wood tanks and their supports should be kept painted and sediment within them removed at regular intervals. Heating equipment needs frequent inspections and floats or other device for indicating water level must be maintained in operative condition.

Pressure tanks should be tested for water level, accuracy of gages, reliability and capacity of air and water pumps, and strength of the tank. The latter can be determined by filling with water and increasing the pressure with a test pump to 50 percent in excess of that normally carried. Sediment must be blown out before it becomes objectionable, this maintenance item being particularly important where the tanks are a part of the domestic water-supply system.

\section{SUPERVISION OF FIXED CARBON-DIOXIDE AND FOAM SYSTEMS}

The carbon-dioxide cylinders should be weighed at 6- or 12-month intervals and if the loss in weight of any cylinder exceeds 10 percent it should be recharged. All inclosures for confining the gas are to be kept in good repair and automatic devices for releasing the gas and closing doors or shutters, maintained in operative condition (67).

For wet foam systems the condition of the solutions should be checked at intervals. The bicarbonate solution can be revived by passing carbon dioxide through it (76). An extra $651704-45-9$ 
supply of dry foam-producing material should be kept on hand or readily available.

\section{MAINTENANCE OF PORTABLE FIRE EXTINGUISHERS}

The extinguishers should be examined frequently to make certain that they have not been tampered with or removed from their designated places, and to detect any injuries. Recharges or extra extinguishers should be kept on hand to replace any used in extinguishing fire (58).

Water pails, sand pails, and water-pump extinguishers should be kept full at all times and refilled immediately after use. Pumps should be operated occasionally. Antifreezing solutions can be tested for specific gravity with a hydrometer. Containers should preferably be kept covered.

Soda-acid and foam extinguishers should be protected against temperatures lower than $40^{\circ} \mathrm{F}$. Cabinets heated by electric lamps may be used for the purpose. Inspections to determine whether nozzle is closed, hose cracked, or body dented, should be made. Annual recharging is required, extinguisher to be marked with a tag showing date of recharge and initials of employee. Loaded stream extinguishers require similar maintenance except that they do not need protection against freezing.

Carbon tetrachloride extinguishers should be kept filled at all times with the special fluid required for the purpose. At least once each year a portion of the contents should be discharged to determine operative condition, extinguisher examined for corrosion of parts, and tagged. The discharge can be made into a container and the fluid reused.

Carbon-dioxide extinguishers should be weighed at least once each year and recharged if they have lost more than 10 percent of the charge. They should be recharged immediately after discharge, even if only partly discharged.

The carbon-dioxide cartridge in water-type (self-propelled) extinguishers should be weighed once each year and the weight compared with that stamped on the shell of the cartridge.

\section{FIRE-ALARM AND SUPERVISORY EQUIPMENT}

Where batteries are used for current supply, a routine must be established to effect proper recharging and maintenance. Trouble and alarm circuits, lamps, and bells need 
occasional tests to determine operative condition, with determination of resistance between ground and sides of circuits. Pneumatic tube or bulb systems need adjustment for operating pressure and vent, particularly for the period immediately following the installation.

\section{ORGANIZATION FOR COMBATING FIRES}

All departments and establishments should require that definite and practical plans, appropriate for any given establishment, bureau, or subdivision thereof, be outlined for combating fires in such establishments. This is especially advisable in the case of non-fire-resistive buildings, those housing large numbers of persons or stores, or processes requiring the presence of considerable quantities of highly combustible materials, and also where buildings are exposed to fire from adjacent non-fire-resistive structures or hazardous occupanies. The Federal Fire Council will, on request, give advisory service so far as practicable concerning such plans. Where advisory service from a public fire department is available locally, full advantage should be taken of such assistance. The organization and equipment needed will depend upon the extent, value, and fire hazard of the property, type of building construction and occupancy, and availability of outside assistance, such as from a public fire brigade.

\section{LOW OR MODERATE-HAZARD OCCUPANCIES IN FIRE- PROOF BUILDINGS, WITH PUBLIC PROTECTION AVAIL- ABLE}

For administrative or clerical groups occupying fireproof buildings in cities, the organization as far as the general personnel is concerned, might be limited to instruction in the use of hand fire extinguishers and hose and on the method of sending fire alarms. This might be in the form of a brief instruction sheet sent to all employees and posted on the bulletin boards, supplemented with occasional oral instructions and demonstrations. The method of sending alarms of fire should be given on the front page of the personnel or telephone directory. With proper subdivision of the building and an adequate number of protected exit ways (see sec. VI) no fire exit drills would be needed, although exits should be 
clearly marked and for large buildings diagrams should be posted showing location of all exits. The guards and other personnel connected with the operation and maintenance of the building should be given more detailed instructions on the procedure and training in the use of the equipment provided. Suggestions covering the above condition are given in appendix $\mathrm{E}$.

Whether or not an organization of employees, such as that herein outlined, is to be set up would depend on the size of the establishment and the degree of hazard presented. As indicated in section XVI, inspections to eliminate fire hazards can also be effected through such an organization. The position of chief fire marshal can generally best be assumed by the superintendent of buildings and other physical plant. The assistant fire marshals should be chosen with respect to fitness and the space to be covered. The requirement that all personnel be instructed in the procedure and in the use of equipment is important since the probabilities are that someone other than the assistant fire marshal will have to handle the emergency, at least in its initial stage. Meetings of the fire-marshal group for instruction and demonstration will assist in maintaining interest. Other personnel that would be required to act in emergency could be invited to such meetings. The discharging of hand fire extinguishers preliminary to refilling might be made the occasion for demonstration of their use on fires.

\section{HAZARDOUS AND INSTITUTIONAL OECUPANCIES}

For hazardous occupancies and for institutions such as schools, hospitals, asylums, and prisons, it may be necessary to effect an organization that will respond at all fires, even where a public fire brigade can be called. To prevent undue spread, it may be essential to have means for controlling fire in the shortest time possible, also, as in the case of penal institutions, it may not be desirable to admit men and equipment from the outside. Evacuation of whole buildings may also be necessary, particularly where high hazards or inferior construction are present.

Fire brigades (93) can be formed among the personnel responsible for the building or institution or partly composed of occupants or inmates. The degree of organization and equipment to be provided can be determined only from 
consideration of pertaining conditions. The same applies as concerns the need of fire-exit drills.

\section{ISOLATED LOCATIONS}

Where no assistance from a public fire brigade can be had, or where, due to location, the response would be unduly delayed, organization and equipment for combating fires should be provided up to the limits set by considerations of justifiable cost of protection and safety to life. The type and extent of the organization and equipment to be provided depends so greatly on the local conditions that general suggestions are of little value. For establishments of any considerable extent, the situation should be studied by an experienced fire-protection engineer and a degree of protection provided proportioned to the values and hazards presented, on the basis outlined in section II. The organization required may range up to that approximating a city fire brigade $(93,94)$. The organization and training of such a brigade must in general be done by one experienced in the technique of fire extinguishment and fire-department organization. General information from available sources may be helpful at the different stages $(95,96,97)$.

\section{IMPORTANCE OF TRAINING}

In addition to outlining plans for combating fires, selected personnel should be given actual training from time to time, in 1 , using extinguishers of the type or types provided; 2 , handling hose attached to standpipes in the buildings; and 3 , the procedure to be followed in turning in a fire alarm properly when a city department is to be called. It is especially important that this training be carried beyond the point of merely distributing printed or typewritten orders and directions with the hope that they will function in an emergency. Actual drill at suitable intervals and practice in doing the proper thing at the right time as a matter of habit will give the greatest assurance that an emergency will be handled with maximum effectiveness when it actually develops. In many States training courses are held for the instruction of firemen, at which valuable information on fire prevention is also given. It would be of considerable benefit to men assigned to fire-protection activities to attend such schools in their vicinity. 


\section{INSPECTION OF PROPERTIES}

Millions of dollars are spent annually by insurance associations, industries, and municipalities for fire surveys, plans, and reports, which apparently are bringing returns in reduced fire losses. That such work is effective is further shown by the fact that fire losses increase directly with the interval between inspections. Thus one large insurance group has demonstrated by actual trial the advisability of not more than 6-month intervals, and other underwriting organizations have had similar experience.

Inspections can be classified into two groups, self-inspections and technical inspections. The former, while not covering all conditions and details, can be made at more frequent intervals and have been found very effective in reducing the fire loss. Technical inspections require more time and experience on the part of the inspecting group and supply information on needed major and minor improvements and a basis on which self-inspection procedure most suitable for the property can be planned.

\section{SELF-INSPECTIONS}

Almost all properties require some form of supervision and inspection as an assistance in eliminating fire hazards and maintaining any fire-protection equipment in proper condition. Where an emergency organization has been effected, this may to advantage be utilized for the purpose. In case this is in the form of a fire brigade, its members can be detailed for such duty (98). For less elaborate organizations self-inspections might be based on forms such as those given in appendix F. The self-inspection form is intended to cover all principal hazards and equipment items. Portions of this form, items 1 to 17 , are designed for return by the occupant agency, items 18 to 43 jointly by occupant and custodian agencies, and items 44 to 55 by the custodial agency. While the custodial agency controls the building and its major services and fire-protection equipments, there are many occupancy conditions having a bearing on the fire hazard that can be controlled only by the service occupying the building.

In cases where it is not desirable to use the full self-inspection form for all reports, a brief form referenced to the full form can be used (appendix F). It would, however, be desir- 
able to report on the full form at least once each year to the head of the official responsible for the care of the property. The information from the reports covering the different portions of the property would then be assembled on one form covering the whole property.

Many corrections and needed improvements can be obtained by informal contact with those in immediate charge of properties and occupancies. The form reports can then be reserved for reporting conditions that cannot or have not been corrected by such means, and for obtaining a periodic record of what has been accomplished, the reports thus applied to be transmitted to those having general administrative authority over the property. This would justify increasing the regular intervals between reports with a consequent reduction in the volume of paper records. Whatever plan is used, it is important that those charged with the inspection maintain contact with conditions having a bearing on the fire hazard.

\section{TECHNICAL INSPECTIONS}

The inspecting group should preferably include some one experienced in fire prevention and protection, although very acceptable surveys can be made by those experiencd in management of property aided by information such as is contained in the present manual and references. While it will in general be made up of men from within the organization controlling the property concerned, occasional inspections, by a group from another establishment, or by an outside specialist, may be advantageous.

\section{(a) INSPECTION PROCEDURE}

The inspecting group should report first to the official having general or immediate charge of the premises. Someone intimately familiar with the occupancy and hazards should accompany it and bring to its attention all pertinent facts and conditions. Copies of plans of the property and buildings and previous inspection reports and plans should be procured if available and changes since construction or last inspection noted. Full notes should be taken of all information and for each property or class of property an outline or form for a report should be developed. Note should be made of the number and accessibility of hy- 
drants, size of water mains in the vicinity of the property, distance to nearest public fire-alarm box and fire-department station, exposures in the immediate vicinity, and the conflagration hazard.

Inspection within the property should start at the roof from which point notation can be made of accessibility to fire apparatus and immediate exposure from buildings and properties, and any changes in these respects since the last inspection. As it proceeds, the inspection should cover the entire area of each floor of every building and structure. Notation should be made particularly of spaces not accessible for fire extinguishment, closets, storage rooms, inclosures under stairways, and openings in fire walls and floors, due attention being given to changes made or proposed in construction, occupancy, hazards, and protection. Tests should be made of the operative condition of fire doors, shutters, and fire alarm, supervisory, and fire-extinguishing equipment. The inspection should be made in a manner best fitted to create an interest on the part of the occupants in prevention of fire.

Exact and detailed information should be obtained on all fires, however small, that have occurred since the last inspection and on impairments and improvements in protection measures. The inspectors should develop keenness in discerning hazards and in distinguishing between major and minor causes of fire.

\section{(b) FORM AND CONTENTS OF REPORT}

The report should detail in logical order exposure, construction and occupancy hazards, the protection equipment provided and its maintenance, and recommendation for improvements. The form will vary with type of property, the object to be attained being the greatest clearness and brevity consistent with the necessary degree of inclusiveness (99). In outlining a form for inspection and report, it may be desirable to note the headings and subject material of the present manual, although their sequence need not necessarily be followed and titles not pertaining to the given property should be omitted. The important groups of subjects will be briefly indicated mainly by reference to sections in this manual. It is particularly important to locate by building, room, or portions thereof, the different hazards 
and conditions that need correction. For this purpose a consecutive account for each building or similar group may be necessary. Services and hazards common to all buildings may be treated for the group as a whole. The following items should be considered for inclusion in the inspection and report:

1. Value of property and number of occupants.-Section II. The most reliable method of computing present value of buildings will generally involve computation of cost of reproduction new with deduction for depreciation.

2. Types of building construction.-Section IV.

3. Fire resistance of building members and fixed equipment.--Section III 2.

4. Adequacy of members and equipment to withstand the fire exposure from the occupancy.--Section III 3.

5. Structural control of fire spread.-Section V.

6. Means for egress of occupants.-Section VI.

7. Safeguarding common hazards.-Sections VII, X, XI, and XII.

8. Safeguarding special hazards.-Sections VIII, X, XI, and XII.

9. Protection of records.-Sections IX and XIII, and appendix D.

10. Fire-alarm and supervisory equipment.-Sections $\mathrm{X}$ and XIV. XIV.

11. Fire-extinguishing equipment.-Sections XI and

12. General fre prevention and maintenance conditions.Sections XII, XIV, and XVI, and appendix F.

13. Organization for fire fighting.-Section $\mathrm{XV}$ and appendix $\mathbf{E}$.

14. Maps, diagrams, sketches, and photographs.-Sections XII and XVI, and appendix B.

The amount of details of this type should be kept at a minimum, as they entail considerable time and expense. However, information can be given in concise and clear form by means of such plans. When the report is made to those fully familiar with the property, only sufficient description for reference purposes need be included.

15. Justifiable cost of protection.-Data from report and sections II, X, XI, and XV. 
16. Recommendations.-The recommendations should be given after the description of the condition needing correction and should be summarized in brief form at the end of the report; further attention should be called to important recommendations in the letter of transmittal. Their relative urgency should be indicated, which might be done by placing them under headings such as the following (84) :

Emergency (urgent) recommendations; necessary (essential) recommendations; desirable (conditional) recommendations.

\section{FIRE-LOSS PREVENTION UNDER WAR CONDITIONS}

Fire is one of the most usual weapons of modern warfare against which the defense measures must be adapted to the general and individual conditions applicable for given buildings or building groups. The hazard depends to considerable extent on the type of building construction, spacing of buildings, and their occupancy or contents. It is defined largely by the kind and amount of combustible materials in the building and contents, how the contents are contained or segregated, the integrity maintained by the building construction under fire, and how it serves in preventing the origin of fire and spread of fire within the building and to adjacent construction.

The extent of the protection measures that can be justified for given buildings or groups of buildings would depend on the probability, long-range or imminence, of war or enemy action and the importance of the occupancies housed therein. the latter particularly in its relation to war activities (100).

\section{STRUCTURAL PROTECTIVE MEASURES}

Although fires can originate from a number of forms of enemy action, including sabotage, that employing aerial attack is in general the most effective. The most destructive incendiary bombing has been with small bombs weighing only a few pounds of which a plane can carry several thousand. These have relatively low penetration and serve the intended purpose best if they do not go entirely through buildings, but come to rest in an attic or upper story where the fires set are 
difficult to control. Roofs that withstand without perforation the impact of such bombs are an effective safeguard, particularly in that with any decided attempt to cause destruction, they are dropped in such numbers that control of individual bombs or fires set by them within buildings is most difficult. For all but buildings exceeding in ratio of height to horizontal dimensions the maximum generally obtaining for Government buildings, the roof will receive the most of the hits. Also, as a construction it is less resistive to penetration than enclosing walls.

The resistance of flat roofs can be increased with the addition of concrete protecting layers or these in combination with insulating fills or promenade tile where these latter will increase the utility of the construction. For sloping roofs, the most practical method of decreasing the hazard from bomb hits involves the placing of an incombustible bomb and fire resistive covering on an upper or attic floor. Information on types of materials and thicknesses required to resist the penetration and burning of the smaller bombs has been developed $(101,102)$. Combustible wall and overhead construction can be given heavy fire-retardant coatings that will decrease the probability of ignition and spread of fire $(101,103,104)$.

All general structural conditions that assist in preventing origin and spread of fire within buildings and to adjacent buildings are effective in reducing the damage from incendiary attacks (sec. V). Fireproof construction suitably subdivided with fire division walls, where the occupancy and contents present any considerable degree of fire hazard, and with interior and exterior openings given protection where required by present State and municipal fire regulations, will - give good protection against incendiary attack both as concerns the individual building and the prevention of communication of fire and of conflagrations (105).

\section{CONTROL AND EXTINGUISHMENT}

Knowledge of enemy fire bombs and the preferred methods of dealing with them is essential-publications, circulars, and other information on which is generally issued for civilian defense purposes in time of war. After fires have been set, the method of control and extinguishment is similar to that 
applicable for fires from ordinary origins (sec. XI). Automatic means of detection (sec. $X$ ) and extinguishment (sec. $\mathrm{XI}$ ) have certain limitations in functioning under air raid conditions on account of possible mechanical disarrangement of the system by the bombing. The public or other regular source of water supply may be disrupted and emergency sources may have to be developed. Also, the calls on the public fire department may be so heavy that auxiliary pumping and other fire equipment may have to be provided. In manual equipment, the self-contained water hand pump and re-fillable bucket has been regarded as the most practical and effective. Emergency organizations for control of the incendiary bomb hazard should preferably be based on any existing organization for combatting of fires (sec. XV) (appendix E). Special emphasis may need to be placed on the roof, attic, or upper floor locations, depending on the building construction and occupancy. Location and arrangement of combustible contents to minimize the possibility of rapid spread of fire and difficulty of extinguishment should be given consideration (101).

\section{ARSON BY ENEMY ACTION}

Protection against fire damage attributable to subversive activities is largely a matter of prevention of origin of such fires. Requirements for safeguarding of Government buildings against this and related hazards have been issued (106). For exposed locations and high values the. installation of automatic equipment to detect unauthorized entry into buildings and premises may be justified and be less expensive than watch service giving equivalent protection.

As for fires originating from other forms of incendiary attack, the methods of control and extinguishment are largely the same as for fires from usual causes. The type of building construction, the interior and exterior protection, spacing of buildings, and type and amounts of contents will be found important in consideration of means to prevent the spread of fire. Automatic means of detecting and extinguishing fire have certain limitations for the present purpose on account of the possibility of willful disarrangement of the systems. Automatic means of detecting disarrangement, generally applied in most types of fire alarm systems, and installed also to 
supervise the open position of valves to automatic sprinkler, standpipe, and hydrant systems, afford protection against such contingencies that can be made ineffective only by those well versed in the details of these supervisory systems.

4. PROTECTION OF RECORDS AND CULTURAL RESOURCES

Plans have been prepared involving protection in place or by evacuation, of valuable records and other cultural resources $(107,108)$. This would be coordinated and timed with the general protection program applicable for given areas $(100)$. 


\section{APPENDIX A. REFERENCES}

The following abbreviations are used in the references:

AFM - Associated Factory Mutual Fire Insurance Companies, 184 High Street, Boston, Mass.

ASA - American Standards Association, 70 East 45th Street, New York, N. Y.

ASTM - American Society for Testing Materials, 260 South Broad Street, Philadelphia, Pa.

BFPC - British Fire Prevention Committee, in care of the National Fire Brigades Association, 8 Waterloo Place, Pall Mall, London, SW 1, England.

BS - Bureau of Standards, U. S. Department of Commerce, Washington, $\mathbf{D}$. C.

CU - Columbia University, New York, N. Y.

DA - U. S. Department of Agriculture, Washington, D. C.

NBFU - National Board of Fire Underwriters, 85 John Street, New York, N. $\mathbf{Y}$.

NFPA - National Fire Protection Association, 60 Batterymarch Street, -Boston, Mass.

PBA - Public Buildings Administration, Washington, D. C.

SD - Superintendent of Documents, U. S. Government Printing Office, Washington $\mathrm{D}$. C.

UL - Underwriters' Laboratories, 207 East Ohio Street, Chicago, Ill.

The Government publications listed can be obtained from the Superintendent of Documents at the prices indicated, or consulted in the Department or Bureau libraries. Copies of papers, speciflcations, and Letter Circulars marked BS and for which no price is given can be obtained free from the National Bureau of Standards, unless indicated as out of print thus (*). Single copies of the publications of the National Board of Fire Underwriters and the standards and committee reports of the National Fire Protection Association can be obtained free unless a price is indicated. Complete information relative to the availability of the other references listed cannot be given.

1. Specifications for Fire Tests of Building Construction and Materials, ASA Standard; ASTM, NFPA, BS, sponsors.

2. Fire Tests of Building Columns, AFM, NBFU, BS Technologic Paper $184 ; 75$ cents; SD.

3. Fire Resistance of Concrete Columns, BS Technologic Paper 272; 25 cents; SD.

4. Fire Tests of Columns Protected with Gypsum, BS Research paper $563 ; 5$ cents; SD.

5. Fire Resistance of Brick Walls, BS Letter Circulars 228 and 229.

6. Fire Resistance of Hollow Load-Bearing Wall Tile, BS Research Paper RP37; 75 cents; SD. 
7. Reports on individual fire tests of partitions, floors, opening protectives, and roofing materials by UL.

8. Tests of the Fire Resistance and Stability of Walls of Concrete Masonry Units, Proc. ASTM, vol. 31, part II, p. 607.

9. Fire Tests of Treated and Untreated Wood Partitions. BS Research Paper 1076, 10 cents; SD.

10. Fire Tests of Wood- and Metal-framed Partitions. BS Building Materials and Structures No. 71, 20 cents, SD.

11. Reports on individual fire tests of partitions, floors, and opening protectives by CU.

12. Reports on individual fire tests of partitions, floors, and opening protectives by BFPC.

13. Fire Resistance of Gypsum Partitions, Proc. ASTM, vol. 25, part 2, p. 299.

14. Fire Resistance Classiffations of Building Constructions, BS Building Materials and Structures No, 92, 25 cents, SD.

15. *Fire Tests of New Post Cap for Mill Construction, Engineering News-Record, vol. 87, No. 24, p. 972, Dec. 15, 1921.

16. Mathematical Theory of Heat Conduction, by Ingersoll and Zobel, p. 78, 113, Ginn and Co., Boston, Mass.

17. Fire Tests of Floors in the United States, Proc. International Society for Testing Materials, paper 27, second section, ASTM.

18. Regulations for the Protection of openings in Walls and Partitions, NFPA.

19. Recommended Building Code, NBFUU.

20. Consolidated Report of the Committee on Protection of Records, NFPA; 50 cents.

21. Report of Committee on Protection of Records, Proc. NFPA, vol. 36,1932 , p. 316; vol. 37, 1933.

22. * Sererity of Building Fires, BS; Proc. 14th annual meeting Building Officials Conference, p. 87, 1928; Quarterly NFPA, vol. 22, No. 1, p. 43, July 1928; Safety Engineering, Aug-Sept. 1928; Architectural Forum, vol. 50, No. 5, p. 775, May 1929.

23. Report on Comparative Fire Tests of Treated and Untreated Wood, Proc. ASTM, vol. 41, 1941, p. 238.

24. The Fire Resistance of Wood Treated with Zinc Chloride and Diammonium Phosphate, Proc. American Wood Preservers Association, p. 130, 1930.

25. Federal Specification SS-A-118 for Prefabricated Acoustical Units ; 5 cents ; SD.

26. Report of Committee on Building Construction, NFPA, Proc., vol. 32, p. 226, 1928.

27. Recommended Minimum Requirements for Small Dwelling Construction, BS, BH18; 10 cents ; SD.

28. Report of Committee on Protection of Openings in Walls and Partitions, Proc. NFPA, vol. 34, p. 417, 1930.

29. Building Exits Code, ASA Standard, NFPA; $\$ 1.00$.

30. Design and Construction of Building Exits, BS, M151; 10 cents; SD.

31. A Standard Ordinance for Chimney Construction, NBFU.

32. Fire Hazard of Domestic Heating Installations, BS Research Paper RP 596; 5 cents ; SD.

33. National Electrical Code, NFPA. 
34. National Electrical Safety Code, BS,

Part 1. Safety Rules for the Installation and Maintenance of Electrical Supply Stations, BS, H31; 10 cents; SD.

Part 2. Safety Rules for the Installation and Maintenance of Electric Supply and Communication Lines, BS, H32; 65 cents; SD.

Part 3. Safety Rules for the Installation and Maintenance of Electric Utilization Equipment, BS, H33; 15 cents ; SD.

Part 4. Safety Rules for the Operation of Electric Equipment and Lines, BS, H34; 10 cents ; SD.

Part 5. Safety Rules for Radio Installations, BS, H 35; 10 cents ; SD.

Part 6. Safety Rules for Electric Fences, BS, H36; 5 cents; SD.

35. Requirements for House Piping and Appliance Installation, American Gas Association, 420 Lexington Avenue, New York, N. Y.

36. Recommended Good Practice Requirements for the Installation, Maintenance, and Use of Piping and Fittings for City Gas, NFPA.

37. Propane, Butane and Related Fuels, BS Circular C420 ; 5 cents ; SD.

38. Code for Protection Against Lightning, BS, H40; 20 cents ; SD.

39. Regulations for Nitrocellulose Motion Picture Film, NFPA.

40. Regulations for the Storage and Handling of Photographic and X-ray Nitrocellulose Film, NFPA.

41. Report of Committee on Construction Operations, Proc. NFPA, vol. 34, p. $362,1330$.

42. American Table of Distances Between Storage Magazines for Explosives and Inhabited Buildings, Public Railways, and Public Highways, American Institute of Makers of Explosives, New York, N. Y.

43. Dust Explosions, ASA Standard Z-12; $\$ 1.00$.

44. The Control of Dust Explosives in Industrial Plants, Mechanical Engineering, vol. 60, No. 12 , pp. 836-38, Dec. 1938.

45. Construction, Equipment, and Maintenance of Buildings in their Relation to Protection of Records, Proc. NFPA, vol. 35, p. 227, 1931.

46. Federal Specification AA-S-81a for Safes ; insulated; 5 cents ; SD.

47. Federal Specification AA-C-23 for Insulated Fire-Resisting Filing Cabinets ; 5 cents ; SD.

48. Cabinet for the Storage of Film. Patent No. 2190229, granted under Act of March 3, 1883, as amended April 30, 1928; 3700.G.757; U. S. Patent Office; 10 cents.

49. Federal Specification W-F-391 for Fire-Alarm Systems; Electric Hand-Operated, 5 cents; SD.

50. Federal Specification W-F-396 for Fire-Alarm Systems; Electric Hand-Operated, Shunt-Type; 5 cents ; SD.

51. Regulations for the Installation, Maintenance, and Use of Central Station Protective Signaling Systems for Watchman, Fire Alarm, and Supervisory Service, NFPA.

52. Regulations for the Installation, Maintenance, and Use of Proprietary, Auxiliary, and Local Systems for Watchman, Fire Alarm and Supervisory Service, NFPA.

53. Specifications for the Installation, Maintenance, and Use of FireDetecting Systems on Vessels, Merchant Marine Inspection, U. S. Coast Guard. 
54. Automatic Fire Alarm Systems, BS.

55. Recommendations for Fire Alarm and Watchman's Supervisory Equipment, PBA.

56. Federal Specification W-W-101 for Watchmen's-Report-Apparatus ; 5 cents; SD.

57. Federal Speciflcation O-F-380 for Fire-Extinguishing Liquid ; Carbon-tetrachloride Base; 5 cents ; SD.

58. Regulations for the Installation, Maintenance, and Use of First Aid Fire Appliances, NFPA. Fire Extinguishers, AFM.

59. Federal Specification O-F-355a for Fire Extinguishers; Chemical, Hand, Soda and Acid Type ; 5 cents ; SD.

60. Federal Specification O-F-361, for Fire Extinguishers ; Hand, Portable, Foam Type; 5 cents ; SD.

61. Federal Specification O-F-351 for Fire Extinguishers; Chemical, Hand, Cárbon-Tetrachloride Type; 5 cents ; SD.

62. Regulations for the Installation of Standpipe and Hose Systems, NFPA.

63. Speciflcations for Gravity Water Tanks and Steel Towers, AFM. Regulations for the Construction and Installation of Tanks, Gravity, Pressure, Towers, etc., NFPA.

64. Federal Speciflcation JJ-H-571, for Hose; Fire, Linen, Unlined; 5 cents; SD.

65. Rules for the Installation of Sprinkler Equipment, Automatic and Open Systems, AFM.

66. Standards for the Installation of Sprinkler Equipments, NFPA.

67. Standards for Carbon Dioxide Fire Extinguishing Systems, NFPA.

68. Report on Carbon Dioxide as an Extinguishing Medium for Fires in Buildings, BS.

69. Inert Gas for Fire and Explosion Prevention, Proc. NFPA, vol. 35, p. 121, 1931.

70. Methods for Calculating the Volumetric Composition of Fluid Mixtures, Physics, vol. 5, No. 3, p. 64, March 1934.

71. Regulations for Foam Fire Extinguishing Systems, NFPA.

72. Standards for Water Spray Nozzles and Extinguishing Systems, NFPA.

73. Regulations for Outside Protection, NFPA.

74. Federal Specification $\mathbf{Z Z}-\mathbf{H}-451 \mathrm{a}$, for Hose ; Fire, Cotton, RubberLined ; 5 cents ; SD.

75. Suggested Municipal Ordnance to Regulate the Use, Handling, Storage, and Sale of Flammable Liquids and the Products Thereof, NFPA.

76. Fire Protection in Refineries, American Petroleum Institute, New York, N. Y.

77. Regulations for the Starage and Handling of Liquefied Petroleum Gases, NFPA.

78. Standards for Safeguarding of Dry-Cleaning Plants, NFPA.

79. Standards for Paint Spraying and Spray Booths, NFPA.

80. Standards for Dip Tanks, NFPA.

81. Regulations for the Storage and Sale of Pyroxylin Plastic, NFPA

82. A Table of Common Hazardous Chemicals, NFPA ; 25 cents.

83. Properties of Flammable Liquids, Gases, and Solids, AFM. 
84. Fire and Explosion Risks, by Von Schwartz (English translation by Saltor), Chas. Grifiin \& Co., London; J. B. Lippincott Co., Philadelphia, Pa.

85. Fire Hazard Properties of Certain Elammable Liquids, Gases and Volatile Solids, NFPA ; 25 cents. .

86. Record Protection and Office Equipment, Quarterly, NFPA, vol. 24, No. 4, p. 410, April 1931.

87. Preservation and Destruction of Records, Edison Electric Institute, New York, N. Y.; 40 cents.

88. Action of Charred Records on the Photographic Plate and a Method of Deciphering Charred Records. Scientific Paper 454, BS; 5 cents; SD.

89. The Repair and Preservation of Records, Bulletin 5, The National Archives, Washington, D. C.

90. Field Manual for Museums, National Park Service; 70 cents; SD.

91. Supervision and Care of Valves Controlling Water Supplies for Fire Protection, NFPA.

92. Rules for the Installation of Centrifugal Fire Pumps, NFPA. Notes and Suggestions on Fire Pumps, AFM. Specifications, Selection, and Installation of Centrifugal Fire Pumps, AFM.

93. Private Fire Brigades, NFPA. Private Fire Brigades, AFM,

94. Functions and Organization of the District of Columbia Fire Department, by E. R. Pierce. Minutes of Jan. 1932 meeting of Federal Fire Council.

95. Rural Fire Departments, Equipment and Organization, NFPA ; 20 cents.

96. Fire Fighting, An Analysis of the Fireman's Job with Suggestions as to the Organization and Operation of Training, Federal Board for Vocational Education; 30 cents ; SD.

97. Municipal Fire Alarm System of the District of Columbia, by W. E. Kern. Minutes of the Oct. 1931 meeting of Federal Fire Council.

98. Organization and Operation of a Municipal Bureau of Fire Prevention, by H. A. Stone and G. E. Stecher, Syracuse University, Syracuse, N. Y.

99. Report on Form for Reports. Minutes of October 1931 meeting of Federal Fire Council.

100. Air Raid Protection Code for Federal Buildings and their Contents, PBA; 20 cents; SD.

101. Protection Measures Against Aerial Incendiary Bombing, Minutes of Dec. 1942 meeting of Federal Fire Council.

102. Report of Committee on Emergency Fire Defense, Minutes of the December 1943 meeting of the Federal Fire Council.

103. Fire Retarding Coatings. U. S. Forest Products Laboratory Circular No. R1280.

104. Fire-Retardant Treatments for Wood. Quarterly NFPA, vol. 36, No. 3, p. 201, Jan. 1943.

105. The Building as a Fire Defense Against Bombing. Proc. 27th Annual Meeting of the Building Officials Conference of America, p. 114.

106. Code for the Protection of Federal Buildings and their Contents from Subrersive Hostile Acts. PBA; 10 cents; SD.

107. Care of Records in a National Emergency. Bulletin No. 3, The National Archives. 


\section{PROTECTION}

ב WATER PIPE-EXPOSED

\section{$=====$ WATER PIPE-BURIED}

SUCTION PIPE

FOOT VALVE I STRAINER

$\|==\begin{aligned} & \text { FROST-PROOF HYORANT } \\ & \text { TWO-WAT PRIVATE }\end{aligned}$

$\|==7$ PUELIC CMUCK OR FLUSH

$\mathrm{F}=2$ hTORANT

$L==$ PUAMLIC MUORANT-TWO OUTLETS

WT PAITATE SUCTION CONNECTION

$1=$ PAIVATE HYORANT-FOUR-WA

DONITOR NOZZLE

OSP. STAMDPIPE - LABEL SIZE

OHC. HOSE CONNECTION ON PIPE-

TOX.X. HIGH PRESSUAE HTDRANT

D Deluge valve

$\longrightarrow 0^{\prime \prime}$ AUTOMATIC SPRINKLER RISER
LAEEL SIZE

$=0$ OPEN SPRINKLER RISER

* $\rightarrow$ OPEN SPRINKLERS

$==\neq==$ UNDERGROUND VALVE REQUIRING

oroINART Gate VALVE

$=\bar{O}=$ GLOBE VALVE

+ INOICATOR VALVE

$==-==$ POST INOICATOR VALVE

$\Longrightarrow=$ CHECK VALVE-ARAOW IHOICATES

$\Longrightarrow=$ CHECK VALVE WITH ALARM

ALARM VALVE

$=$ DRY PIPE VALVE

FIRE DEP'T. CONNECTION

-1) ALARM GONG WITH HOOD

STEAM FIRE PUMP WITH HOSE
CONNECTION-SAMPIE IOOO GAL KNOWLES UNDERL
WRITER, PUNP, IOX $10 \times 12=$

CENTRIFUGAL FIRE PUMP-SAMPLE
LABEL: 1OOO GAL KNOWLES,
CENTRIFUGAL PUMP, L'TO B'HEAD

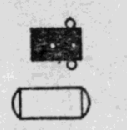
HOTARY FIRE PUMP-SAMPLE LAECL:
IOOO GAL NATONAL STANDARD TYPE B, RODNEY HUNT ROTARY
PUMP, IO' TO IS' HEAO SPRINKLER PRESSURE TANK-SAMPL

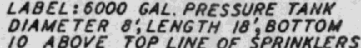

SPRINKLER GRAVITY TANK -

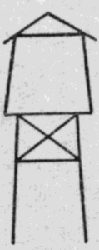

50. SECTION - SAMPLE LABEL : STEEL TRESTLE, DIAMCTER 21 ':
HEIGHT 20,BOT TOM 3O'ABOVE TOP LINE OF SPRINKLERS, BY TANK HEATER, FILLED BY CITY WATER THROUGH

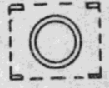

SPRINKLER GRAVITY TANK-- ON $P L A N-L A B E L$ AS NOTEO ABOVE
ON SECTION

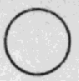

RESERVOIR OR CISTEAN-IF FOR FIRE PUMP, INDICATE CAPACITY
AND DEPTH ALSO USE TO SHOW
MILL USE. YANKS

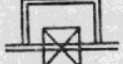

METER-GIVE SIZE ANO NADAE,
SHOW BY-PASS \& VALVES

=争栗== VALVE IN PIT

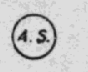

AUTOMATIC SPRINKLERS
ON PLAN

A.S.

AUTONATIC SPRINKLERS

C.R.L. COTTON RUABER-LINEO HOSE

L.U.L. LINEN UNLINEO HOSE

TIRE ESCAPE

\section{MISCELLANEOUS}

4,BAA FOUR STORIES,BAS'T. RATTIC

10) HEIGHT OF BLOG. IN FEET

- COMPOSITION ROOF, NOTE TYPE

of METAL, TILE,OR SLATE ROOF

× WOOD SMINGLE ROOF i: DRIVEWAT ON FIRST FLOOR

[WW] LIGHT WELL-2 STORIES

(II) SKI LIGHTS-W.G. WIAEO GLASS

SL] M.F. = ME TAL FRAME, W.NEWIRE NET

Ii PARAPET WALLS - ONE LINE FOR

III PACH 6 INCHES IN HEIGHT _. . INTERIOR WALLS NOT COMPLETE TO ROOF UNPROTECTED INTERIOR WALL OPENINGS

* UNPROTECTED INTERIOR

F- FIRE DOOR-SINGLE, STANDARO

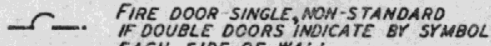

EACH SIDE OF MALL

SIOES OF OPEN SHEOS, ALSO SIOES OF WINDONS WITH NON-STANOARO

, SHUTTER IST STORY

WINOOWS WITH STANDARD SHUTTERS

IST \& 2NO STORIES

NON-STANOAAD MIREO GLASS WIMDOWS IST, 2ND, \& 3RO STORIES

STANOARO WIREO GLASS WINDOWS

WINOOWS-PROTECTEO SECONO \& FOURTH;

NO OPENING, FIRST.
NO DOT REPRESENTS OPENING, COUNTING
LE TO RIGHT LOOKING TOWARDS
BUILING.

GI - GA SOLINE OR FUEL OIL TAMK
I UNDERGROUNO, LAEEL CA PACITY

PuMP o. Gasoline aUMP

- - - Propertr LINE OR FENCE

FIRE WALLS- BETTER THAN FAIR

$\perp \perp$ RETAIRING WALL

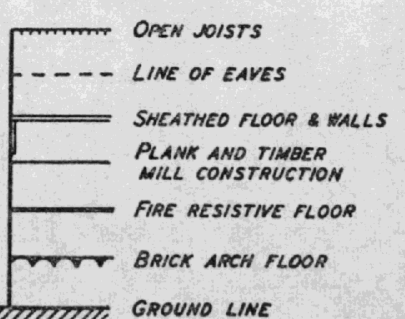

㬰 PARAPET WALL H IN OPEN MOIST OR OUAN WAITER
IST TO 3 RO FLOOR
H.T. TRAPPED HOISTWAY

E OPEN ELEVATOR IF TRAPPED

SO INOICATE

F.E. ENCLOSED ELEVATOR-FRAME

E ELEVATOR IN MASONRT SHATT.

OPEN STAIRWAY-IF TRAPPEO SO INOICATE, S.T.

ENCLOSED STAIRWAY

STAIRHAY IN HASONRY SMAFT USE APPROPRIATE SYMBOLS TO INDICATE PRESEACE OF FIRE DOOR
TO STAIR OR ELEVATOR SHAFT

BOILER-NOT BRICK ENCLOSEO

BOILER-BRICK ENCLOSEO

VERTICAL BOILER

O Do iron CHIMNEY

BRICK CHIMNEY

(F) FIRE ALARM BOX

\section{COLORS}

YELLOW- WOODEN WALLS-JOIST, T-A RED-BRICK WALLS-JOIST OR MILL, T-2 NOTE IF TILE

BROWN WITH YELLOW RECTANGLE FIAE RESIST. WITH WOOOEN ROOF, T-1-2

BROWN - FIRE RESISTIVE, T-I

BROWN WITH GRAT OUTLINE, T-1-2 FIRE RESIST WITH UNPROT STEEL IN PART BLUE - STONE, CONCRETE, HOLLOW CONCRETE BLOCK, OR ADOBE -JOIST, MILL, T-2 GRAY-INCOMBUSTIBLE WALLS SUCH AS SKELETON STEEL, METAL LATH \& PLASTER, T-3 YELLOW WITH GRAY OUTLINE, T-A WOOD, AETAL CLAD GRAY WITH YELLOW RECTANGLE, T-9-4 NON-COMAUSTIBLE EXCEPT WOOO AOOF YELLOW WITH RED OUTLINE T-S
WOOD, SRICK VENEERED-JOIST OR MILL YELLOW WITH OLUE OUTLINE-JOIST OR AALLL WELLO, STUCCO OR STONE VENEERED, T-4
WOOL, STITH BLUE WATER COUASES

651704-45 (Face p. 138) 


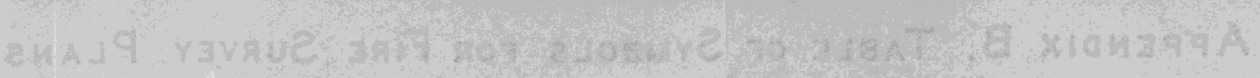

$\operatorname{290102}$

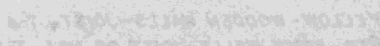

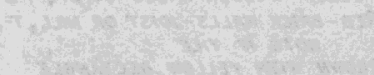

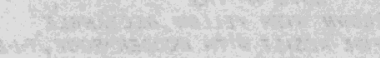
and mathe of (25.

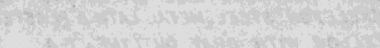

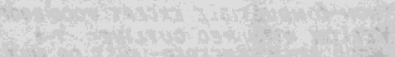

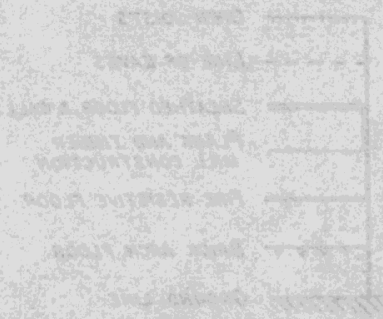
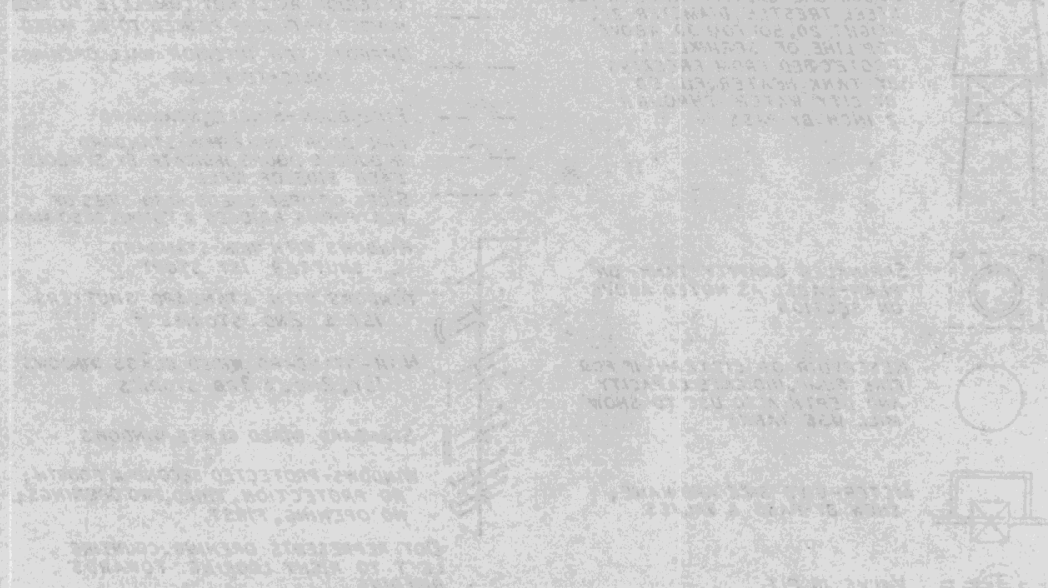

thing

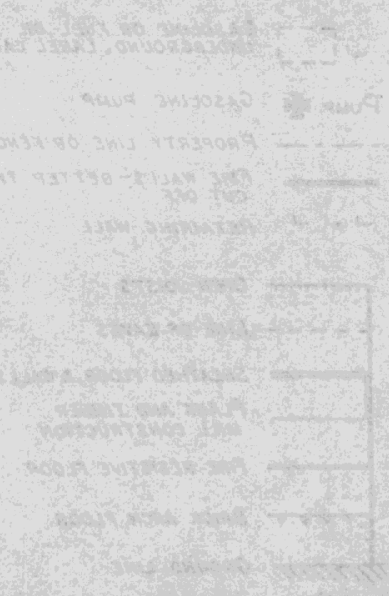

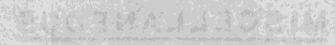

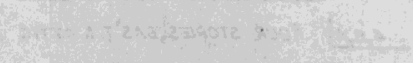

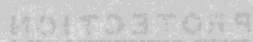
$+\frac{10}{20}$

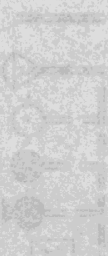

,

. 
108. The Protection of Cultural Resources against the Hazards of War. National Resources Planning Board; 10 cents; SD.

\section{GENERAL REFERENCES}

(a) Industrial Fire Hazards, by Gorham Dana and W. D. Milne, Lakeview Press, Framingham, Mass.

(b) Suggestions on Fire Fighting and Fire Extinguishment, issued by Bureau of Yards and Docks, Navy Department, Femack Company, 205 West 19th Street, New York, N. Y. \$1.00.

(c) Field Practice Inspection Manual, NFPA; $\$ 1.50$.

(d) Handbook of Fire Protection, by Crosby-Fiske-Forster, NFPA.

(e) Fire Prevention and Protection, The Spectator Co., New York, N. Y., and Chicago, Ill.

(f) Fire Prevention and Protection as Applied to Building Construction, by J. K. Frietag, John Wiley \& Sons, NYC.

(g) Automatic Sprinkler Protection, by Gorham Dana, John Wiley \& Sons, Inc.

(h) Fire Protective Construction on the Farm, DA Farmers' Bulletin $1590 ; 5$ cents ; SD.

(i) Fire Safeguards for the Farm, DA Farmers' Bulletin 1643 ; 5 cents ; SD.

(j) Dust Control in Grain Elevators, DA Department Bulletin 1373; 10 cents; SD.

(k) Dust Explosions, Theory and Nature of Phenomena, Causes and Methods of Prevention, by David J. Price and Harold H. Brown, NFPA ; $\$ 3.00$.

(1) Report of the Joint Committee on Standard Specifications for Concrete and Reinforced Concrete, ASTM.

(m) The Fire Chief's Handhook, by Fredrick Sheppard Case, Sheppard-Mann Publishing Co., New York, N. Y. 


\section{APPENDIX C. FEDERAL FIRE COUNCIL BLANK FORM FOR REPORT OF FIRE ON GOVERNMENT PROPERTY}

For explanation of information desired under the different headings, see p. 141. Report in full or in part depending on extent of information available, should be made of all fires large or small, an estimate of the property damage to be included in all cases.

Reports should be transmitted promptly to the officer in general administrative charge of the property. The Federal Fire Council, National Bureau of Standards, Washington, D. C., will appreciate receiving copies of all fire reports. They will be used to determine the general ratio of fire losses to value of Government property and its trend. The individual or departmental loss figures will not be made public.

1. Location

2. Time (date and hour)

3. Department, Bureau or Independent Establishment.

4. Point of Origin.

5. Size of Building (length and width) - Height (stories) -

6. Type of Construction :
(a) Framing-
(b) Exterior walls
(c) Floor construction
(d) Floor surface
(e) Roof construction
(f) Roof covering
(g) Partitions
(b) Interior finish

7. Occupancy

(a) Amount of property damage in dollars:

2. Buventoried contents

2. Inventoried contents

(b) Highly valuable documents, works of art, or other irreplaceable contents

(c) Loss of life

9. (d) Injury to persons

10. How was Fire Extinguished?

11. What Fire-Alarm and/or Fire-Extinguishing Equipment is Provided in the Building?

12. Was there any Defect or Inadequacy in Fire Apparatus or any other Deficiency? (Explain fully if any)

13. Suggestons as to Preventing Similar Fires in Future

14. Story of the Fire

Report by

Titre

Date of report 
Explanatory Notes on Information Desired Under the Different Headings of the Report of Fire. (Numbers refer to questionnaire items of appendix $\mathrm{C}$ ).

1. Identify building by name, street number, city, and State.

3. Designate Department, Bureau, or independent establishment having jurisdiction over the building and/or contents.

4. Indicate the room, floor, or part of building in which fire started and where applicable, the equipment in which fire originated.

6. The following materials are suggestive of common types used in building construction. For small fires controlled in their early stages details of building construction and finish need be given only if they contributed to the origin and assisted or retarded the spread of the fire.

(a) Framing: Reinforced concrete; structural steel protected; structural steel unprotected; heary timber; wood frame; etc.

(b) Exterior walls : Brick; solid concrete; stone with brick or hollow-tile backing ; brick veneer on wood frame and sheathing; corrugated iron or sheet metal on steel or wood framing; stuceo on wood or metal lath on wood sheathing; wood shingles or boards on wood framing; etc.

(c) Floor construction: Solid reinforced concrete of beam and girder type or flat alab; concrete joist with metal pans or hollow tile; steel joist ; heavy timber; wood joist; etc.

(d) Floor surface: Granolithic; terrazo; ceramic tile; cork tile; rubber tile; mastic; linoleum; wood block; wood; etc.

(e) Roof construction: Reinforced concrete of beam and girder type or flat slab; same on protected steel beams and girders; same on unprotected beams and girders: wood on timber trusses; wood on unprotected steel trusses ; wood sheathing on wood joist ; etc.

(f) Roof covering: Tar and gravel; slate; tile; cement-asbestos ; asphalt roll roofing or shingles; wood shingles; ete.

(g) Partitions: Hollow tile; gypsum block; wood stud; metal stud; steel and glass; wood and glass ; etc.

(h) Interior fnish: Plaster on masonry; on wood lath, on metal lath, plasterboard, wood, wood-pulp board; ete.

7. Give general nature of occupancy of building such as offlce, Iaboratory, storage, mess hall, machine shop, etc., and specific occupancy where fire probably started.

8. Under (a) for 1 and 2 give estimated cost of damage to building and inventoried contents as the cost of reproduction less depreciation, the latter being taken as the ratio of age to total useful life, multiplied by the cost of reproduction.

(a) 3 applies to correspondence, accounts, tracings, etc. Describe briefly and give best estimate possible.

(b) Itemize those damaged or destroyed and give estimate of value If possible.

For (c) and (d) state number of persons and whether men, women, or children, and whether disabled.

9. Where cause is definlte, it can be stated; where problematical, give

best information available and an opinion as to the cause. Common causes of fires are exposure from other buildings, forests, etc.; matchessmoking; defective chimness and flues; stoves, furnaces, boilers, and their pipes; electricity ; sparks on roofs; petroleum and its products; spontaneous ignition; lightning; sparks from machinery; and hot ashes and coals, and open fires. Contributory causes include spilled on, and accumulations of rubbish and packing materials.

10. State whether fre was extinguished by sprinklers; hand extinguishers ; hand hose; or public fire department; if by hand extinguishers, state whether soda and acid, carbon-tetrachloride, carbon dioxide, foam, water pails, or other hand device.

13. This report of your experience may be helpful in preventing similar fires on U. S. Government properties.

14. Give a concise story covering cause, discovery, sprinkler action if any, how alarm and extinguishing devices operated, how construction details withstood the fire, lessons of the fire, and other general information. Plans, sketches, or photographs, if obtainable, will be helpful in making a study of the fire. 


\title{
APPENDIX D. FEDERAL STATUTE ON DISPOSI- TION OF CERTAIN GOVERNMENT RECORDS
}

\author{
[Publio Law-78th Congress] \\ [Chapter 192-1St Session]
}

[H. R. 2943]

\begin{abstract}
AN ACT
To provide for the disposal of certain records of the United States Government.
\end{abstract}

$B e$ it enacted by the Senate and House of Representatives of the United States of America in Congress assembled, That when used in this Act, the word "records" includes all books, papers, maps, photographs, or other documentary materials, regardless of physical form or characteristics, made or received by any agency of the United States Government in pursuance of Federal law or in connection with the transaction of public business and preserved or appropriate for preservation by that agency or its legitimate successor as evidence of the organization, functions, policies, decisions, procedures, operations, or other activities of the Government or because of the informational value of data contained therein. Library and museum material made or acquired and preserved solely for reference or exhibition purposes, extra copies of documents preserved only for convenience of reference, and stocks of publications and of processed documents are not included within the definition of the word "records" as used in this Act.

SEc. 2. The National Archives Council shall promulgate regulations, not inconsistent with this Act, establishing (1) procedures for the compiling and submitting to the Archivist of the United States of lists and schedules of records proposed for disposal, (2) procedures for the disposal of records authorized for disposal, and (3) standards for the reproduction of records by photographic or microphotographic processes with a view to the disposal of the original records. Such regulations, when approved by the Presi- 
dent, shall be binding on all agencies of the United States Government.

SEc. 3. The head of each agency of the United States Government shall submit to the Archivist of the United States, in accordance with regulations promulgated as provided in section 2 of this Act (1) lists of any records in the custody of the agency that have been photographed or microphotographed in accordance with the said regulations and that, as a consequence thereof, do not appear to have sufficient value to warrant their further preservation by the Government; (2) lists of any other records in the custody of the agency that are not needed by it in the transaction of its current business and that do not appear to have sufficient administrative, legal, research, or other value to warrant their further preservation by the Government; and (3) schedules proposing the disposal after the lapse of specified periods of time of records of a specified form or character that either have accumulated in the custody of the agency or that may accumulate therein at any time after the submission of such schedules and that apparently will not after the lapse of the period specified have sufficient administrative, legal, research, or other value to warrant their further preservation by the Government.

SEC. 4. The Archivist shall submit to Congress, at such times as he shall deem expedient, the lists or schedules submitted to him in accordance with the provisions of section 3 of this Act, or parts of such lists or schedules, and lists or schedules of any records in his legal custody, insofar as it shall appear to him that the records listed in such lists or schedules do not, or will not after the lapse of the period specified, have sufficient administrative, legal, research, or other value to warrant their continued preservation by the United States Government: Provided, That the Archivist shall not submit to Congress lists or schedules of records of any existing agency of the Government in his legal custody without first having obtained the written consent of the head of such agency.

SEc. 5. Whenever the Archivist shall submit lists or schedules to Congress, it shall be the duty of the presiding officer of the Senate to appoint two Senators who, with the members of the Committee on the Disposition of Executive Papers of the House of Representatives, shall constitute a joint committee to which all such lists or schedules shall be referred, and the joint committee shall examine such lists or schedules and 
submit to the Senate and House of Representatives, respectively, a report of such examination and its recommendations.

SEC. 6. If the joint committee reports that any of the records listed in a list or schedule referred to it do not, or will not after the lapse of the period specified, have sufficient administrative, legal, research, or other value to warrant their continued preservation by the Government, the Archivist shall notify the head of the agency by which the list or schedule was submitted of the action of the joint committee and the head of such agency shall cause such records to be disposed of in accordance with regulations promulgated as provided in section 2 of this Act.

SEc. 7. If the joint committee fails to make a report during any regular or special session of Congress on any list or schedule submitted to Congress by the Archivist not less than ten days prior to the adjournmert of such session, the Archivist may empower the head of the agency who submitted the list or schedule to cause the records listed therein to be disposed of in accordance with regulations promulgated as provided in section 2 of this Act.

SEC. 8. Whenever it shall appear to the Archivist that any agency has in its custody, or is accumulating, records of the same form or character as any records of the same agency previously authorized by Congress to be disposed of, he may empower the head of such agency to dispose of such records, after they have been in existence a specified period of time, in accordance with regulations promulgated as provided in section 2 of this Act and without listing or scheduling them.

Sec. 9. Records pertaining to claims and demands by the Government of the United States or against it, or to any accounts in which the Government of the United States is concerned, either as debtor or creditor, shall not be disposed of by the head of any agency under any authorizations granted pursuant to the provisions of sections 6,7 , and 8 of this Act, until such claims, demands, and accounts have been settled and adjusted in the General Accounting Office, except upon the written approval of the Comptroller General of the United States.

SEc. 10. Whenever the Archivist and the head of the agency that has custody of them shall jointly determine that any records in the custody of any agency of the United States Government are a continuing menace to human health or life 
or to property, the Archivist shall cause such menace to be eliminated immediately by whatever method he may deem necessary. If any records in the custody of the Archivist are disposed of under this section, the Archivist shall report the disposal thereof to the agency from which they were transferred.

SEc. 11. At any time during the existence of a state of war between the United States and any other nation or when hostile action by a foreign power appears imminent, the head of any agency of the United States Government may authorize the destruction of any records in his legal custody situated in any military or naval establishment, ship, or other depository outside the territoral limits of continental United States (1) the retention of which would be prejudicial to the interests of the United States or (2) which occupy space urgently needed for military purposes and are, in his opinion, without sufficient administrative, legal, research, or other value to warrant their continued preservation : Provided, That within six months after the disposal of any such records, the official who directs the disposal thereof shall submit a written report thereon to the Archivist in which he shall describe the character of such records and state when and where the disposal thereof was accomplished.

SEC. 12. The Archivist shall transmit to Congress at the beginning of each regular session reports as to the records authorized for disposal under the provisions of section 7 of this Act and as to the records disposed of under the provisions of sections 9 and 10 of this Act.

SEc. 13. Photographs or microphotographs of any records made in compliance with regulations promulgated as provided in section 2 of this Act shall have the same force and effect as the originals thereof would have and shall be treated as originals for the purpose of their admissibility in evidence. Duly certified or authenticated reproductions of such photographs or microphotographs shall be admitted in evidence equally with the original photographs or microphotographs.

SEc. 14. All moneys derived by agencies of the Government from the sale of records authorized for disposal under the provisions of this Act shall be paid into the Treasury of the United States unless otherwise required by existing law applicable to the agency.

SEC. 15. The procedures herein prescribed are exclusive and no records of the United States Government shall be alienated 
or destroyed except in accordance with the provisions of this Act.

SEC. 16. The Act entitled "An Act to provide for the disposition of certain records of the United States Government", approved August 5, 1939 (53 Stat. 1219), the Act entitled "An Act to provide for the disposition of certain photographed records of the United States Government, and for other purposes", approved September 24, 1940 (54 Stat. 958 ), and all other Acts or parts of Acts inconsistent with the provisions of this Act are hereby repealed.

Approved July 7, 1943. 


\title{
APPENDIX E. SUGGESTED PROCEDURE TO BE OBSERVED FOR COMBATING FIRES
}

\author{
Where No Private Fire Brigade Is Organized and Public \\ Protection Is Readily Available \\ (Copies to be Supplied to all Employees)
}

\section{Chief fire marshal}

The chief fire marshal when present at fires will assume general supervision of operations until the arrival of the city fire department, at which time he or the assistant fire marshal in charge will give such information as to the exact location and nature of the fire, precautions to be taken, valuable equipment or material subject to damage, etc., as he may possess and stand by to render whatever assistance may be necessary.

\section{Assistant fire marshals}

The assistant fire marshals shall assist the chief fire marshal in combating fires in the areas to which they are assigned and assume full charge in the absence of the chief, until relieved by the city fire department. It shall also be the duty of these men to familiarize themselves with all activities on the floors, building, or area to which they are assigned, learn the location of shut-off valves in the various pipe lines, electric switches, stowage space for highly combustible or explosive materials, which knowledge would be of great value in combating fires. They shall also learn the location of valuable material, records, equipment, etc., in case they have an opportunity to salvage such material. They shall also familiarize themselves and other occupants with the most effective method of using fire extinguishers and handling hose. They shall inspect the fire equipment at frequent intervals and report any condition that may need attention to the superintendent's office. They shall inspect the various laboratories and offices in their jurisdiction at frequent intervals and report any hazardous conditions or practices to the chief of the division concerned and to the chief fire marshal.

\section{Chief electrician and chief plumber}

The chief electrician and chief plumber with their available mechanics, shall report at all fires prepared to render such assistance in their lines as may be necessary.

\section{Laborer force}

The laborer force shall report at all fires for such duty as those in charge may assign them. 


\section{First aid}

Members of the first-aid team not otherwise engaged, shall report at fires with equipment to render first-aid treatment under direction of the staff physician, if needed.

\section{Telephone operator}

The telephone operator shall, upon receipt of a fire alarm, instruct the guard to turn in an alarm at the nearest alarm box and give him the location of the fire. She shall then telephone in an alarm to the city fire department. She shall then receive the report back from the guard and record the time, location, and name of the person calling and then notify the superintendent of the building or building group and the general administrative official in charge, giving the location of the fire.

\section{Guard on duty}

The guard on duty shall, upon being notified of a fire by the telephone operator, immediately turn in an alarm on the nearest city fire-alarm box and then report back to the operator that the alarm has been turned in. If the fire is located in any of the buildings not reached through the usual entrance, he shall proceed as quickly as possible to the main entrance to the grounds and direct the fire department's apparatus to the building concerned. Apparatus not so directed would proceed to the group of buildings served by the main entrance or nearest the box pulled.

All watchmen shall familiarize themselves with the location of telephones connected to the city exchange after working hours and shall use these telephones in turning in alarms to the city fire department whenever such telephones are more accessible than the alarm box and the use of the latter would result in delay in transmitting the alarm.

All fires occurring after regular working hours shall be reported immediately to the chief fire marshal or his designated substitute, by the guard on duty.

\section{Engineman on duty}

In case of a fire of such magnitude that it requires the use of outside fire lyydrants supplied by a metered connection, the engineman on duty shall, after safeguarding the power plant, immediately open the by-pass around the water meter to permit an unobstructed flow of water.

\section{other employees}

Employees not in the immediate vicinity of the fire and having no interest therein or not needed to assist in combating it, shall remain at their usual place of employment.

Employees in the building or part of building affected and not needed to assist in combating the fire, shall leave the building. Assistant fire marshals shall assist in enforcing this requirement in the interest of safety.

\section{Report on fire}

The fire marshal or assistant fire marshal shall prepare a report in duplicate on each fre on the form provided, one copy to be sent to the administrative officer in charge and the other to the Federal Fire Council. 


\section{Publicity}

Employees shall refrain from discussing with newspaper representatives, the probable cause of fires and the damage caused thereby. Information of this character shall be released only through the administrative office.

Procedure in case of fire

Immediately upon the discovery of a fire, the discoverer shall summon such assistance as may be near at hand and proceed to extinguish the fire if in his opinion this can be accomplished with the apparatus and help available. However, if there is any doubt as to their ability to extinguish the fire immediately, the telephone operator shall be notified from the nearest telephone, giving the location of the fire and the name of the person calling. Meanwhile, all available employees shall attack the fire with all available means to the end that the fire may be confined as much as possible until further assistance or the city fire department arrives. Men not required to handle fire hose or extinguishers, should be directed by the occupant of the room to close windows and doors not needed, shut off apparatus using electricity or gas, and salvage valuable material, apparatus, and records. The discoverer of the fire or occupant of the room shall direct operations until relieved by the assistant fire marshal, bureau fire marshal, or the city fire department.

(Signed)

(Chief of Office, Bureau, or Establishment) 


\section{APPENDIX F. SELF-INSPECTION FORMS}

\section{REPORT OF ASSISTANT FIRE MARSHAL}

Department

Bureau

Location

To.

Chief of Bureau, and.

Chief Fire Marshal

(Office) (Establishment)

The following matters referenced to items on the self-inspection form of the Federal Fire Council, where applicable, are noted and conditions now needing correction are called to your attention:

\begin{tabular}{c|c|c|c|c|}
\hline $\begin{array}{c}\text { Form } \\
\text { number } \\
\text { number }\end{array}$ & $\begin{array}{c}\text { Hazard, deficiency, } \\
\text { etc. }\end{array}$ & $\begin{array}{c}\text { Location, building, } \\
\text { room }\end{array}$ & $\begin{array}{c}\text { Recommendation, } \\
\text { date }\end{array}$ & $\begin{array}{c}\text { Condition } \\
\text { corrected, } \\
\text { date }\end{array}$ \\
\hline & & & & \\
\hline
\end{tabular}

Date

Assistant Fire Marshal.

NoTE.-This report must be sent to the officer in general administrative charge of the property or occupancy and the chief fre marshal not later than 3 days after the close of the prescribed period (month, quarter, half year) to be covered by the report. Conditions that need immadiate attention and for which correction cannot otherwise be obtained, should be made the subject of ad interim reports.

The assistant fire marshal should make frequent inspections and maintain contact with conditions having a bearing on the fire hazard with a view to obtaining elimination of elre causes, maintenance of flre-protection equipment, and proper functioning of the organization for combating fires, by obtaining the cooperation of those immediately concerned. 


\title{
FIRE PROTECTION INSPECTION REPORT FOR GOVERNMENT ESTABLISHMENTS
}

\author{
FEDERAL FIRE COUNCIL
}

Date of report

\author{
Quarterly Report \\ (Indicate which, by check in square) Annual \\ Report $\square$ \\ Department, Establishment, Bureau, Office:
}

Space, building, or building group covered by this report, and location:

Report by (For occupant activity)

Official title

Report by

(For manager activity)

Official title

Inspections with this form as a basis (which supersedes all previously used forms) should be made at the prescribed intervals and sent to the officer in general administrative charge of the property. All reports should be signed and dated by the official preparing same in space provided. Answers to questions in all instances should be given in sufficient detail to clearly illustrate the conditions, identifying the building concerned if one of a group covered in report. If additional space is required a separate sheet should be used, properly identifying by number the question concerned.

Questions 1 to $\mathbf{1 7}$, inclusive, require reports by the occupant of the premises quarterly or at such intervals as designated by the proper authority.

Questions 18 to 43 , inclusive, require reports made jointly by the occupant and the manager quarterly or at such intervals as designated by the proper authority. (When it is not practicable for the occupant and manager to submit a joint report, then the occupant shall submit a report answering questions 1 to 43 , inclusive, and the manager shall submit a separate report answering questions 18 to 43 .)

Questions 44 to 55, inclusive, require reports by the manager of the premises annually or at such intervals as designated by the proper authority, and shall not be answered in the quarterly reports. Hence, the last quarterly report and the annual report together will supply answers to all 55 questions.

The occupant is the Government agency actually using the facilities. The manager is the Government agency who has custody of the facilitles. When the occupant also has custodial care of the facilities he is then also manager in the sense of this questionnaire and he then should sign the report in both capacities. 


\section{QUESTIONS 1 TO 17}

\section{(To Be Filled Out by Occupant of Premises Quarterly)}

1. Are combustible materials in unnecessary amounts creating fire hazard within buildings?

The hazard from books, newspapes, etc., may be reduced by storage in enclosed metal cablnets or shelves. Paints, oils, lumber, and other combustible stocks should be segregated in fire-resistive enclosures or separate buildings, and accumulations of waste prevented.

2. Are packing and ghipping operations properly safeguarded?

Excelsior and similar packing materials should be kept in covered metal bins and the rooms swept and put in order at the end of each day's operations.

3. Are combustibles unnecessarily stored in the yard or court?

Rubbish should be removed promptly to avoid accumulations that would be difficult to have removed.

4. Is oily waste, etc., present outside of covered metal waste cans?

Oily waste is readily ignited and under some conditions is subject to spontaneous ignition.

5. Are waste cans emptied at auficiently frequent intervals?

If waste cans are not emptied when required, waste materials may be placed outside of them, which is ohjectionable.

6. Are open-flame lights near combustible material?

7. Are raleg on smoking violated?

Matches and lighted cigars and cigarettes thrown out of windows may set fire to awnings and automnbiles.

9. Is clothing kept in wooden lockers?

Lockers of incombustible material are preferable.

10. Are the storage, handling, and use of gasoline, kerosene, fuel oil, alcohol, and other hazardous liquids and chemicals, and films properly eafeguarded? Preferably not more than 2 gallons of flammable liquids should be kept at individual points in bulldings and they should be contalned in safety cans. Storage of relatively small quantities of flammable oils or other hazardous substances should be in protective cabinets and larger quantities In drained and vented vaults or in separate buildings. Large supplies of fammable liquids should be stored in underground tanks. Fuel-oil storage in closed steel tanks in buildings should not exceed 275 gallons in Individual tanks or 550 gallons total, unless enclosures highly resistive to fire and pressure are provided for the tanks. Spillage should be avoided and all pipe connections kept tight. Where chemicals are used, their nature should be ascertained and precations taken against fire or explosion. Nitrocellulose fllm, celluloid, or other pyroxylin products should be kept in metal containers away from radiators or other sources of heat, and in excess of 25 pounds stored in vented vaults or cabinets. Lights should not be in contact with or too near the storage. See Manual, Sec. XII-4 (F).

11. Are any electric fixtures or wires loose or broken?

12. Are electric cords Jooped over nails or in contact with any other metallic objects or surfaces?

13. Are there any electric cords excessively long and exposed to damare?

Such as extension cords leading to desk lamps, electrically operated adding or tabulating machines, call bells, telephones, etc. Often such cords are run on floor, under rugs, etc., and thus exposed to much wear, representing a highly objectionable hazard.

14. Are there any portable or temporary hesters? State kind and location State whther these heaters are a hazard and why. If a bazard-defects of heater, improper connection, too close to combustible niaterial, etc.the condition should be immediately corrected or the use of the heater discontinued.

15. Are records properly protected?

Records should be classifled as to value, useless records destroyed, and the others given protection by duplication or placing in protective containers. Records of high value should be kept in vaults or insulated safes having fre resistance adequate for the location and, if taken out during the day, should be replaced at the close of working hours. See Manual, Sec. XI and XIII.

16. Does fire drill include placing of records in to their protective containers? 
17. Are eprinklerg obstructed by furniture and other movable equipment used by the occupant (such as file cases, piles of materials, etc.)?

Preferably none should be less than 18 inches below sprinkler heads and 12 inches clearance should be had in all cases.

\section{QUESTIONS 18 to 43}

\section{(To Be Filled Out by Occupant and Manager Quarterly)}

18. Are hot ashes properly disposed of?

A shes and ash containers should not be placed in contact with wood or other combustible material. Ashes should not be kept in combustible containers.

19. Are any electric fuses replaced by wire or other improper currentcarrying materials or devices?

20. Are fuse or switch cabinet doors open or coverg of other boxes open or missing?

If fuse or switch cabinet doors are open, fire from short circuits may ignite adjacent combustible construction or materials.

21. Are there extra fuses on hand?

Fxtra fuses of proper size will eliminate the temptation to insert fuses of improper size, wire, pennies, etc.

22. Are circuits properly fused? When fuses are blown, there is temptation to fuse circuits higher than their safe capacity.

23. Are fire pails, hose, nozzles, chemical extinguishers in place, in good condition, and unobstructed?

First aid extinguishers should be full and water pails subject to freezing filled with nonfreezing solutions. Soda-acid and foam extinguishers should be discharged and recharged annually, with date of recharging marked on tag on extinguisher. They should not be placed in locations subject to freezing. Nozzles on hand extinguishers should be kept open and defective hose replaced.

24. Are watehman's rounds checked regularly? By what method and by whom?

Records from portable or stationary recorders should be checked daily. If reporting by telephone or signal to central station, failure to report should receive immediate attention.

25. Give date of last fire drill, number of men responding, and time taken to man equipment

26. Note existing fre hazards or deficiencies in fire protection not specifically indicated in previous questions

27. Is wood work or other combustible material too near steam pipes, boilers, flues, or furnaces?

In general, scorching or charring indicates a dangerous condition.

28. Are any stoves, furnaces, pipes, chim neys, or flues defective? Stovepipes are corroded by furnace fumes and joints of horizontal runs may separate. Chimneys become defective at the roof line from rain washing out mortar joints.

29. Are there any broken windows, plastering, partitions, fooring, or similar deficiencies?

30. Do temporary partitions, enclosures, and containers of combustible construction increase the fire hazard?

Fire resistive huildings can be made hazardous thereby.

31. Are all valves in lines supplying water to standpipe and sprinkler systems al ways open?

If it is necessary to close the valves, special precautions should be taken while they are closed and also to see that they are opened as soon as possible.

32. Are sprinklers obstructed by partitions, piles of materials, etc.?

Partitions, piles of materials, etc., should be not less than 18 inches below the sprinkler heads.

33. Are fire hose, fire hose houses, and standpipe valves accessible and free from rubbish?

34. How are fire alarms transmitted? Are fire alarm boxes or telephones accessible at all times? Is personnel instructed in the procedure to be ohserved in case of fire?

Fire alarm boxes or telephones should be accessible at all times. Rooms in which they are located should be unlocked. Private slarm systems should be tested at intervals.

$$
651704-45-11
$$


35. Are adequate exits and fire escapes provided, carefully indicated and free from obstructions?

Two independent means of exit should be provided with not more than 150 feet of exit travel to reach a stairway, which distance should be shorter where hazardous occupancies or conditions are involved. See Manual, Sec. VI.

36. Are vents provided for explosives, dust, or noxious gases?

Explosion hazards cover a wide field and if there are indications that the hazard is not adequately cared for, further investigation should be made and proper preventive measures applied.

37. Are fire doors or shutters installed where needed and are they in condition to operate freely?

Fire doors should not be obstructed. Self-closing fire doors should not be wedged open. If required to be open for certain periods, they should be kept closed at other times.

38. Are combustible stocks or hazardous operations isolated by fire walls?.. In general, areas subject to one fire should not exceed 10,000 square feet in buildings of fre resistive construction, or 3,000 to 5,000 square feet in buildings of nonfire resistive construction. For hazardous materials and occupancies the areas should be smaller. For low-hazard occuphncies in fire resistive buildings the areas may be larger or unrestricted. Where buildings are protected with automatic sprinklers, the areas may be increased.

39. Are hydrants free from obstruction and are they tested?

Hydrants should be tested annually for static and flowing pressures but not by opening in freezing weather. A slight turn of the stem will show if hydrant is frozen or for a dry hydrant, a weight lowered through hose outlet will determine presence of ice by sound, and water by wetting of the weight.

40. Are post indicator valves strapped open?

To prevent tampering, strap post indicator valve open in a manner that will permit breaking the strap when shutting the valve to stop water flow.

41. Is lettering on post indica tor valve legible?

42. Is there a fire brigade or other group organized to respond in case of fire?

For information on different forms of emergency organizations, see Manual of Fire Loss Prevention of the Federal Fire Council, Sec. XV and Appendix E.

43. Summarize fire safety corrections and improvements efiected since last report.

\section{QUESTIONS 44 TO 55}

\section{(To Be Filled Out by Manager Annually)}

44. Are there any unnecessary concealed spaces?

The fluc effect produced by concealed spaces in walls and partitions can be reduced by fire-stopling at loor and roof lines.

45. Are any roof coverings defective?

Flying brands from chimncys, Jocomotives, and other sourses wi] lodge and start fires more readily in weathered wood shingles and oid torn or cracked roll roofings than in roofings in good condition. Fires may start in roof boards or inside of buildings by brands entering through holes in corroded metal or other roof coverings.

46. Is wiring installed in accordance with accepted practice?

Reference may be made to the building code for the city or State in which the building is located, the National Electrical Code, or the National Electrical Safety Code.

47. Are window openings protected from exposure fires?

Openings in exterior walls of buildings exposed by nonfire resistive buildings, lumber piles, ete., at distances of 30 feet or less should have windows with metal sash and wired glass, or shutters, or for severe exposure, both.

48. Are elevator and stair shafts enclosed?

It is desirable to have elevators and stairways completely enclosed with self-clesing metal doors for the openings, to prevent s] read of fire fromi foor to floor.

49. Are sprinkler heads coated, white washed, painted, or corroded?

50. Are any portions of wet pipe sprinkler system exposed to freezing?

51. Are any gprinklers disconnected, and if so, why? 
52. What is air pressure for dry valve of eprinkler system?

The air pressure for the dry valve can be read from the gage provided in the installation.

53. What is water pressure for dry valve of sprinkler system?

This can be read from the gage provided. The usual ratio of water to air pressure is about $6: 1$ for differential dry valves. It is customary, however, to carry an air pressure of 30 or 40 pounds to provide a factor of safety.

54. Are aprinklers obetructed by temporary or permanent installation in the building (such as partitions, ghelving, etc.)?

None should be less than 18 inches below sprinkler heads.

55. Is cotton rubber-lined hose tested regularly?

Cotton rubber-lined hose should be tested once each year capped, or with shut nozzle at the highest static pressure available at its connection to the water system. Drain and dry thoroughly afterward. Tests of some typical lengths only should be made of unlined linen. hose, since wetting reduces the lifo of the hose. 


\section{INDEX}

Acetate cellulose film . . . . .

Air-raid protection measures.

Alcohol, calorific value $\ldots \ldots \ldots \ldots \ldots$

Alteration, hazards during.................

Animal oils, calorific value

Application of hand-fire extinguishers

Arches, fire-resistance classiflcation .

Area limitations in buildings

Arson by enemy action

Asphalt, calorifie value

Asphalt and asbestos-roofing classification

A sphalt and rag-felt roofing classification

Automatic fre-alarm systems.... $\ldots \ldots \ldots$

Automatic-sprinkler equipments scope

Automatic-sprinkler systems, installation details ${ }_{1}$

Automatic-sprinkler systems, types

Automatic-telephone exchanges, fre alarm use

Barricades for explosion protection.

Beams, fire-resistance classiflcation

Bitumen, calorific value $\ldots \ldots \ldots \ldots$

Brick arches, fire-resistance classification

Brick walls, fire-resistance classiffeatıon

Bullding fire severity $\ldots \ldots \ldots \ldots$

Building type classifications.

Buildings, fire-resistance classification of

Built-up roofing classification........ .13

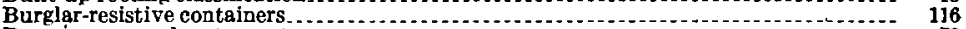

Bypasses around water meters...

Cabinets, fling .................. 104

Cabinets, film

Cabinets for flammable liquids

Cabinets, insulated ..................

Calcium chloride as freezing-point depressant

Calcium-chloride extinguishers

Carbon dioxide, extinguishing effects

Carbon-dioxide extinguishers . . $\ldots \ldots \ldots, 122$

Carbon-dioxide extinguishing systems, fixed

Carbon dioxide for flooding enclosed spaces .

Carbon tetrachloride, extinguishing effects

Carbon-tetrachloride extinguishers $\ldots \ldots$...

Casks, water . . .

Cast-iron columns, fire-resistance classification

Causes of fires.

Celluloid .

Cement concrete coverings for metal columns.

Charred records, deciphering . .

Chests, burglar-resistive

Chimneys .

Chutes _..

Circuit-breaker panels.

Classification of automatic-sprinkler systems

Classification of fire resistance.

Columns, fire-resistance classification
Combsting fires, procedure.

Combating fires, procedure

Combustibles, calorific value

Common hazards

Concrete-block walls, frre-resistance classification. .

Concrete coverings for metal columns. 
Page

Conductors, electric.

35,37

Construction hazards

Containers, record, portabile

Cotton, calorific value.

Cultural resources, protection in war.

Current-carrying capacity of wires.

Deaths from fire.

Demolition, hazards during

Desks - . . . . .

Distributing mains .

Doors, exit capacity. ........

fre, classiffcation . .

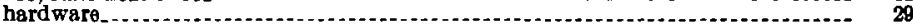

mounting

Dry cleaning, safeguarding

Dry-pipe sprink]er systems.

Dry-powder extinguishers. . .

Dry-powder, extinguishing efiects

Duplication, protection of records by . .

Dust hazards

Egress, means of

Electric apparatus, lighting, and power.

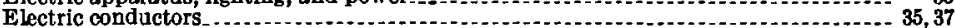

Electric lighting, safeguarding

Eloctric power, safeguarding

Elevator-shaft enclosures: .

Elevators

Elevators, exit capacity of

Equipment, fire-xtinguishing ...

Exhaust gas for flooding inclosed spaces

Exhaust ventilating systems

Exit capacity, determination.

Exit lighting and marking

Exit locations .

Exit requirements $\ldots \ldots \ldots \ldots \ldots$

Exits, required number of _.

Exit ways, inclosure.

Exit width, unit

Explosion hazard, precautions against.

Explosives, storage. . . .

Exposure, protection against. ...

Exposure conditions in non-fire-resistive buildings

Exterior exposure, protection against . _ _

Exterior openings, protection of

Extinguishers, portable, applicetion

care

location.

rating

recharges . .

spacing

support...

types

Extinguishing agents for flres

Failures of sprinkler equipment.

Fats, calorific value

Filing cabinets. . . . . . . . . . . . . . . . . . . .

Film cabinets.

F ilm, cellulose...

Film vaults.

Fire-alarm equipment. .

Fire alarm systems, automatic.

Fire alarm systems, installation requirements

Fire-alarm systems, manual. . . .

Fire alarms, municipal. .

Fire alarm, unit type.

Fire brigade, public.

Fire causes. ...............

Fire-combating procedure... 
Fire-control possibilitics .

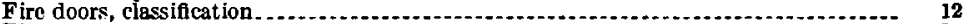

Fire cscapes. . . .

Fire-ext inguishing equipment, general types..

portable

Fire-cxtinguishing systems, carbon-dioxide.

foam...

Fire extinguishment.

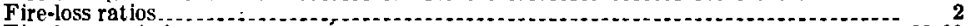

Fire-loss stat istics

Fire-prevention measures, general $\ldots$

Fire-protection expense, calculations

Fire-protective coverings for metal columns.

Fire report form $\ldots \ldots$

Fire-resistance classifications

Fire-resistive buildings, classification.

Fire shutters, classification. . .

Fire survey plans, table of symbols . . . .

Fire tests of building materials.

Fire walls, classification _ _ _

Fire windows, clascification

Fires, classes. severity _ .

First-gid unit ...

Fixtures, electric

Flammable liquids

Floor beams. fire-resistance classification

Flue gas for flooding inclosed spaces

Foam, extinguishing effects
Foam extinguishers...

Foam-xtinguishing systems

Frame building construction, classification

Freczing-point depression of freextinguishing media .

Fuel-st orage inclosures.... . .

Furniture for record storage......

Fuses, elentric

Gas installations...

Gases, liquefied

Qirders, fire-resistance classification

Grain, calorifie value .

Gravity tanks. .

Grounding of electrical circuits

Grounding of electrical equipment.

Gypsum-block partitions, fire-resistance classification.......

Hardware for doors.

Hazardous locations, electrical equipment for

Hazardous materials. . . . . . . . . . .

Hazardous occupancies, fire extinguishment

Hazards, common.

Geads, gutomatic-sprinkler.

Heating ..........

Heating equipment

Height limitations in buildings.

Hollow-tile arches, fire resistance classification

Hollow-tile as column protection

Hollow-tile walls, fire-resistance clessification
Horizontal communications, protection of .

Horizontal communications, protection of

Hose, flre......... 71

large, water supply

rubber-lined, maintenance...

small, water supply $\ldots$

unlined linen.

Hose outlets, nozzles....

Hose streams, range

Housing, records

Hydrants, maintenance 
Incendiary bomb, combat of flre hazard $\ldots \ldots \ldots$

Incinerators . . .

Inclosures, combustible

Incombustible construction, fire resistance classiflestion.

Induction regulators

Inspection of properties.

Insulated safes

Insulation for electric conductors

Insulation, wire, lead-sheath

rubber....

westher-resistant.

Isolated locations, fire extinguishment

Justifable expense for protection . . . . . . . . .

Ladders. .

Lighting, electric.

Lighting equipment....

Lighting of exits

Lightning protection

Liquefied gases

Liquids, hazardous

Loaded stream extinguishers

Lockers .

Losses, fire.

Magazines for explosive storage

Mains, water

Maintenance of fire-protection equipment

Maintenance of property ...

Manual fire-alarm systems.

Marking of exits

Masonry-walled building construction, classification.....

Metal building construction, classiflcation ${ }_{\text {Mets, }}$ water.
Meters

Meters, water

Motors, electric

Municipal fire alarms.

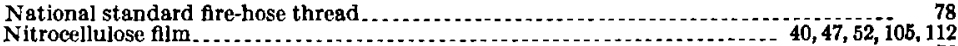

Nozzles, hose

Oil-filled electric spparatus

Oils, calorific value. .........

Opening protectives, fire-resistance classification

Openings, protection .

Organic materials, calorific value

Organization for combating fires...

Organization for fire-loss prevention.

Outlets, hose.

Outside central station service.
Outside private protection.

Outside stairs...
Overcurrent protection

Packing operations, hazards

Pails, sand, care.

water

Paint spraying, safeguarding

Painting, hazards.

Panels, electric.

Paper, calorific value .......

Paraffin, calorific value

Partitions, combustible

fre-resistance classification

Party walls, fire-resistance classification.

Petroleum oils, calorific value.
Pipe lines, size.

Pitch, calorifle value. 
Page
Pans

Plans for new construction and equipment, review of $\ldots \ldots \ldots \ldots$

Plaster partitions, fire-resistance classification

Plastics, casein base and phenol-formaldehyde

Plug fuse panels

Population density in buildings

Portable fire-extinguishing equipment.

Portsble record containers . .

Powder-type extinguishers.

Powdered material, extinguishing effects....

Power equipment

Prepared rooflngs, classification.

Pressure-reducing devices.

Pressure tanks. .

Pressures, water, allowable

Property inspections _...

Protection, justifiable expense

Protection measures, coordination.

Public fire brigade. . .

Public water supply

Pumps, flre

Pyroxylin products.

Rag-felt rooflng, classification .......... 13

Ramps, exit capacity of

Range of hose streams . .

Rating of hand fire extinguishers.
Ratios, fire-loss.

Ratios, fire-loss
Receptacles, waste

Recharges for portable fire extinguishers

Record containers, portable.

Record room opening protectives, classification

Record rooms

Record storage buildings.

Record vaults

Records, charred, deciphering

classification ...

protection

useless, destruction

Reinforced concrete columns, fire-resistance classification
Reports on fires

Reports on fires. .
Rods, lightning

Roofing materiale, classification

Rooms, record

Safes, burglar-resistive.

insulated.

Salvage of fire-damaged records.

Sand, extinguishing effects...

Sand pails, care ..............

Self-inspection forms

Self-inspection of property

Service equipment.

Severity of building fires.

Shelring, incombustible ...

Shipping operations, hazards

Shunt-type fire alarm system
Bhutters, fire

Siamese inlets for standpipes.....

Sienal-corps fire alarm system

Silk, calorific value

Slabs, fire-resistance classification

Slide escapes

Smoke pipes ....

Smoking in hazardous areas

Sockets, electric light, hazards

Soda-acid, extinguishing effects

Soda-acid extinguishers

Sodium chloride as freezing-point depressant.

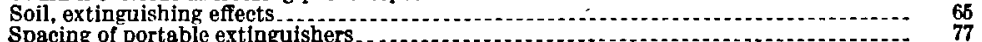




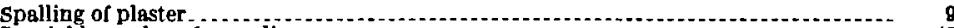

Special hazards, safeguarding

Sprinkler head temperature ratings

Sprinkler supervisory equipment.

Sprinkler systems, maintenance. . ................................................... 118

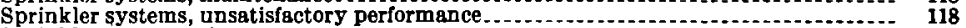

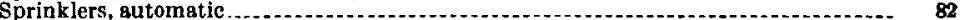

Stair shaft inclosures . . . .

Stafrs, construetion of

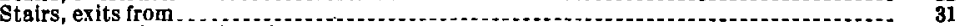

Stairways, exit capacity of

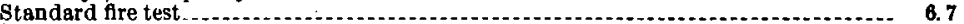

Standpipe systens

Standpipes, size of

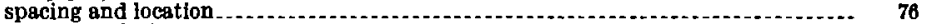

water supply for

Steam, extinguishing effects.

Stesm-hesting systems $\ldots . . . . . .$.

Straw, calorific vahue ......................................

Structural-steel columns, fire-resistance classification ....... 18

Sugar, caloriffe value

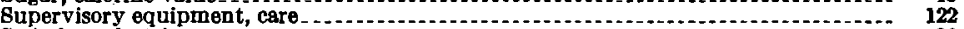

Switches, electric

Symbols for fire-survey plans.................................. 140

Tanks, water.....

gravity

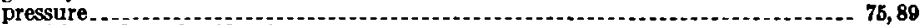

Tar rag-felt roofing, classification.

Technical inspection of property

Telephone exchanges, automatic, adeptation......................................... $\quad 65$

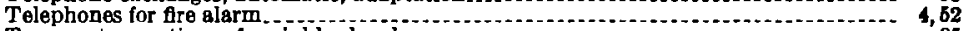

Temperature ratings of sprinkler heads ........ 85

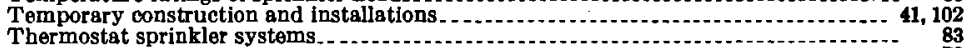

$\begin{array}{ll}\text { Threads, fre hose, standard } & \\ \text { Tile, hollow-clay, as column protection } & \mathbf{7 8}\end{array}$

Tile, hollow-clay, as column protection

Tile walls, fire-resistance classiflcstion

Timber columns, fle-resistance classification

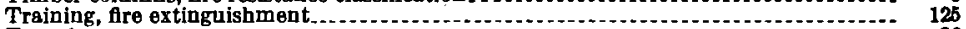

Transformers. ............ 36

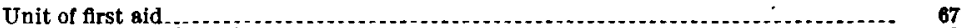

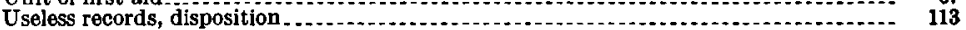

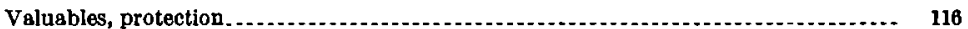

Valves....

Vault opening protectives, classification.

Vaults, record

Vaults for flammable liquids

Vaults for hazardous materials

Vegetable oils, calorific value

Vehicles, oil-propelled, hazards........

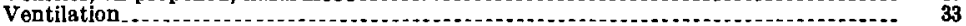

Vertical communications, protection of

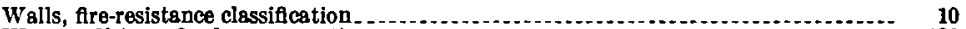

War conditions, flre loss prevention

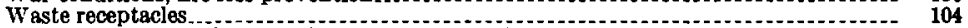

Watchman's supervisory equipment

Watchman's supervisory systems

Water, extingushing effect........... 60

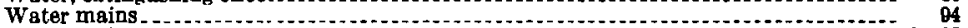

Water pails

Water supply, private ...................

public

Sprinkler

standpipe

Water-tank extinguishers with pump 


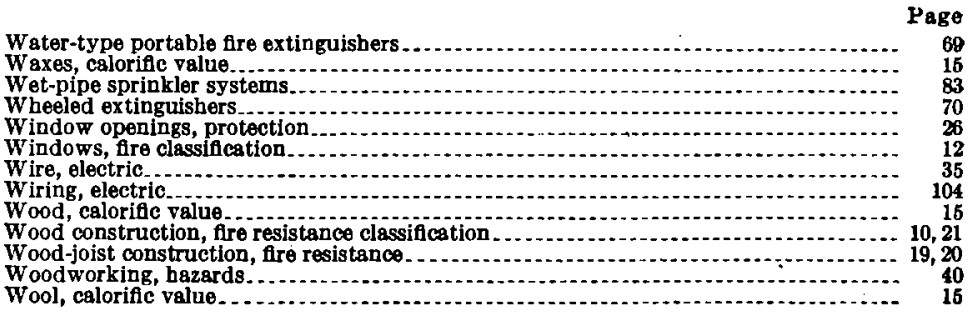



